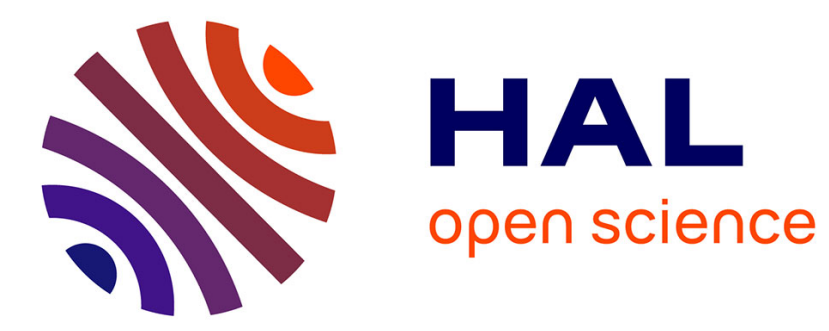

\title{
Luminescent materials incorporating pyrazine or quinoxaline moieties
}

\author{
Sylvain Achelle, Christine Baudequin, Nelly Plé
}

\section{To cite this version:}

Sylvain Achelle, Christine Baudequin, Nelly Plé. Luminescent materials incorporating pyrazine or quinoxaline moieties. Dyes and Pigments, 2013, 98 (3), pp.575-600. 10.1016/j.dyepig.2013.03.030 . hal-00879623

\section{HAL Id: hal-00879623 \\ https://hal-univ-rennes1.archives-ouvertes.fr/hal-00879623}

Submitted on 10 Dec 2013

HAL is a multi-disciplinary open access archive for the deposit and dissemination of scientific research documents, whether they are published or not. The documents may come from teaching and research institutions in France or abroad, or from public or private research centers.
L'archive ouverte pluridisciplinaire HAL, est destinée au dépôt et à la diffusion de documents scientifiques de niveau recherche, publiés ou non, émanant des établissements d'enseignement et de recherche français ou étrangers, des laboratoires publics ou privés. 


\title{
Luminescent materials incorporating pyrazine or quinoxaline
}

\section{moieties.}

Sylvain Achelle, ${ }^{1 *}$ Christine Baudequin, ${ }^{2}$ and Nelly Plé. ${ }^{2}$

${ }^{1}$ Institut des Sciences Chimiques de Rennes, UMR CNRS 6226, I.U.T. Lannion, rue Edouard Branly BP 30219, F22302 Lannion Cedex, France

${ }^{2}$ Normandie Univ, COBRA, UMR 6014 et FR 3038; Univ Rouen; INSA Rouen; CNRS, IRCOF, 1 rue Tesnière, 76821 Mont Saint Aignan Cedex, France

\begin{abstract}
:
Though the past few decades, the development of new luminescent materials has received a lot of attention due to their applications as fluorescent sensors, in biological microscopy and in optoelectronic devices. Most of these applications are relied on intramolecular charge transfer (ICT). Presence of electron withdrawing N-heterocycles such as pyrazine and quinoxaline rings appeared therefore particularly interesting to be used as electron-attracting part in $\pi$-conjugated structures. Moreover, presence of nitrogen atoms with lone electron pairs allows to the pyrazine and the quinoxaline ring to act as effective and stable complexing agent or as base that can be protonated. This review reports luminescent small molecules and oligomers including a pyrazine or quinoxaline ring in their scaffold highlighting their applications related to photoluminescence and electroluminescence.
\end{abstract}

Keywords: pyrazine, quinoxaline, fluorescence, OLEDs, $\pi$-conjugated molecules, sensors

- Author for correspondence: sylvain.achelle@univ-rennes1.fr tel: +33296469448 fax: + 33296469354

1. Introduction 
Diazines which belong to the most important heterocycles containing nitrogen are sixmembered aromatics with two nitrogen atoms. Three different structures can be distingued according to the relative position from the nitrogen atoms: pyridazine (1,2-diazine) [1], pyrimidine (1,3-diazine) [2] and pyrazine (1,4-diazine) [3]. Quinoxaline, also called benzopyrazine is a heterocyclic compound containing a ring complex made up of a benzene ring and a pyrazine ring [4]. Pyrazine and quinoxaline derivatives have been intensively studied because the 1,4-diazine core is found in many natural and man-made compounds [5]. Alkylpyrazines, produced from proteins by fermentation are for example the constituents of the aroma of coffee [6], some cheeses [7] or roasted meat [8]. The more complex imidazopyrazine moiety is found in the scaffold of the Coelenterazine, a bioluminescent compound isolated from the jellyfish Aequorea Vistoria [9]. Moreover numerous pyrazine and quinoxaline derivatives exhibit a large range of biological activities and are used for pharmaceuticals or phytosanitary applications [10]. Besides their medicinal uses, pyrazine and quinoxaline derivatives have found technical applications as dyes, electroluminescent materials, organic semi-conductors and as suitable ligands in coordination chemistry. We report herein the main results dealing with this kind of applications during the last two decades.

The elaboration of electro-optical (EO) and nonlinear optical (NLO) materials has attracted considerable attention because of their wide range of potential applications in optical data processing technologies. The synthesis of extended $\pi$-conjugated systems has been the key to provide organic materials with such properties. These compounds are often based on a push-pull system, which is constituted by an electron-donating group (D) and an electronwithdrawing group (A) linked through a $\pi$-conjugated spacer. The molecular properties of the chromophores depend on the strength of the "push-pull" effects which are function of the ability of the donor to provide electrons and the acceptor to withdraw electrons. 
Pyrazine and quinoxaline, which are highly $\pi$-deficient aromatic heterocycles, can be used as electron withdrawing part in push-pull structures for intramolecular charge transfer (ICT). Such important ICT along the backbone of the molecule can induce luminescence properties. The ability of protonation, hydrogen bond formation and chelation of the nitrogen atoms of the 1,4-diazine ring are also of great importance: such derivatives could be therefore used for the formation of supramolecular assemblies and used as sensors.

Two general methods for the synthesis of $\pi$-conjugated pyrazine derivatives are described in the literature. The first method consists of the construction of the pyrazine ring by condensation reactions of $\alpha$-diketones with vicinal diamines [11] but these methods disappoint in the preparation of unsymmetrical substituted pyrazines. The second one involves the functionalization of the 1,4-diazine ring [12]. The advantages of the latter one are a greater versatility and the use of easily available starting materials. Indeed, a large variety of halogeno (more particularly chloro), amino and methyl derivatives are commercially available and can be used as building blocks to elaborate $\pi$-conjugated scaffolds. Among the synthetic strategies, the cross-coupling reactions involving halogenated pyrazines and / or quinoxalines constitute a method of choice to access such structures. It should be noted that the $\pi$-electrondeficient character of the 1,4-diazine ring makes easier the oxidative addition of palladium to a chlorine-carbon bond without the use of specific and expensive ligands [13]. Therefore, a wide range of cross-coupling reactions (Suzuki [14], Stille [15], Negishi [16], Sonogashira [17], Heck [18] and Corriu-Kumada [19]) have been carried out with halogenated pyrazine or quinoxaline building blocks. Another synthetic way to access to vinylpyrazines or vinylquinoxalines is the condensation reaction of various aldehydes with methyl derivatives [20].

Recently we have reviewed the use of pyrimidine and pyridazine as building blocks for the synthesis of $\pi$-conjugated materials [21]. This article is the last part of this series of 
papers and has for aim to review the use of pyrazine and quinoxaline moieties in the synthesis of fluorescent materials. Only small molecules and oligomers will be described here, this review will not treat polymer materials. The first part of this review deals with pyrazine derivatives while the second part is dedicated to quinoxaline compounds. Each part will be organized by molecule classes.

\section{Pyrazine derivatives}

Because the 2,3-dicyanopyrazine ring has specific properties resulting from the two strong withdrawing cyano groups, this moiety has been introduced in the scaffold of a wide range of fluorophores.

\subsection{Diamino and dicyanopyrazines}

A first family of 2,5-diamino-3,6-dicyanopyrazines was synthesized and studied in 1998 by Matsuoka and coworkers [22]. The 2,5-diamino-3,6-dicyanopyrazine 1 absorbs at $\lambda_{\text {abs }}=458$ $\mathrm{nm}$ and emits at $\lambda_{\mathrm{em}}=538 \mathrm{~nm}$ with a quantum yield $\Phi_{\mathrm{F}}=0.3$. This compound is an interesting intermediate to access other fluorescent dyes. Alkylation of the amino groups leads to compounds 2 which present a bathochromic shift of $\lambda_{\text {abs }}=449-522 \mathrm{~nm}$ and a red fluorescence $\lambda_{\mathrm{em}}=532-603 \mathrm{~nm}$. On the contrary, acylation of the amino groups (compounds 3 ) induces a hypsochromic shift of $\lambda_{\text {abs }}(378-403 \mathrm{~nm})$ and of $\lambda_{\mathrm{em}}(432-488 \mathrm{~nm})$. It is noteworthy that the imine 4 has similar $\lambda_{\mathrm{abs}}(452 \mathrm{~nm})$ and $\lambda_{\mathrm{em}}(527 \mathrm{~nm})$ than 1 but a higher quantum yield $\left(\Phi_{\mathrm{F}}=\right.$ 0.8) (Scheme 1).
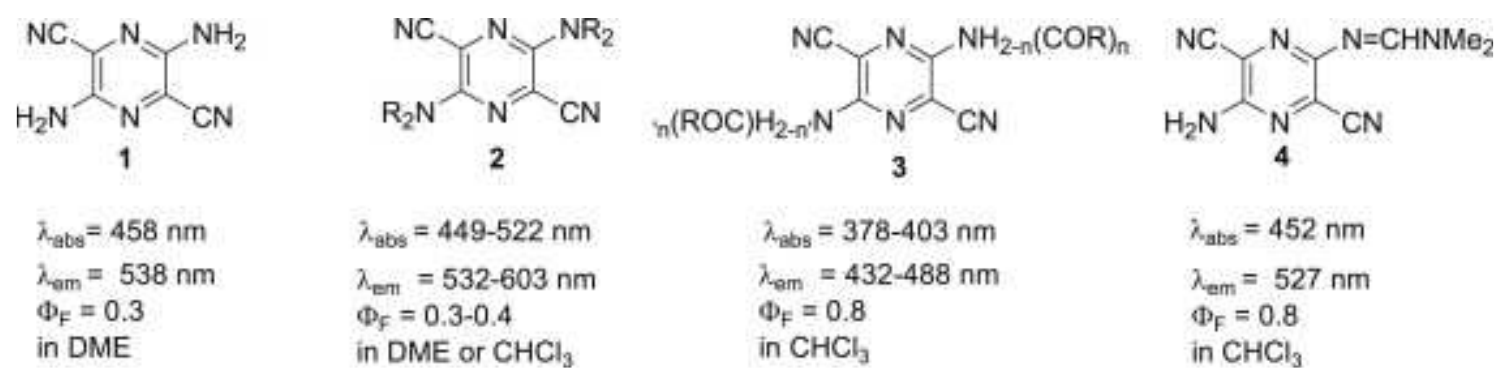

Scheme 1. Structure and photophysical data of compounds 1-4. 
A series of mono- and diazomethines dyes derived from 1 were also developed by Matsuoka and coworkers and have proved to be red light emitters for electroluminescence devices (Scheme 2) [23].<smiles>N#Cc1nc(/N=C/[Ba])c(C#N)nc1N</smiles><smiles>N#Cc1nc(N=CBr)c(C#N)nc1N=C[Al]</smiles>

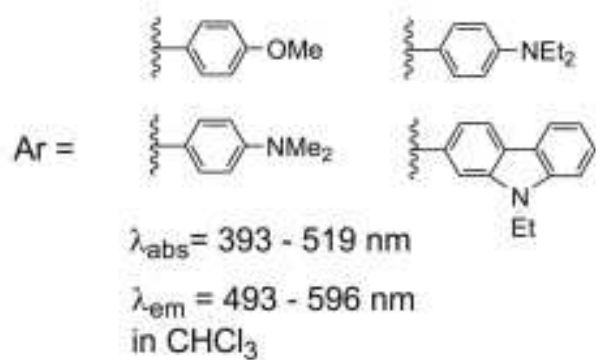

Scheme 2. Structure and photophysical data of compounds $\mathbf{5}$.

More recently a comparative study of the photophysical properties of the 2,5-diamino-3,6dicyanopyrazine $\mathbf{1}$ with other diaminodicyanopyrazines was performed in acetonitrile by Angulo et al [24]. The compound 1 exhibits red shifted absorption and emission in comparison with those of $\mathbf{6}$. These results could be explained by a more important ICT between the nitrile and amino groups due to their opposite position in the symmetrical compound 1 (Scheme 3).
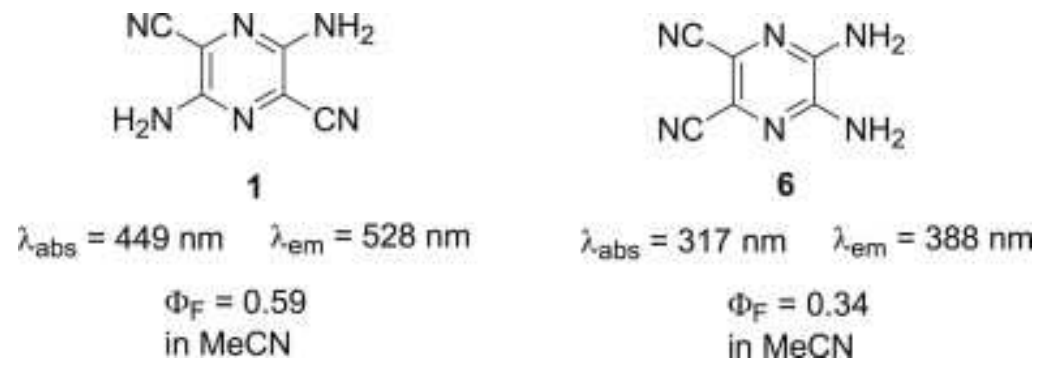

Scheme 3. Structure and photophysical data of compounds 1 and 6. 


\subsection{Diamino and dicarboxypyrazine derivatives}

Using the 2,5-diamino-3,6-dicarboxypyrazine 7 as starting material, various thioester and carbamoyl derivatives $\mathbf{8}$ and $\mathbf{9}$ were synthesized and their photophysical properties established in $\mathrm{CHCl}_{3}$ (Scheme 4) [25].

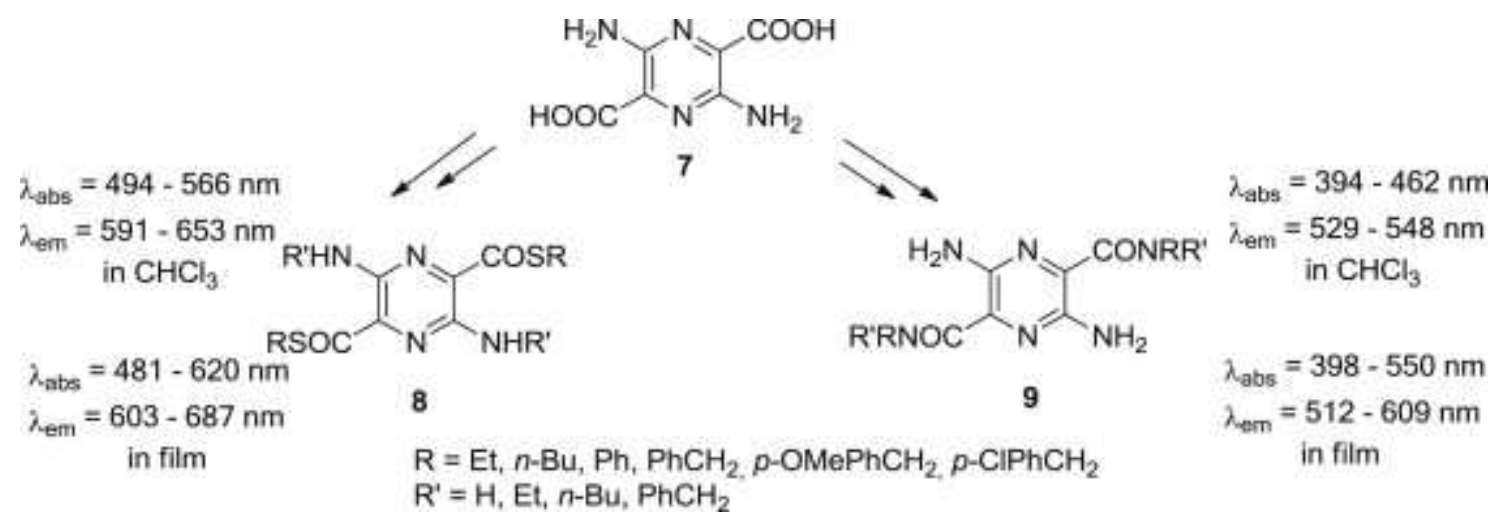

Scheme 4. Structure and photophysical data of compounds 7-9.

The solid state spectra of compounds $\mathbf{8}$ and $\mathbf{9}$ were evaluated with respect to their molecular staking. In the case of the 2,5-diamino-3,6-bis(butoxycarbonyl)pyrazine, the X-ray crystal analysis has shown space-filling intermolecular interactions of diaminopyrazines making possible the construction of strong three dimensional molecular staking in single crystals, which affects their solid state absorption spectra.

Starting from chromophores 10, easily obtained by reductive amination reaction, Poreddy and coworkers have developed hydrophilic red fluorescent N,N'-dialkylated aminopyrazines 11 and 12 [26]. These compounds absorb and emit at higher wavelengths $(\sim 50 \mathrm{~nm})$ than their corresponding aminopyrazines and could found potential applications in medical diagnostic (Scheme 5). 


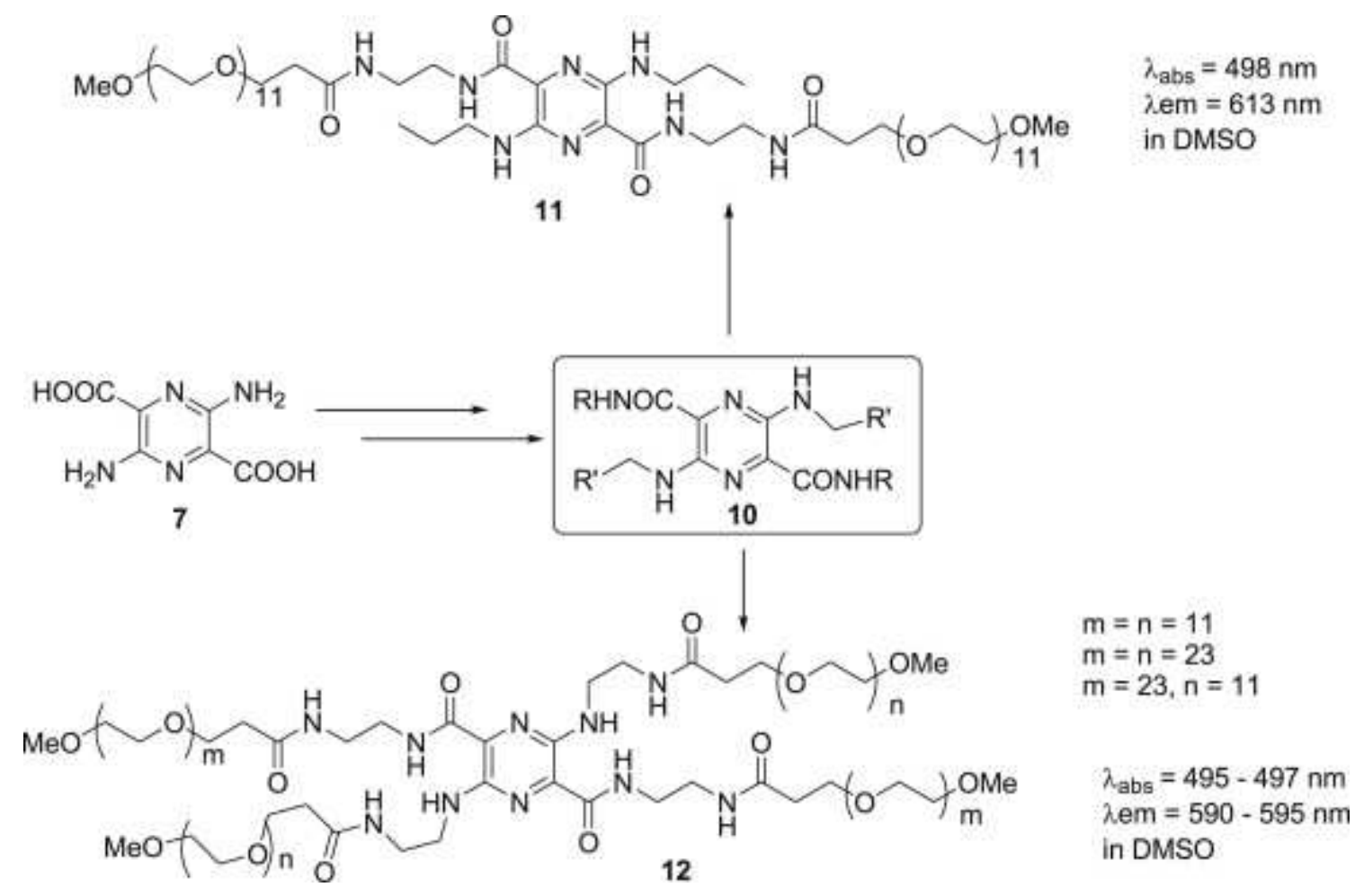

Scheme 5. Structure and photophysical data of compounds 10-12.

More recently, the same team has described similar hydrophilic pyrazine dyes $\mathbf{1 3}$ and $\mathbf{1 4}$ that have neutral and anionic groups [27]. These molecules have emission wavelengths $\lambda_{\text {em }}$ ranging between 557-600 $\mathrm{nm}$ and quantum yield around 0.4 in DMSO for the enantiomer of 13a (Scheme 6). Besides their interesting photophysical properties, some of these compounds could be used as fluorescent glomerular filtration rate (GFR) tracer agents.

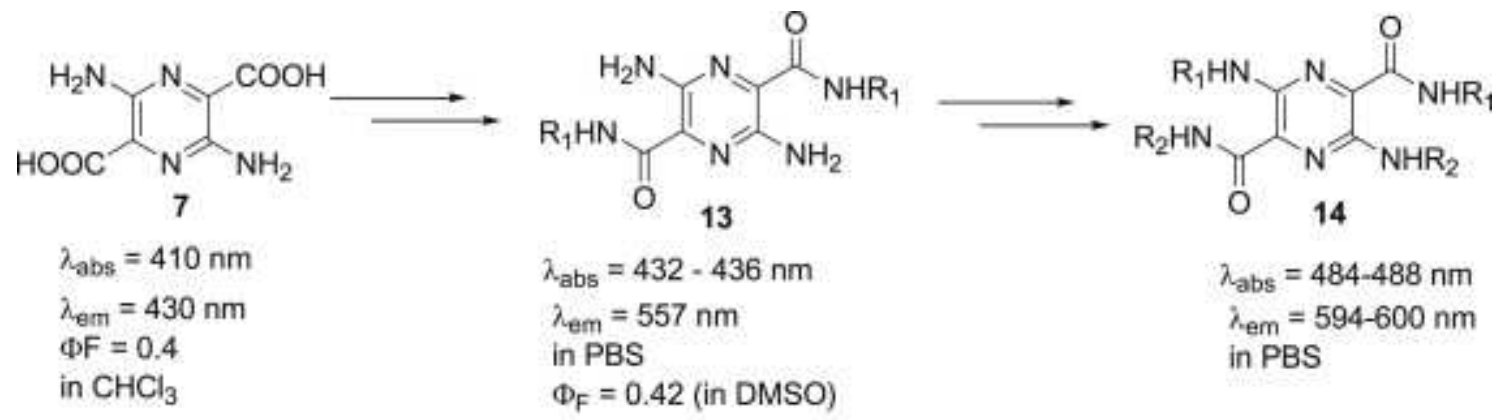

13a $\mathrm{R}_{1}={ }^{*} \mathrm{CH}\left(\mathrm{CH}_{2} \mathrm{OH}\right) \mathrm{CO}_{2} \mathrm{H}$ (R, R-isomer)

14a $\mathrm{R}_{1}=\mathrm{CH}_{2} \mathrm{CH}(\mathrm{OH}) \mathrm{CH}_{2} \mathrm{OH}, \mathrm{R}_{2}=\mathrm{CH}_{2}{ }^{*} \mathrm{CH}(\mathrm{OH}) \mathrm{CH}_{2} \mathrm{OH}$ (S, S-isomer)

14b $\mathrm{R}_{1}={ }^{\circ} \mathrm{CH}\left(\mathrm{CH}_{2} \mathrm{OH}\right) \mathrm{CO}_{2} \mathrm{H}_{1} \mathrm{R}_{2}=\mathrm{CH}_{2}{ }^{*} \mathrm{CH}(\mathrm{OH}) \mathrm{CH}_{2} \mathrm{OH}$ (R, R, S, S-isomer)

Scheme 6. Structure and photophysical data of compounds 7, 13 and 14. 
Chromophoric crosslinkers constituted by tetra-functionalized 3,6-diaminopyrazines 15-17 bearing a set of terminal aliphatic and anilino amine groups were recently synthesized (Scheme 7). With these molecules, Wooley et al, have developed dual-emitting photonic nano-objects that can sense changes in the environmental $\mathrm{pH}[28]$.

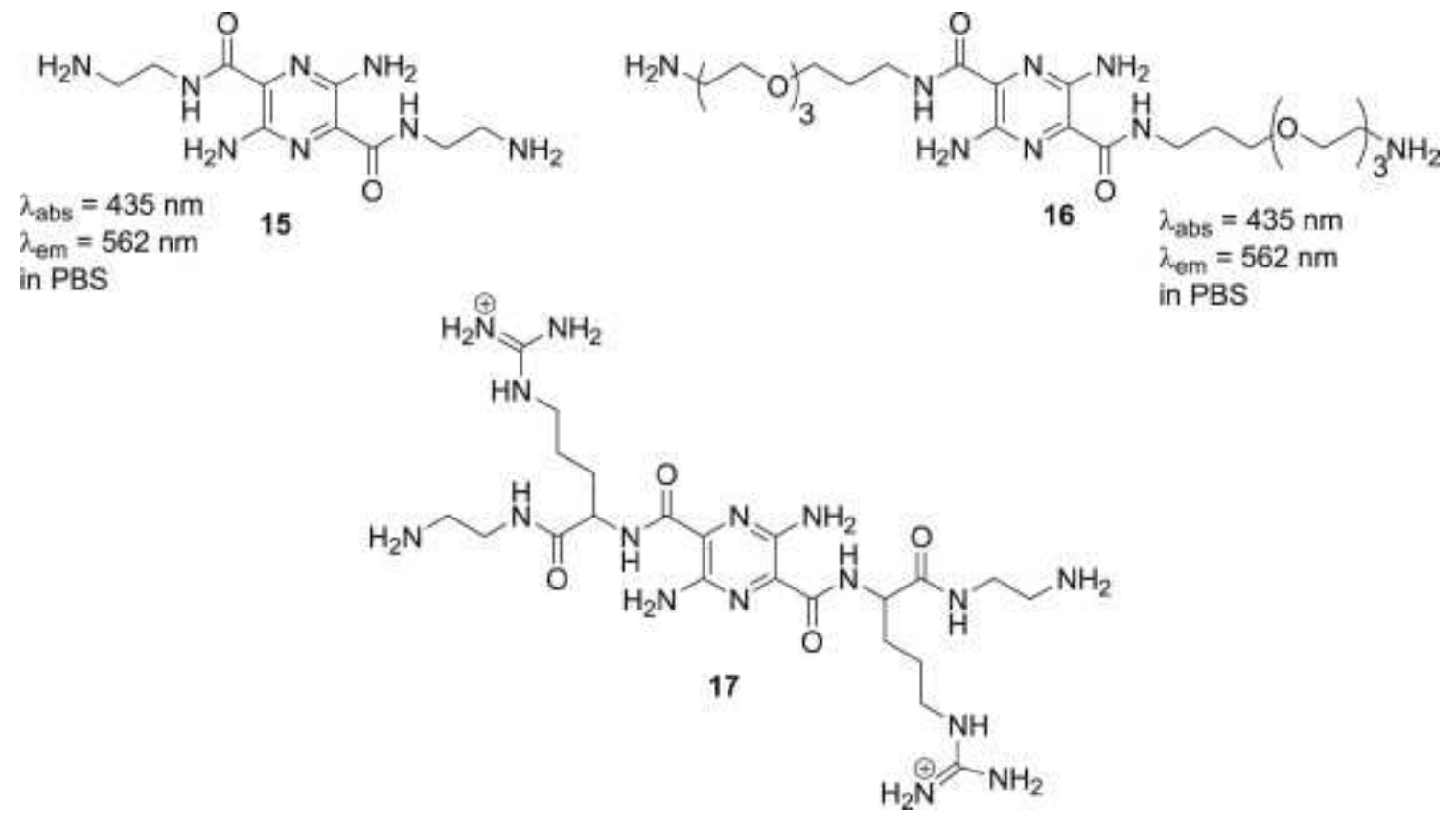

Scheme 7. Structure and photophysical data of compounds $\mathbf{1 5}-\mathbf{1 7}$.

Compounds 15-17 have demonstrated a morphology-dependent reactivity towards physical or chemical change leading to fine tuning of dual-emission over ca. $60 \mathrm{~nm}(496$ to $560 \mathrm{~nm})$ in a physiologically relevant $\mathrm{pH}$ range.

Teramae and coworkers have described the selective binding of Amiloride 18 (Scheme 8), a 2,6-diaminopyrazine derivative, to abasic (AP) site in RNA [29]. A dramatic increase of the fluorescence of amiloride at $415 \mathrm{~nm}$ was observed selectively in the presence of AP-RNA, making such a response applicable to microRNA detection. 


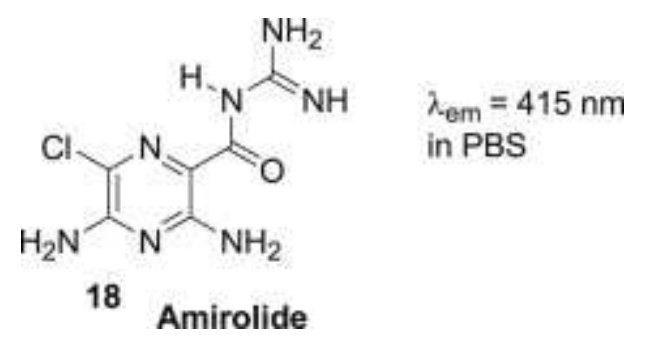

Scheme 8. Structure and photophysical data of compound $\mathbf{1 8 .}$

\subsection{Arylvinyl and aryldicyanopyrazines}

2,3-dicyanopyrazines which are powerful electron acceptors were used as building blocks to synthesize chalcone analogues and styryldicyanopyrazines. The chalcone derivatives $\mathbf{2 0}$ were obtained by the Knoevenagel condensation of 2-acetyl-4-methyl-5,6-dicyanopyrazine 19 with various arylaldehydes whereas the styrylpyrazines $\mathbf{2 1}$ and $\mathbf{2 2}$ have resulted from a similar condensation reaction of the methyl group with arylaldehydes (Scheme 9). These compounds are highly fluorescent ( $\lambda_{\text {em }}$ comprised between 479 and $610 \mathrm{~nm}$ in $\mathrm{CHCl}_{3}$ ), showed solvatochromism depending from polarity of the solvents and an intramolecular charge transfer confirmed by semi-empirical calculations (MOPAC PM3 method) [30]. When the pyrazine is substituted by a hydroxyl group, a large negative solvatochromism is observed due to tautomerism between the hydroxypyrazine and the pyrazinone forms. 
<smiles>CC(=O)c1nc(C#N)c(C#N)nc1C</smiles>

19 piperidine/acetic acid

Benzene<smiles>[R2]Nc1ccc(/C=C/C(=O)c2nc(C#N)c(C#N)nc2C)c([R2])c1</smiles>

$\mathrm{R}_{1}=\mathrm{Me}, \mathrm{Et}$, julolidinyl $\mathrm{R}_{2}=\mathrm{H}, \mathrm{OH}$

$\lambda_{\text {abs }}=526-575 \mathrm{~nm}$ in $\mathrm{CHCl}_{3}$<smiles>[R]c1cc(N([R12])[R12])ccc1/C=C/c1nc(C#N)c(C#N)nc1[R]</smiles>

$\mathrm{R}=\mathrm{COPh}, \mathrm{COOEt}$

$\mathrm{R}_{1}=\mathrm{Me}, \mathrm{Et}$, julolidiny!

$\mathrm{R}_{2}=\mathrm{H}, \mathrm{OH}$

$\lambda_{\mathrm{abs}}=498-580 \mathrm{~nm}$ $\lambda_{\text {em }}=582-610 \mathrm{~nm}$ in $\mathrm{CHCl}_{3}$

Scheme 9. Structure and photophysical data of compounds 19-22.

Di-(arylvinyl)dicyanopyrazines $\mathbf{2 3}$ and $\mathbf{2 4}$ and V-shaped structures $\mathbf{2 5}$ with a benzene or a pyridine as central core were also synthesized (Scheme 10) [31]. The physical properties of these fluorophores were determined and a reasonable correlation was found between calculated (PPP MO) and experimental data. 


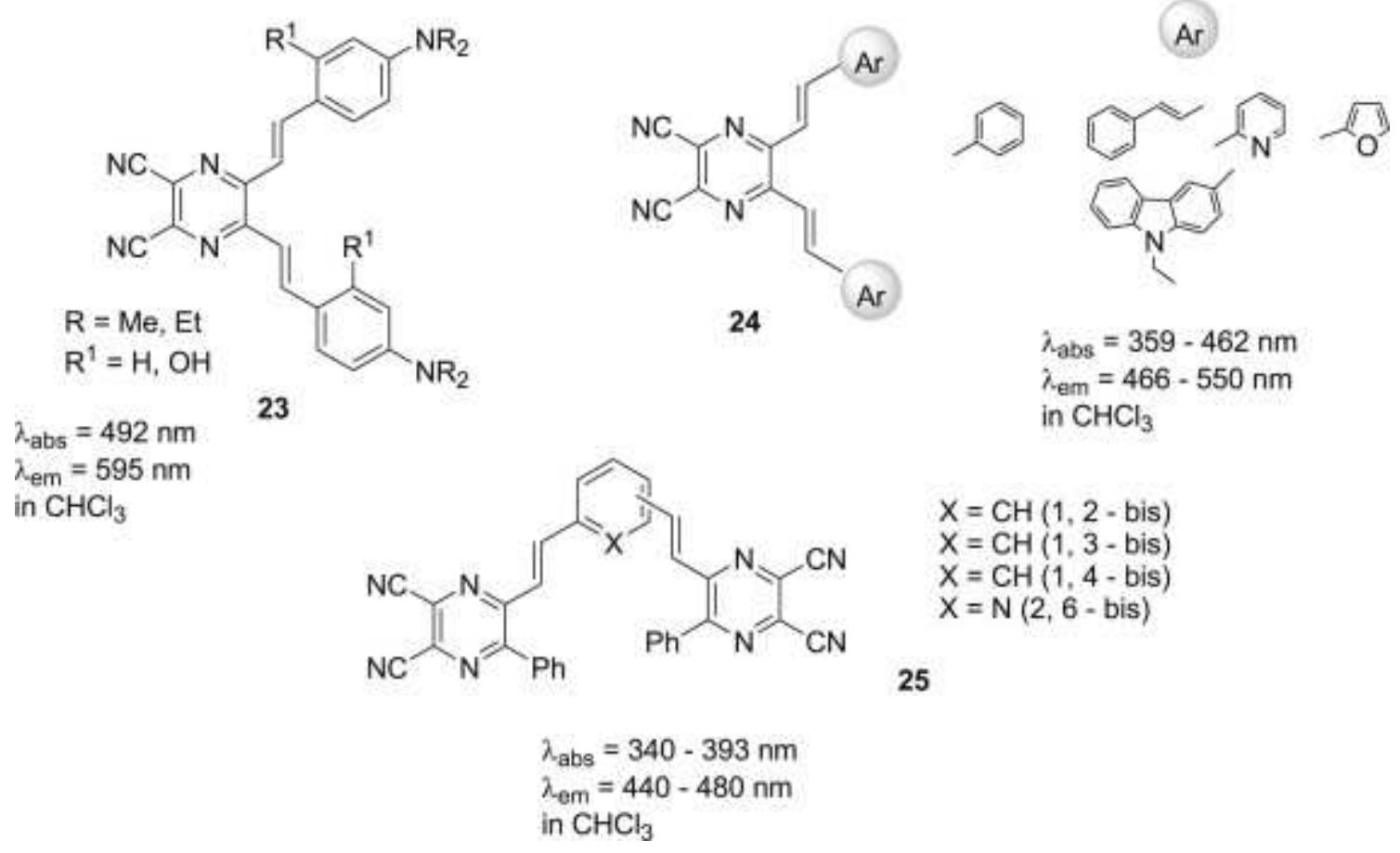

Scheme 10. Structure and photophysical data of compounds 23-25.

The 2,3-bis(phenylethenyl)-5,6-dicyanopyrazine $\mathbf{2 6}$ was studied as fluorescent material in solid state [32]. The single crystals of this compound underwent a morphological phase transformation (at $174^{\circ} \mathrm{C}$ ) from a yellow crystal to an orange one via a thermal phase transition without the crystal state collapsing (Scheme 11). The crystal lattice transformation was explained in terms of the lattice contraction and the intermolecular $\pi-\pi$ interaction in the solid state.

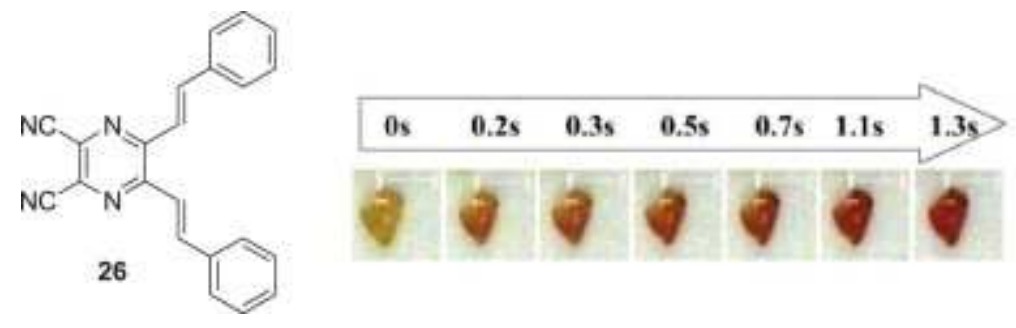

Scheme 11. Structure of compound $\mathbf{2 6}$ and color change of cristal via a thermal phase transition. 
Matsumoto and coworkers have described the J-aggregate structure of a chloroform solvate of the 5-t-butyl-2,3-dicyano-6-[4-(dimethylamino)styryl]pyrazine 27a (Scheme 12) [34]. The dye was found to form a two-dimensional brick-wall structure, separated by chloroform molecules in the solvated crystals, which emits intense red fluorescence.

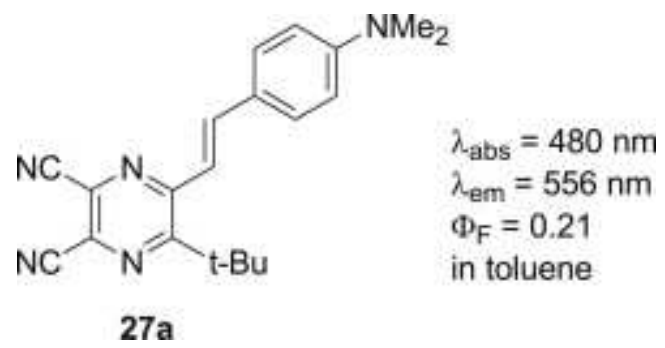

Scheme 12. Structure and photophysical data of compound 27a.

Moreover, other 2,3-dicyanopyrazine derivatives $\mathbf{2 7}$ with ester linkers were designed (Scheme 13) [35]. These molecules have a similar V-shaped geometry, confirmed by the X-ray structure of the central core, with lack of planarity between the two arms. The optical and thermal properties of these compounds were evaluated highlighting a blue fluorescence in solution $\left(\lambda_{\mathrm{em}} 437-445 \mathrm{~nm}\right)$ with low to moderate quantum fluorescence yields $\left(\Phi_{\mathrm{F}}\right)$ from 0.003 to 0.1 and Stokes shifts of around $6000 \mathrm{~cm}^{-1}$. 


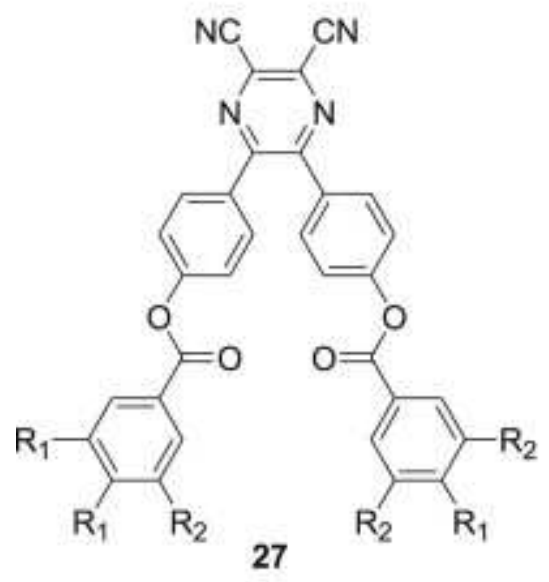

$\lambda_{\text {abs }}=347-359 \mathrm{~nm}$

$\lambda_{\text {em }}=437-445 \mathrm{~nm}$

$\Phi_{\mathrm{F}}=0.003-0.01$

in $\mathrm{CHCl}_{3}$

$$
\begin{array}{ll}
\mathrm{R}_{1}=\mathrm{OC}_{10} \mathrm{H}_{21}, & \mathrm{R}_{2}=\mathrm{H} \\
\mathrm{R}_{1}=\mathrm{R}_{2}=\mathrm{OC}_{12} \mathrm{H}_{15} & \mathrm{R}_{2}=\mathrm{H} \\
\mathrm{R}_{1}= & \mathrm{R}_{2}=\mathrm{H} \\
\mathrm{R}_{1}=\mathrm{RC}_{10} \mathrm{H}_{21} & \\
\mathrm{R}_{1}=\mathrm{R}_{2}=\mathrm{OC}_{12} \mathrm{H}_{25} &
\end{array}
$$

Scheme 13. Structure and photophysical data of compounds 27.

The [2+2] photocycloaddition of 2,3-dicyanopyrazine derivatives $\mathbf{2 8}$ were achieved by irradiation at $365 \mathrm{~nm}$ under a high-pressure Hg lamp, leading to the photodimers 29 (Scheme 14) [36]. Spectral changes of UV-visible absorption and fluorescence intensity were examined at specific exposure intervals. While the cyclobutane ring of dimers induced a discrete $\pi$ conjugation with aryl substituents showing a hypsochromic shift of absorption and emission spectra. For example, change of fluorescence spectra of $\mathbf{2 8}$ with $\mathrm{R}=t$ - $\mathrm{Bu}$ in a thin film under irradiation became brighter and was blue shifted from $478 \mathrm{~nm}$ to $467 \mathrm{~nm}$ 
<smiles>[R]c1ccc(/C=C/c2nc(C#N)c(C#N)nc2-c2ccc(C(C)(C)C)cc2)cc1</smiles>

28

$\lambda_{\text {abs }}=358-408 \mathrm{~nm}$

$\lambda_{\text {em }}=425-502 \mathrm{~nm}$

in $\mathrm{CHCl}_{3}$

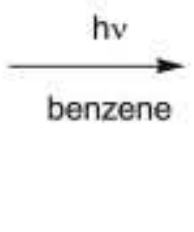

$\mathrm{R}=\mathrm{H}, \mathrm{CH}_{3}, t \mathrm{Bu}, \mathrm{OCH}_{3}$

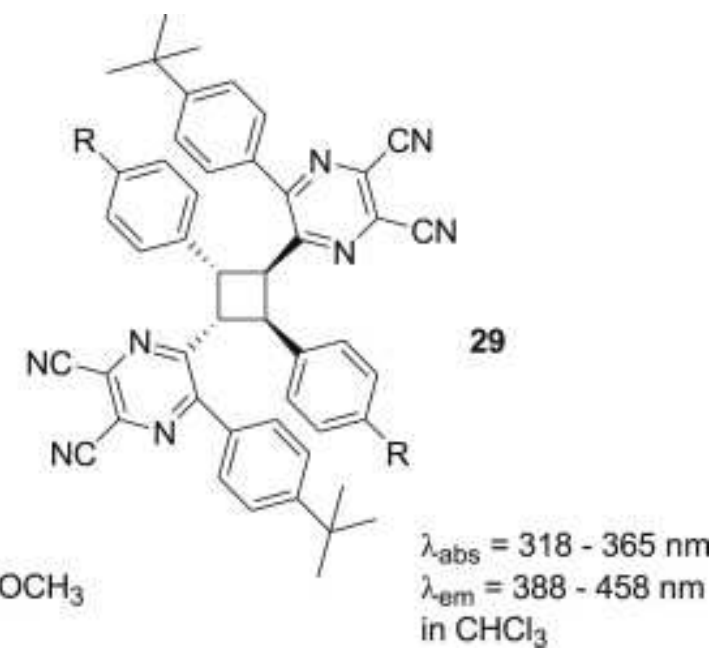

Scheme 14. Structure and photophysical data of compounds 28 and 29.

Lee and coworkers have developed dicyanopyrazine dyes $\mathbf{3 0}$ containing spiropyran groups [37]. These compounds have emission at $484 \mathrm{~nm}$ in $\mathrm{CHCl}_{3}$ as well as photochromic properties under UV irradiation. The spiropyran part is used due to its ability to exhibit two forms: a colorless closed spiro form 30a and a colored open merocyanine form 30b (Scheme 15). Such derivatives have potential applications for data storage, electronic devices and optical filters.
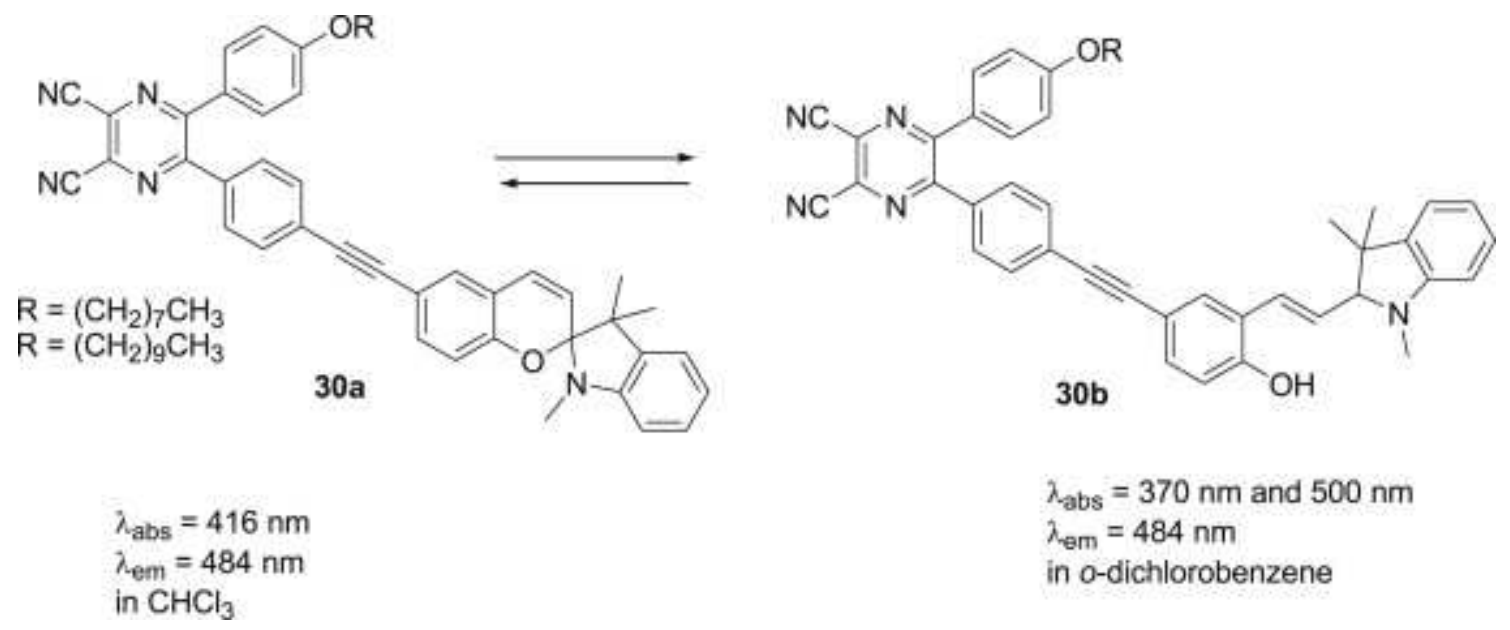

Scheme 15. Structure and photophysical data of compounds 30. 
A compound with ICT properties: the 5,6-bis-[4-(naphthalene-1-yl-phenyl-amino)-phenyl]pyrazine-2,3-dicarbonitrile 31 (BNPPC) was synthesized by Chew et al (Scheme 16) [38]

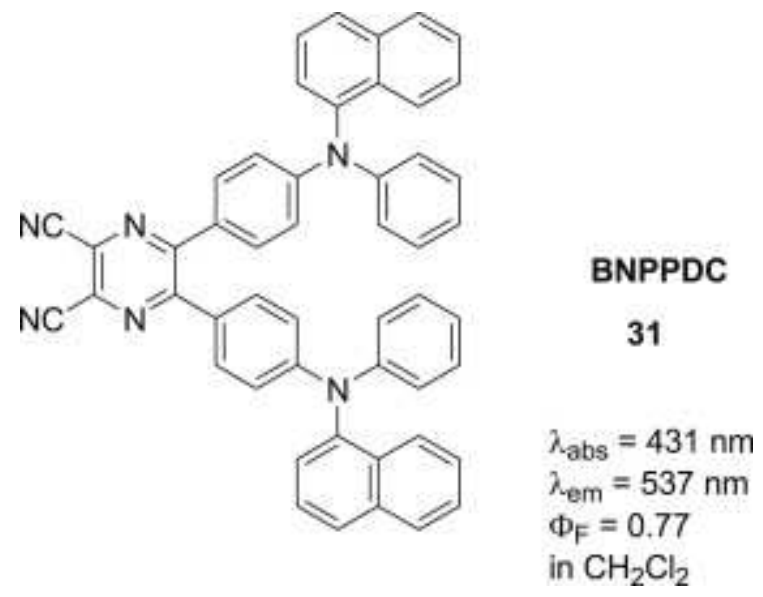

Scheme 16. Structure and photophysical data of compound 31.

This compound was strongly fluorescent in non-polar and moderately polar solvents, as well as in thin solid film. The absorption and emission maxima shifted to longer wavelength with increasing solvent polarity. The fluorescence quantum yield also was also improved with increasing solvent polarity from non-polar to moderately polar solvents, then decreased with further increase of solvent polarity. This indicates that both "positive" and "negative" solvatokinetic effects co-exist. Using this material as hole-transporting emitter and host emitter has allowed elaboration of green-yellow electroluminescent (EL) devices.

Condensation reaction of pyrrole and a bis-styryl derivative containing the 2,3dicyanopyrazine moiety has allowed Jaung to synthesize pyrazine-linked porphyrins 32 (Scheme 17) [39]. These systems with a strong ICT revealed specific spectral properties such as emission of red fluorescence with a large Stokes Shift (over $7300 \mathrm{~cm}^{-1}$ ). The protonation/deprotonation were shown to affect the spectral properties of the compounds. 


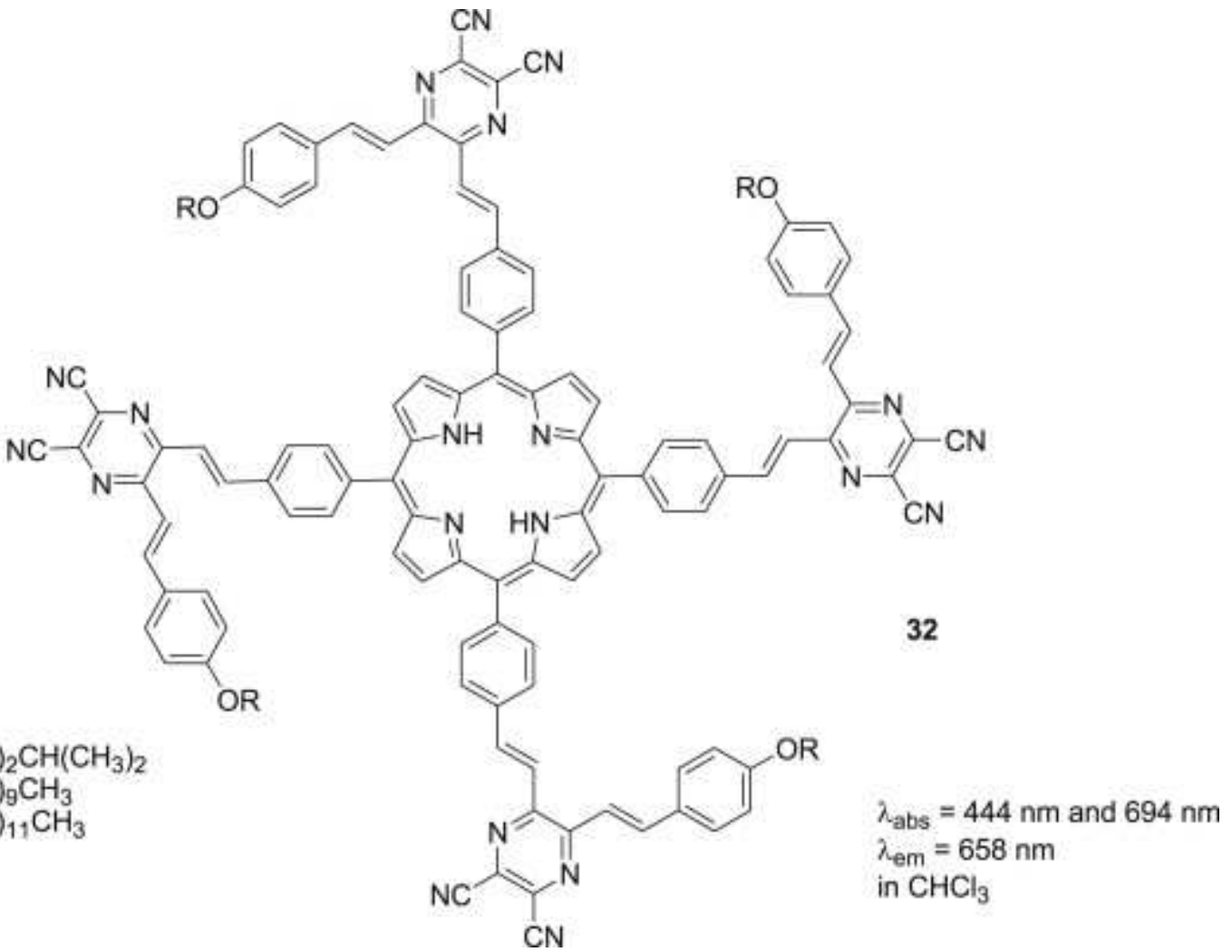

Scheme 17. Structure and photophysical data of compounds 32.

Starting from the 2,3-dicyanopyrazine derivative 33, Hill and coworkers have described a tetrapyrazinoporphyrazine 34 substituted at its periphery with eight antioxidant 3,5-di- $t$-butyl4-hydroxyphenyl groups which behave as a turn-on fluorescent sensor for fluoride anions (Scheme 18) [40]. 

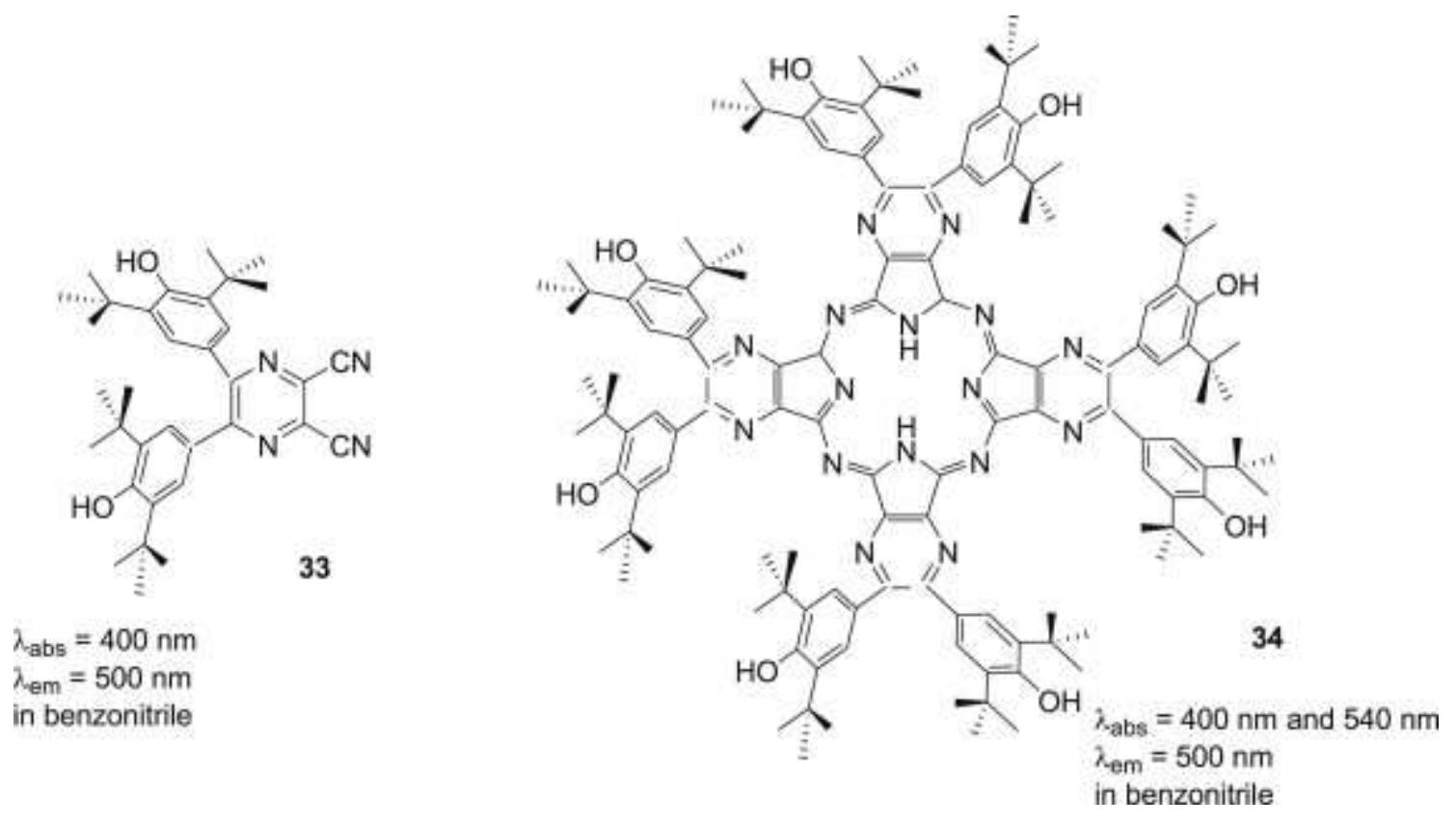

Scheme 18. Structure and photophysical data of compounds $\mathbf{3 3}$ and $\mathbf{3 4 .}$

Two series of new stable V-shaped push-pull chromophores $\mathbf{3 5}$ with two dimethylamino as the donor, a pyrazine-2,3-dicarbonitrile moiety as the acceptor and with systematically extended and varied $\pi$-linkers were reported by Burěs et al. (Scheme 19) [41].

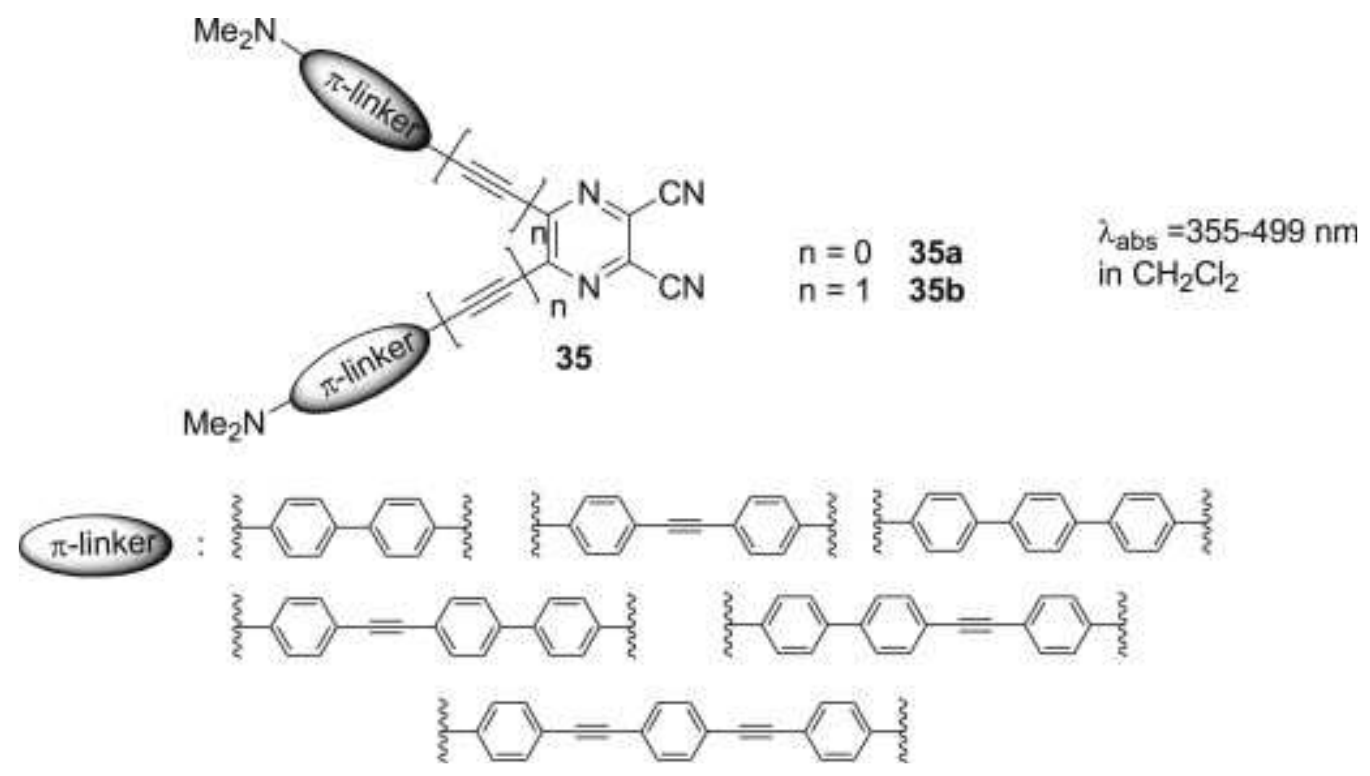

Scheme 19. Structure and photophysical data of compounds 35. 
The nature and the length of $\pi$-linkers were investigated and the UV/Vis spectra, electrochemical data and $2^{\text {nd }}$ order nonlinear optical (NLO) properties of these CT chromophores were studied. Compounds $\mathbf{3 5} \mathbf{b}$ with an additional triple bound to separate the $\pi$-linker from the pyrazine-2,3-dicarbonitrile moiety, are the most planar and exhibit the best D-A conjugation and the best NLO properties $\left(\beta_{\mathrm{av}}=3.1 \mathrm{pm} \mathrm{V}^{-1}\right)$.

\subsection{Arylvinyl and arylethynylpyrazines}

Synthesis, absorbance and fluorescence properties of the 2-(4'-hydroxystyryl)pyrazine 36a was reported (Scheme 20) [42]. The spectral data of 36a are better than those of the pyridine analogous and have exhibited a strong dependence on solvent polarity and $\mathrm{pH}$. Recently, other 2-(4'aminostyryl)pyrazines $\mathbf{3 6} \mathbf{b}$ and 36c were synthesized. Their optical absorption and emission properties have highlighted strong emission in dichloromethane $\left(\lambda_{\mathrm{em}}=511\right.$ and 532 $\mathrm{nm}$ respectively) with high Stokes shift $\left(6137\right.$ and $\left.6534 \mathrm{~cm}^{-1}\right)$, they have also exhibited an important positive emission solvatochromism and presented halochromism properties [43]. The second order NLO properties of compound $\mathbf{3 6} \mathbf{b}$ were also reported and compared with those of other diazine derivatives. With a value of $\mu \beta=22010^{-48}$ esu, the pyrazine derivative 36b exhibits a better value than the pyridazine derivative but a lower value than the pyrimidine derivative.

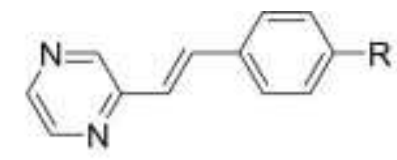

$\mathrm{R}=\mathrm{OH} \quad 36 \mathrm{a} \lambda_{\text {abs }}=350 \mathrm{~nm} \lambda_{\text {em }}=491 \mathrm{~nm}$ in $\mathrm{EtOH}$

$\mathrm{R}=\mathrm{NMe}_{2} 36 \mathrm{~b} \lambda_{\text {abs }}=389 \mathrm{~nm} \lambda_{\text {em }}=511 \mathrm{~nm} \Phi_{\mathrm{F}}=0.17$ in $\mathrm{CH}_{2} \mathrm{Cl}_{2}$

$\mathrm{R}=\mathrm{NPh}_{2} \quad 36 \mathrm{c} \lambda_{\mathrm{abs}}=394 \mathrm{~nm} \lambda_{\mathrm{em}}=532 \mathrm{~nm} \Phi_{\mathrm{F}}=0.41$ in $\mathrm{CH}_{2} \mathrm{Cl}_{2}$

Scheme 20. Structure and photophysical data of compounds 36. 
Vinylpyrazine triphenylamine derivative $\mathbf{3 7}$ and its dimethylated salt $\mathbf{3 8}$ (Scheme 21) were described by Aranda and coworkers [44]. The neutral compound 37 revealed strong fluorescence in dichloromethane solution $\left(\lambda_{\mathrm{em}}=569 \mathrm{~nm}, \Phi_{\mathrm{F}}=0.94\right)$, whereas the dimethylated salt $\mathbf{3 8}$ is non-luminescent. Nevertheless, this last compound exhibits a strong selective interaction for duplex DNA.
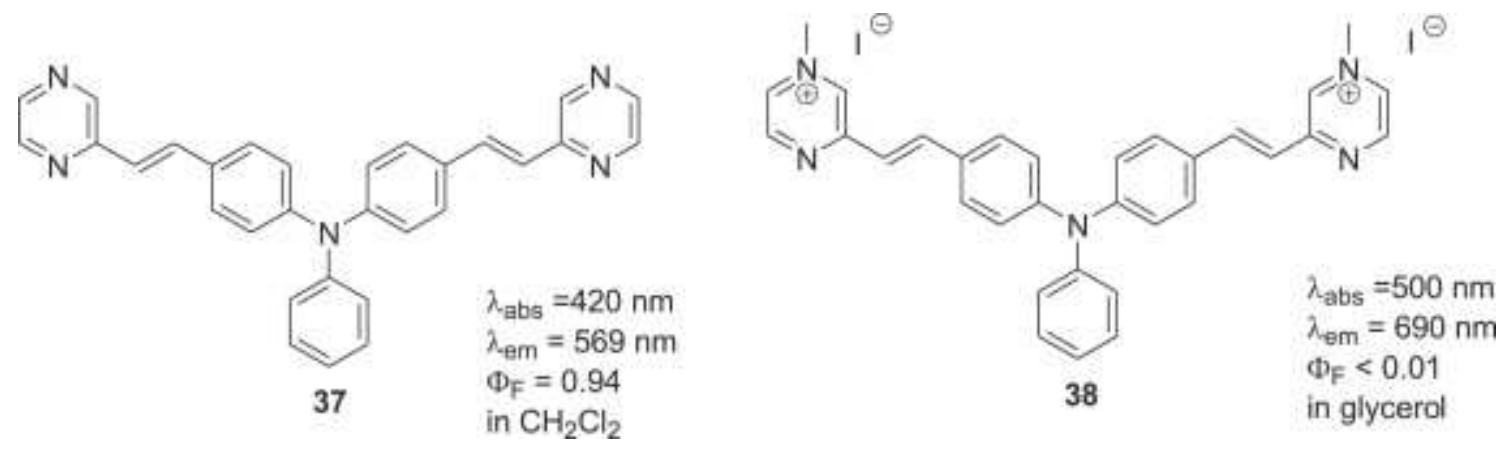

Scheme 21. Structure and photophysical data of compounds $\mathbf{3 7}$ and $\mathbf{3 8 .}$

Linear and angular distyrylpyrazines 39 and 40 with a donor-acceptor-donor electronic structure were synthesized and their fluorescence studied by Schmitt et al (Scheme 22) [45]. The materials display a strong solvatochromism of the emission that is reflected by large red shifts of their fluorescence emission maxima on increasing the solvent polarity. This behavior suggests a highly polar emitting state, which is characteristic of compounds that undergo an internal charge transfer upon excitation. Under acidic conditions, the UV-vis spectra are altered, and the fluorescence intensity of the neutral compound vanishes. These molecules can be used as colorimetric and luminescence polarity and $\mathrm{pH}$ sensors. 


\section{Ar}

39

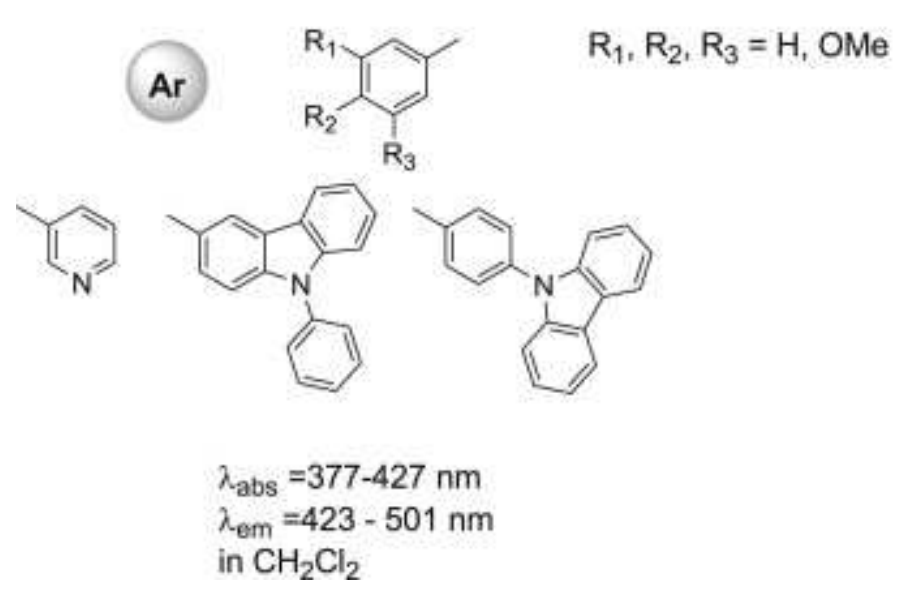

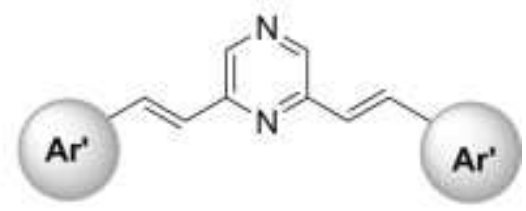

40

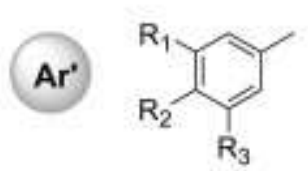

$\lambda_{\text {abs }}=381-400 \mathrm{~nm}$

$\lambda_{\text {em }}=461-474 \mathrm{~nm}$

in $\mathrm{CH}_{2} \mathrm{Cl}_{2}$

Scheme 22. Structure and photophysical data of compounds 39 and $\mathbf{4 0 .}$

Electrooptical and theoretical studies of various oligophenylenevinylenes 41-43 with a pyrazine central core were carried out (Scheme 23) [46]. The dipole moments of these quadrupolar dyes in the ground state are not equal zero, which means that one of the functional end groups of these molecules is not on the axis or on the plane with the central part of the molecule. The localized excitation effect causes a large change of the dipole moments of quadrupolar molecules upon excitation to the Franck-Condon excited state. Due to an efficient ICT, the authors claimed that these pyrazine derivatives must have significant non-linear optical properties. 

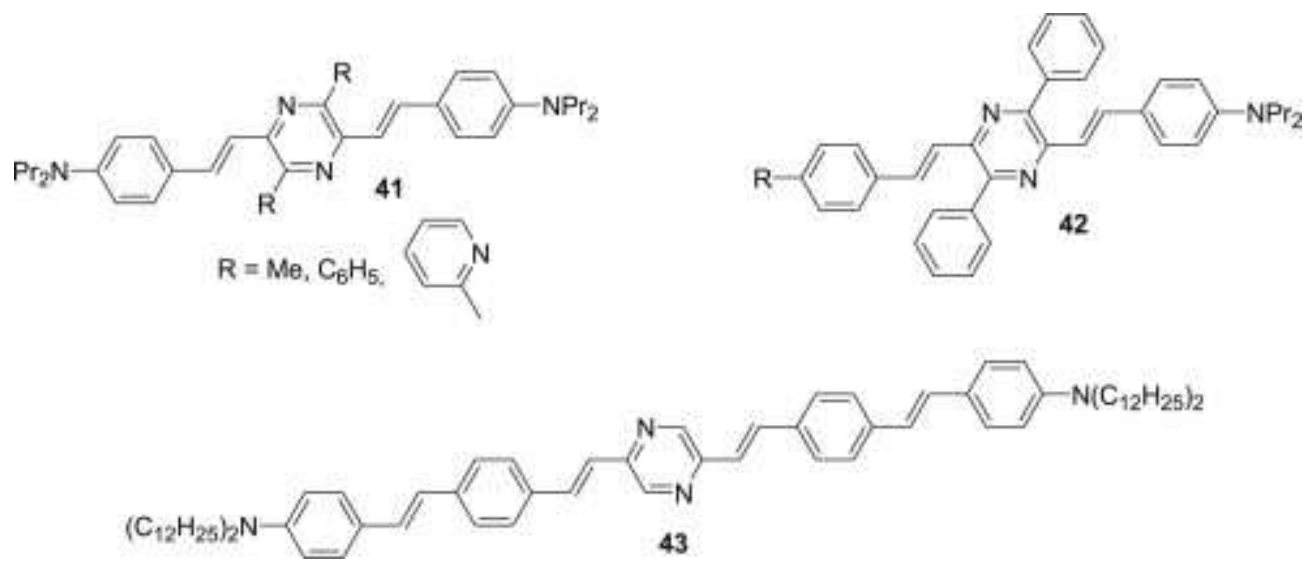

Scheme 23. Structure and photophysical data of compounds 41-43.

Other divinylpyrazine derivative $\mathbf{4 4}$ and $\mathbf{4 5}$ were described by Al-Hazmy et al (Scheme 24) [47]. The compound 44 with $\lambda_{\mathrm{em}}=463 \mathrm{~nm}$ in DMF acts as a laser dye upon pumping with nitrogen laser $\left(\lambda_{\mathrm{ex}}=337 \mathrm{~nm}\right)$.

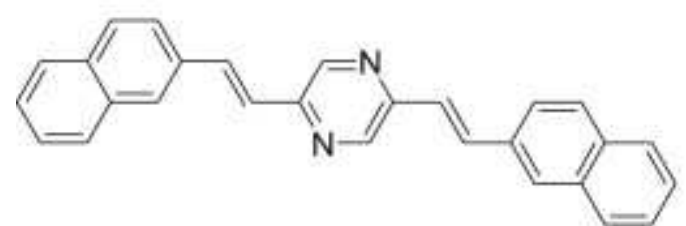

44

$\lambda_{\text {abs }}=397 \mathrm{~nm}$

$\lambda_{\text {em }}=458 \mathrm{~nm}$

$\Phi_{\mathrm{F}}=0.61$

in $\mathrm{CH}_{2} \mathrm{Cl}_{2}$

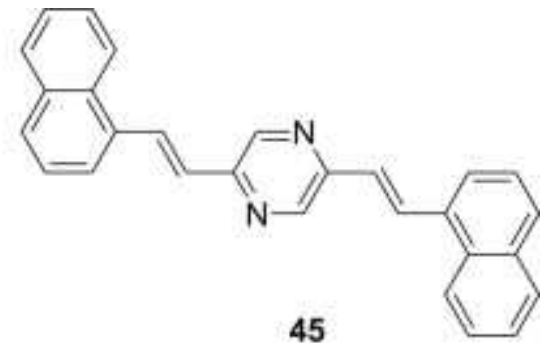

Scheme 24. Structure and photophysical data of compounds $\mathbf{4 4}$ and $\mathbf{4 5}$.

The cross-shaped chromophore $\mathbf{4 6}$ with four arms constituted by a phenyl group substituted by a donor and linked to the pyrazine core through a vinyl bridge were synthesized and compared with its linear analogue 47 with only two branches (Scheme 25) [48]. Their onephoton and two-photon absorption (TPA) properties were investigated. Compounds $\mathbf{4 6}$ and 47 are fluorescent respectively at $563 \mathrm{~nm}\left(\Phi_{\mathrm{F}}=0.67\right)$ and $518 \mathrm{~nm}\left(\Phi_{\mathrm{F}}=0.77\right)$. The TPA 
spectrum in toluene of $\mathbf{4 6}$ is quite similar to that of the two-branch analogue $47\left(\delta_{\max }=1250\right.$ GM, $\lambda_{\max }=790 \mathrm{~nm}$ ). The spectral features observed for these chromophores suggest that electronic coupling between the branches is effective but does not lead to significant enhancement of the two-photon cross section when the branches extend is in more than one dimension. In particular, the type of coupling effective in the four-branch compound 46 should result in a subadditivity of the two-photon cross section of $\mathbf{4 7}$.
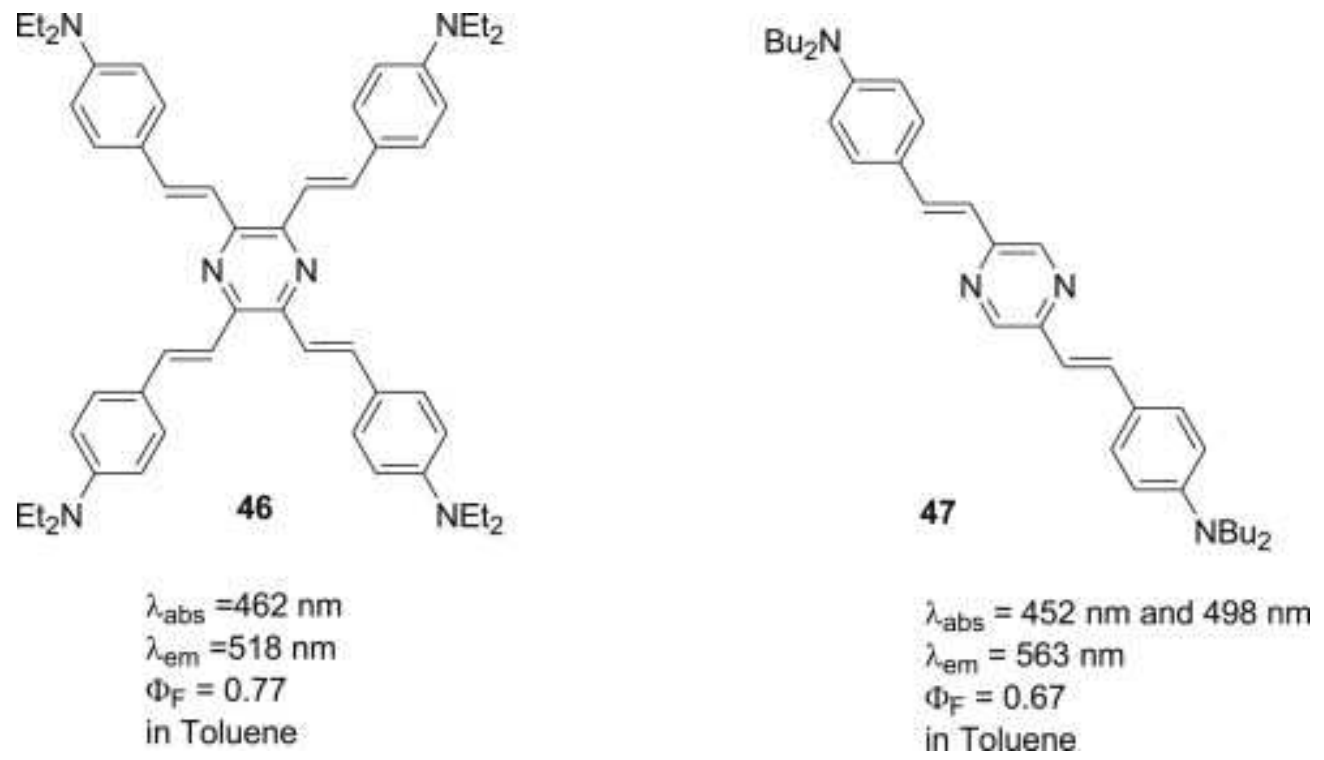

Scheme 25. Structure and photophysical data of compounds 46 and 47.

Detert et al. have described di(p-aminostyryl)pyrazines $\mathbf{4 8}$ with bulky substituents on the nitrogen of external amino groups and in the adjacent positions (Scheme 26) [49]. Steric congestion around the amino groups modulates the ICT in these fluorophores because the orbital overlap between nitrogen and $\pi$-system is modulated by the steric hindrance. Strong solvatochromism of the fluorescence and huge Stokes shifts results from amplified donoracceptor interaction in the excited state. Protonation occurs at the terminal amino groups first, followed by protonation of the central pyrazine only in very strongly acidic media. With 
increasing strength of acid, absorption and emission spectra are first shifted to the blue followed by a red shift.

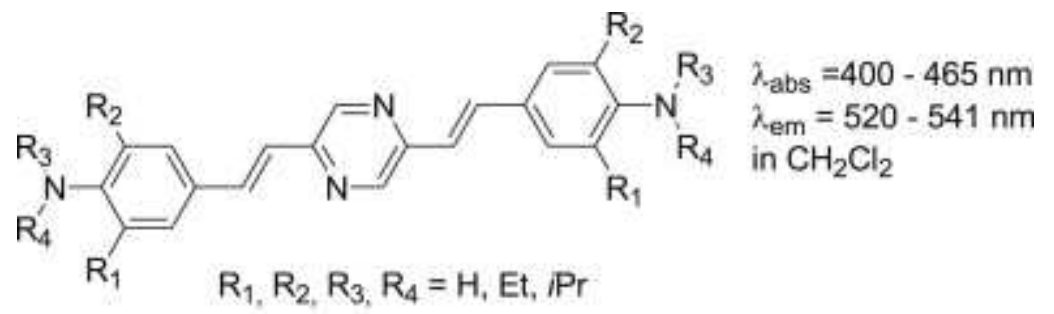

48

Scheme 26. Structure and photophysical data of compounds 48.

Synthesis and fluorescent properties of various bis(arylvinyl)pyrazines were reported by Schmidt et al.(Scheme 27) [50]. These compounds were tested as fluorescent probes for in vitro and in vivo detection of $\mathrm{AD}$-associated protein deposits in human brain tissue by fluorescence microscopy.
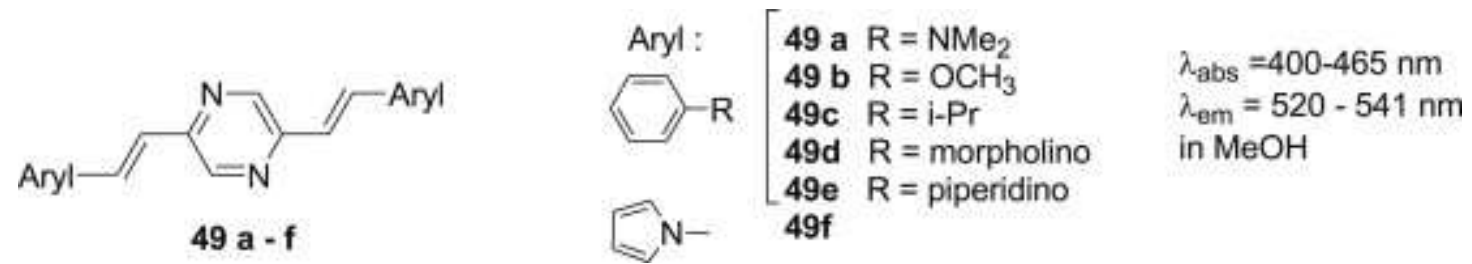

Scheme 27. Structure and photophysical data of compounds 49.

A series of pyrazine derivatives was reported by Collette et al, where the number and substitution pattern of $p$-dimethylaminostyryl branches on the pyrazine core were systematically studied (Scheme 28) [51]. These fluorophores were designed to exhibit large changes in emission in response to changes in solvent composition or addition of various analyte species. These molecules shared the structural and electronic features common to quadupolar two-photon chromophores. Calculations of their second hyperpolarizabilities 
$(\gamma(-\omega ; \omega,-\omega, \omega))$ and comparison to known two-photon molecules showed that these molecules were expected to be good two-photon active molecules.

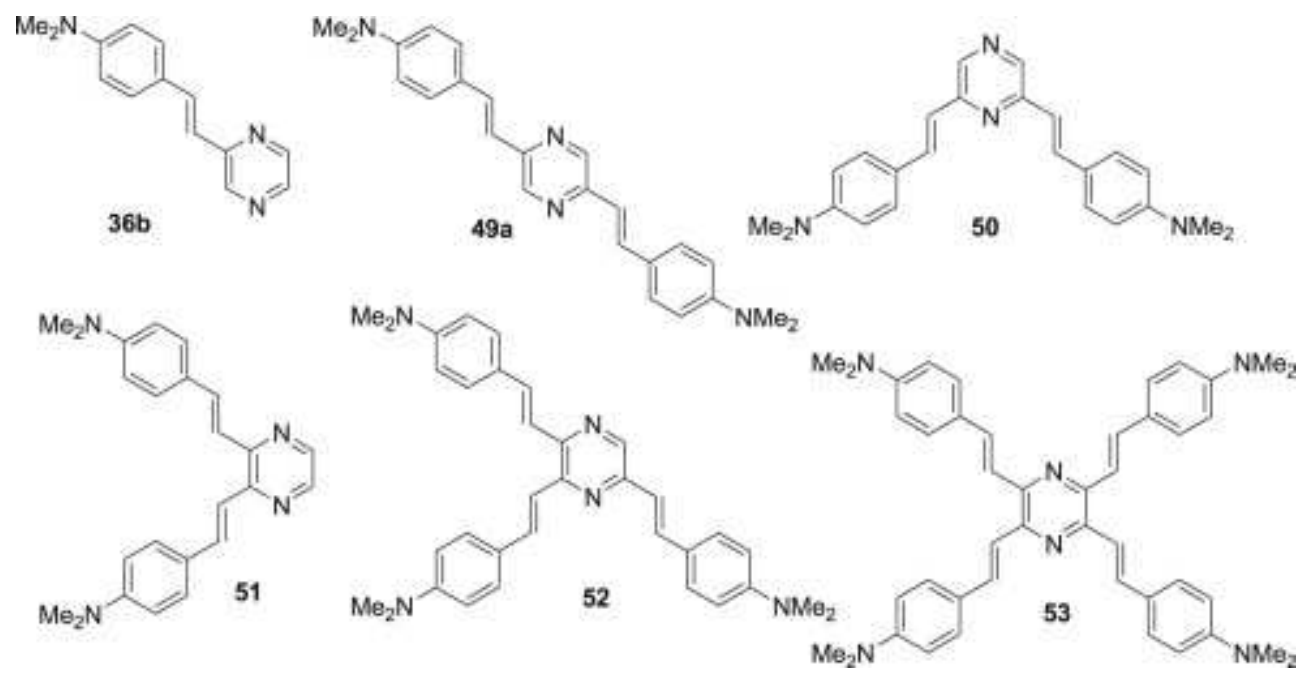

Scheme 28. Structure of compounds 36b, 49a and 50-53.

A four-branched quaternary ammonium pyrazine $\mathbf{5 4}$ (TASPI) was reported by Yan et al. [52]. This compound can be used for selective thrombin detection. In this detection system, the fluorescence of compound is almost eliminated by the DNA aptamer TBA (turn-off). However, in the presence of thrombin, it specifically binds to TBA by folding unrestricted TBA into an anti-parallel G-quadruplex structure and then releasing the pyrazine derivative, resulting in fluorescence recovery (turn-on) (Scheme 29). 

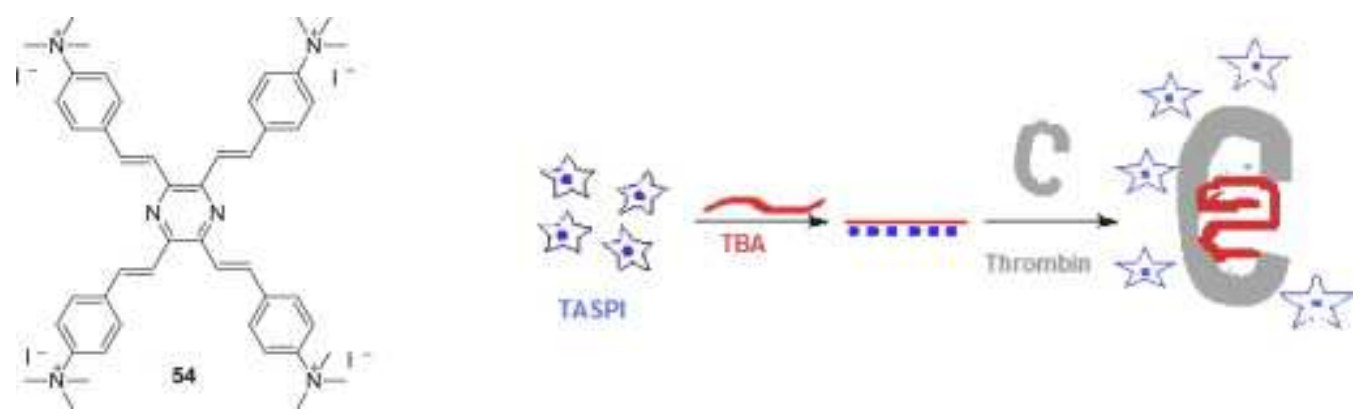

Scheme 29. Structure of compound 54, Schematic representation of the binding of TBA DNA aptamer and thrombin.

A fluorescent sensor 55 containing a pyrazine central core and bis(2-pyridylmethyl)amine groups as a binding moiety for $\mathrm{Pb}^{2+}$ was developed (Scheme 30) [53]. Compound $\mathbf{5 5}$ shows selective response to $\mathrm{Pb}^{2+}$ over other metal ions in $\mathrm{pH}$ 7.0 HEPES buffer solution. The fluorescence intensity enhancement was ascribed to the complex formation between $\mathrm{Pb}^{2+}$ and 55 which blocked the photo-induced electron transfer process.

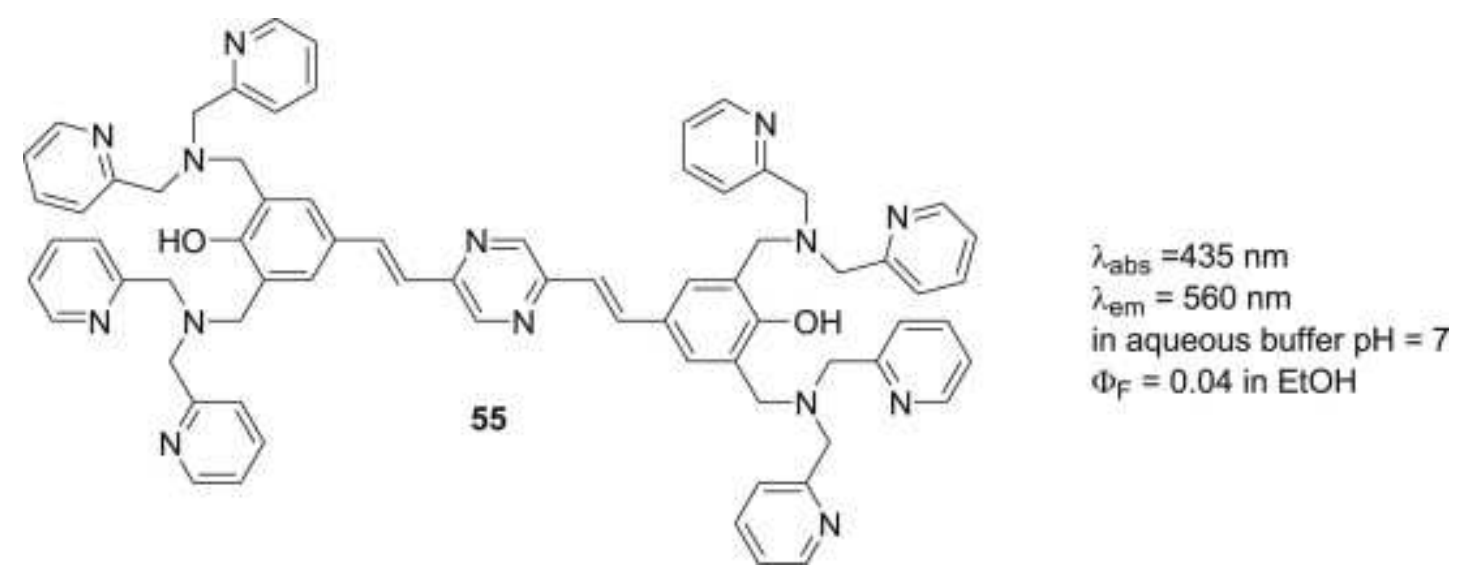

Scheme 30. Structure and photophysical data of compound 55.

$\mathrm{Wu}$ and coworkers have explored the nature of binding interaction of a fluorescent pyrazineZn probe 56 with calf thymus deoxyribonucleic acid (ct-DNA) (Scheme 31) [54]. Absorption titration of DNA with 56 was performed by fluorescence polarization measurements. All 
results showed that the interaction mode between the complex Zn-56 and the (ct-DNA) was electrostatic interaction.

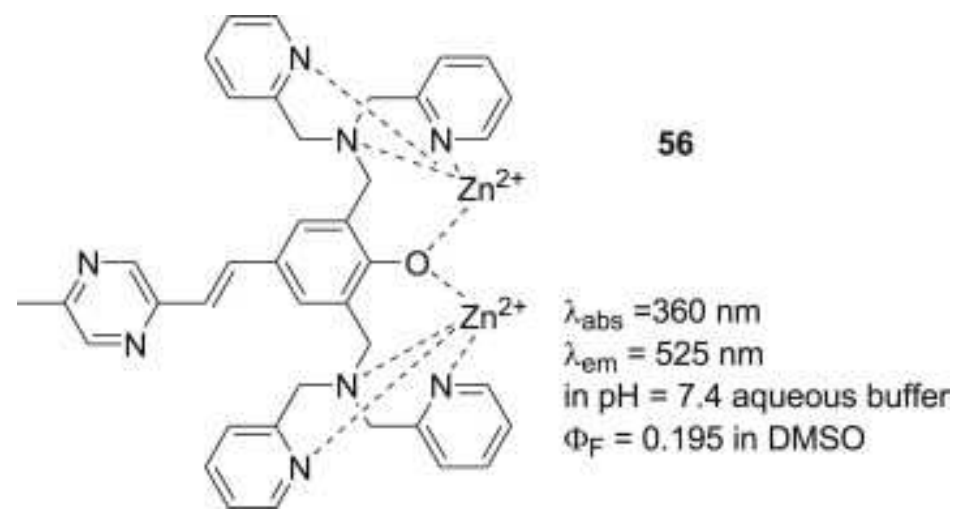

Scheme 31. Structure and photophysical data of compound $\mathbf{5 6 .}$

The synthesis of various push-pull molecules with a central pyrazine unit connected to a hexatriene chain terminated by various 4-substituted phenyl groups were reported (Scheme 32) [55]. These push-pull compounds 57- 59 have interesting light-emitting properties $\left(\lambda_{\text {em }}\right.$ ranging from 536 to $780 \mathrm{~nm}$ with fluorescence quantum yield up to 0.20 in chloroform) and high Stokes shifts. Compounds 57a and 57b were tested for their 2nd order NLO properties and promising results were observed $\left(\mu \beta=104810^{-48} \mathrm{esu}\right)$ for compound $\mathbf{5 7 b}$. 

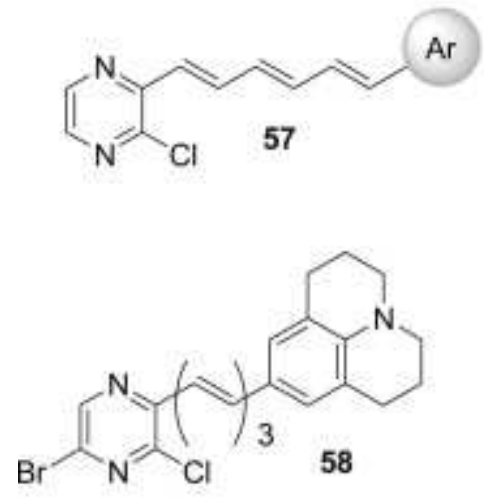

$$
\begin{aligned}
& \lambda_{\text {abs }}=489 \mathrm{~nm} \\
& \lambda_{\text {erm }}=713 \mathrm{~nm} \\
& \Phi_{\mathrm{F}}=0.09 \\
& \text { in } \mathrm{CHCl}_{3}
\end{aligned}
$$
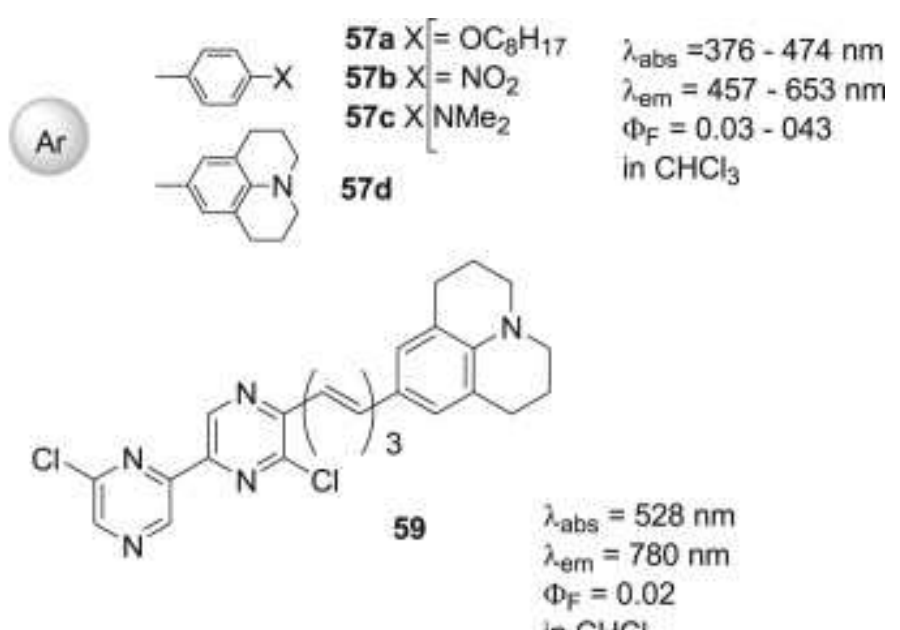

in $\mathrm{CHCl}_{3}$

Scheme 32. Structure and photophysical data of compounds 57-59.

The synthesis of a wide range of other rod-like conjugated molecules $\mathbf{6 0 - 6 4}$ was also described. These compounds incoporate a pyrazine or a bipyrazine core connected to electron acceptor (A) or donor (D) groups through $\pi$-conjugated linkers as transmitters for the internal charge transfer (Scheme 33) [56]. Generally, these derivatives exhibit fluorescence in the red region of the spectra. Incorporation of a double bond or a hexatriene chain as linker and a bipyrazine unit as an electron-withdrawing central core improves the spectroscopic properties. 

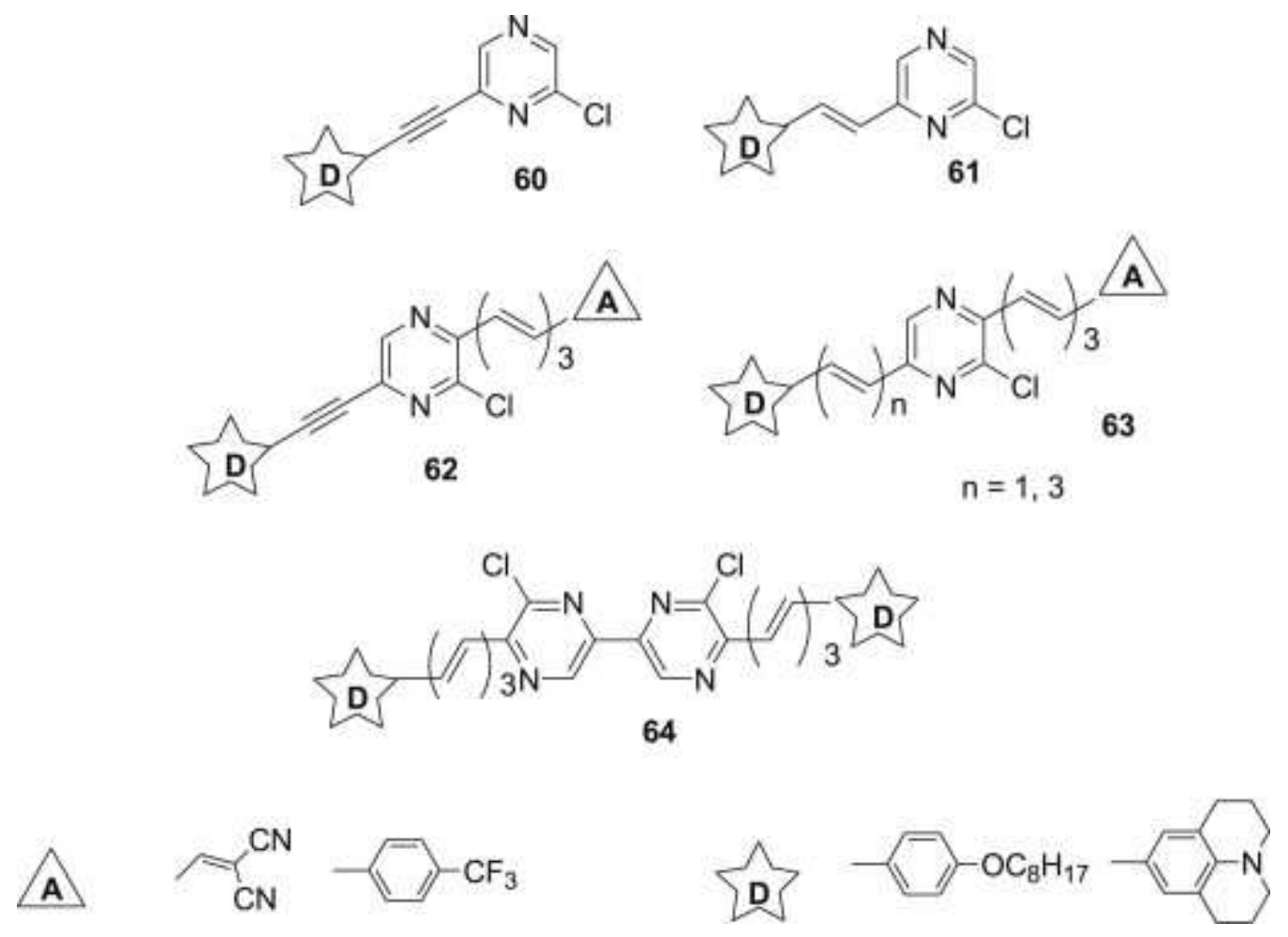

Scheme 33. Structure and photophysical data of compounds 60-64.

A series of 2,5-di(aryleneethynyl)pyrazine derivatives $\mathbf{6 5}$ was synthesized by Zhao et al (Scheme 34) [57]. The structure, electrochemical and photophysical properties of derivative 65a have been compared with those of di(phenylethynyl)benzene 66. The presence of the pyrazine ring leads to a significant enhancement of electron-accepting properties, as revealed by cyclic voltammetry data and was confirmed by quantum chemical calculations. Experiments have established the potential for compound $\mathbf{6 5 b}$ to act as an electrontransporting material as a blend with MEH-PPV in single layer OLEDs. 

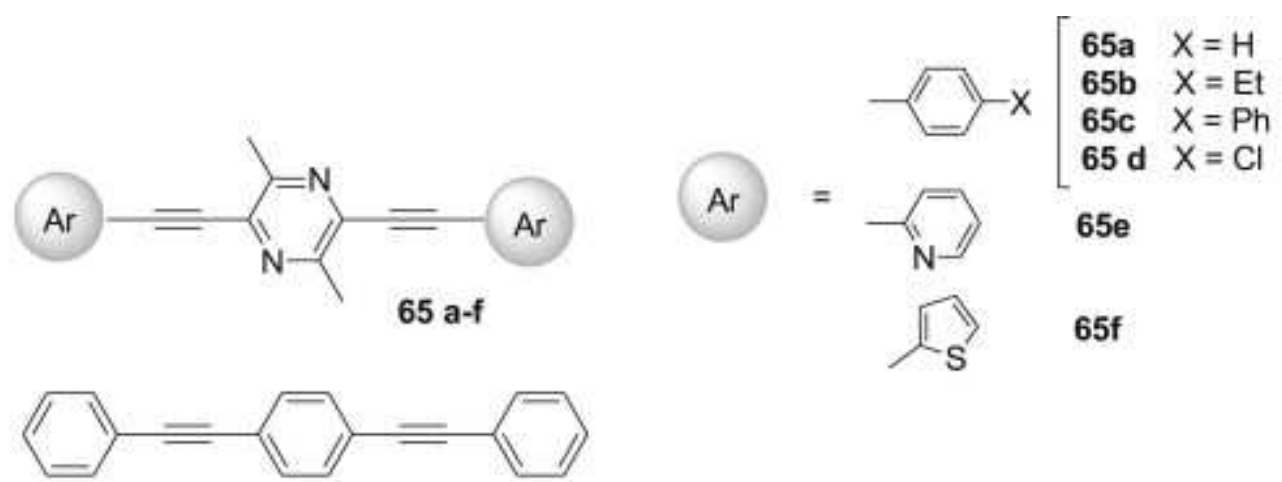

66

$65 a$

$\lambda_{\text {abs }}=354 \mathrm{~nm}$

$\lambda_{\text {em }}=379$ and $395 \mathrm{~nm}$

in Cyclohexane
$65 b$
$\lambda_{\text {abs }}=359 \mathrm{~nm}$
$\lambda_{\text {em }}=384,403$ and $418 \mathrm{~nm}$
in Cyclohexane

$$
\begin{gathered}
66 \\
\lambda_{\text {abs }}=320 \mathrm{~nm} \\
\lambda_{\text {em }}=346,362 \text { and } 375 \mathrm{~nm} \\
\text { in Cyclohexane }
\end{gathered}
$$

Scheme 34. Structure and photophysical data of compounds 65 and 66.

\subsection{Other pyrazine structures}

Phenylene-2,5-dimethylpyrazinyl co-oligomers 67, 68 and the dipyridylpyrazine derivative 69 were synthesized by Türksoy et al (Scheme 35) [58]. The absorption spectra in ethanol show the lowest energy band at wavelengths characteristic of twisted oligoaryl structures with a dihedral angle $\alpha$ determined by X-Ray crystallography. Blue electroluminescence, $\lambda_{\max } 444$ $\mathrm{nm}$, is observed for the device structure ITO/PEDOT/68/Ca with no long-wavelength emission from $\pi$-aggregates or exciton states. 

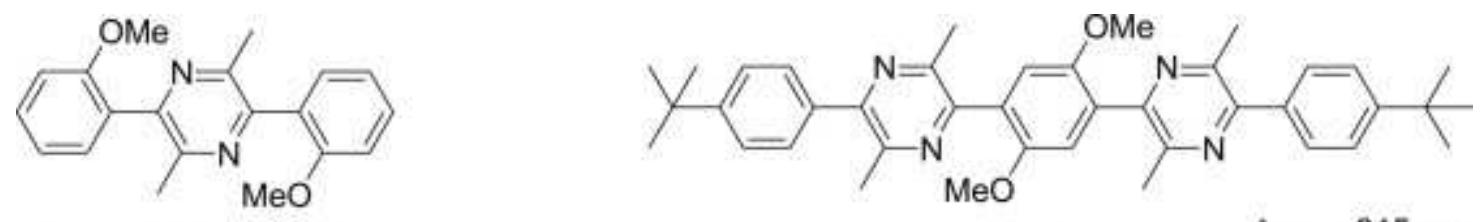

$\lambda_{\text {abs }}=330 \mathrm{~nm} \quad 67$

68

$\lambda_{\text {em }}=372 \mathrm{~nm}$

in $\mathrm{EtOH}$

$\alpha=74^{\circ}$

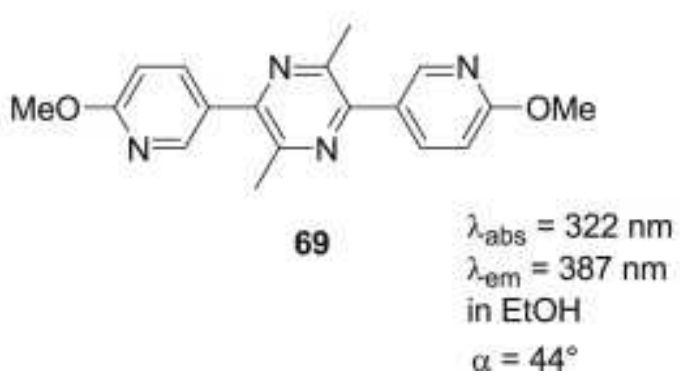

$\lambda_{\text {abs }}=315 \mathrm{~nm}$

$\lambda_{\text {em }}=418 \mathrm{~nm}$

in $\mathrm{EtOH}$

Scheme 35. Structure and photophysical data of compounds 67-69.

Fugisawa et al have reported the complexation of 2,3,5,6-tetra(2'-pyridyl)pyrazine (tppz) 70 and 1-octadecanol with $\mathrm{Eu}^{3+}$ ions through formation of luminescent Langmuir films at the air/liquid interface (Scheme 36) [59].

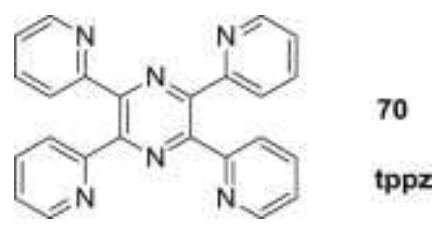

Scheme 36. Structure and photophysical data of compound $\mathbf{7 0 .}$

Saito and coworkers have reported that 2,5-bis(benzimidazol-2-yl)pyrazine (BBPIP) 71 exhibited extremely intensive blue-fluorescence with maximum emission at $444 \mathrm{~nm}$ and a fluorescence quantum yield of 0.90 in DMSO [60]. In order to improve the solubility, derivatives 72 with two alkyl chains at the N-1 and N-1' positions of the two benzimidazole moieties were synthesized (Scheme 37) [61]. Compounds 72 exhibit similar blue fluorescence with a positive solvatochromism. Compound $72 \mathrm{c}(\mathrm{n}=3)$ was used as a microenvironment 
polarity probe to indicate the variation in polarity around the backbone of the temperaturesensitive poly( $\mathrm{N}$-isopropylacrylamide) by measuring the spectral change caused by the thermal phase transition of the polymer.
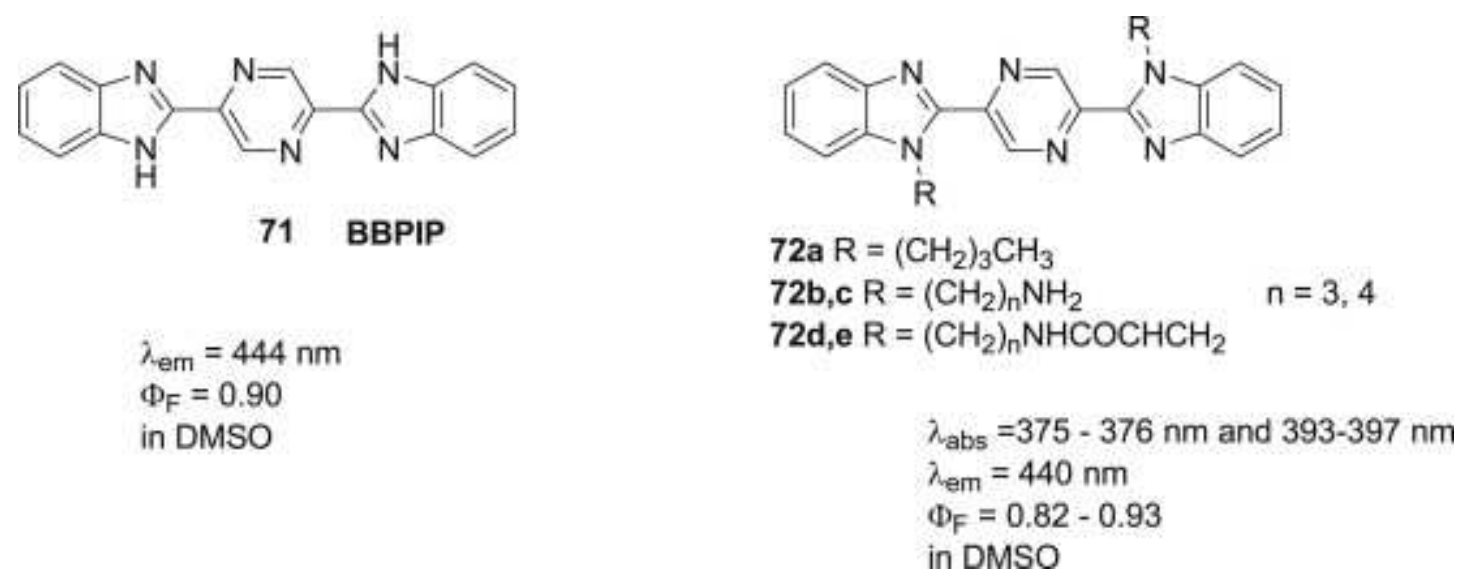

Scheme 37. Structure and photophysical data of compounds $\mathbf{7 1}$ and $\mathbf{7 2 .}$

Various 5,6-bisarylvinyl-3-pyrazine-1,2,4-triazine derivatives $\mathbf{7 3}$ were synthesized by Thirumurugan et al and have highlighted good sensor property with $\mathrm{Fe}(\mathrm{III})$ ions even in micro level concentrations (Scheme 38) [62].
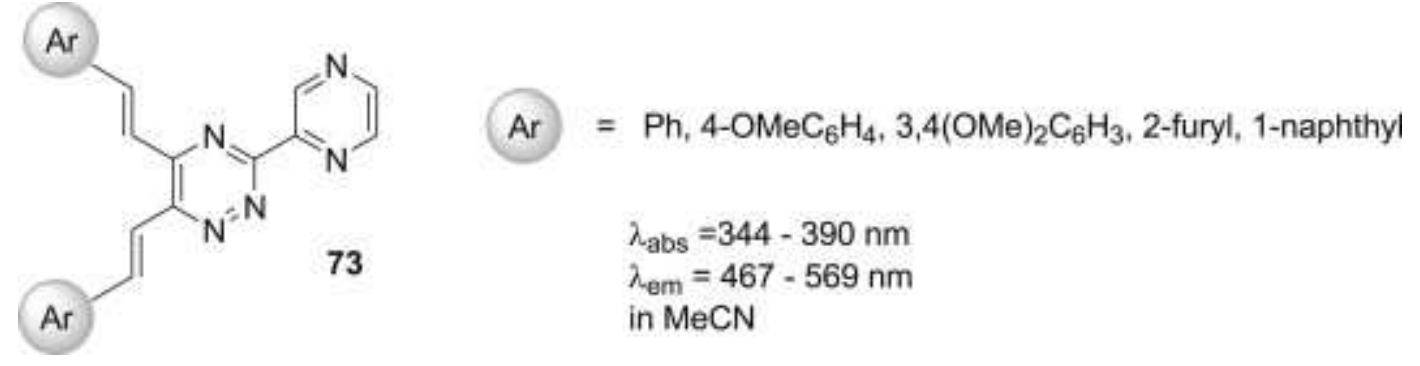

Scheme 38. Structure and photophysical data of compound 73.

New fluorescent sensors for $\mathrm{Zn}^{2+}$ utilizing fluorescein as a reporting group and including pyridine moieties ZP 74 were first reported (Scheme 38)[63]. More recently, substitution of a 
pyridine ring by a pyrazine one at each dipicolylamine (DPA) unit led to new ditopic fluorescent sensors ZPP 75 (Scheme 39) [64].

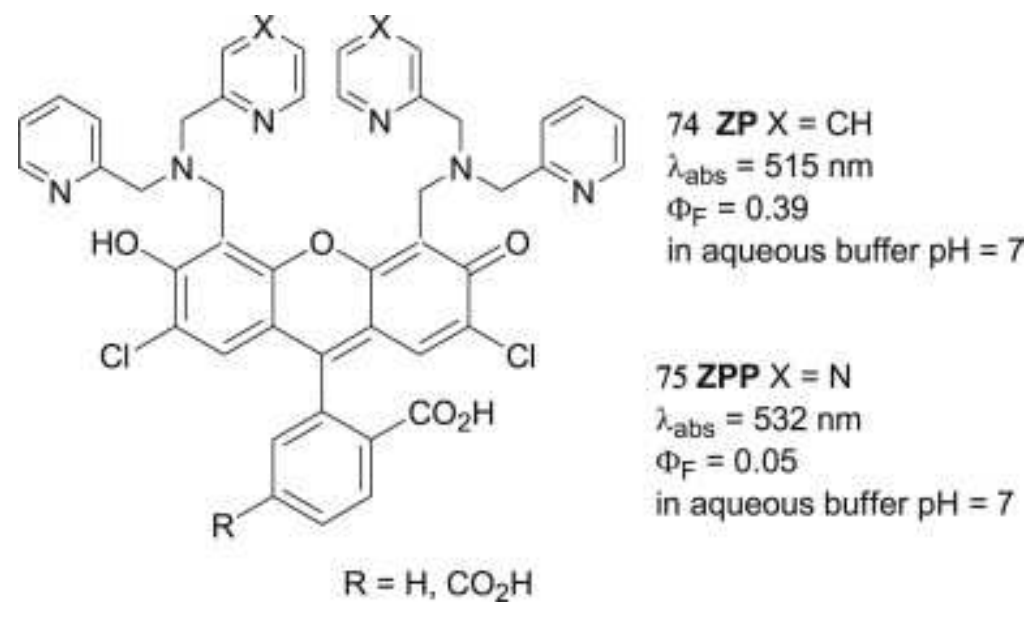

Scheme 39. Structure and photophysical data of compounds $\mathbf{7 4}$ and $\mathbf{7 5 .}$

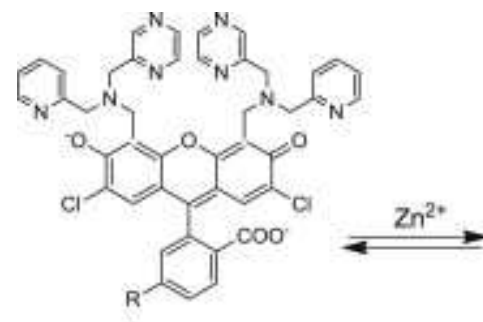

$\mathrm{L}^{2-}$

weakly fluorescent

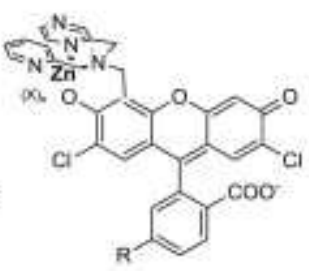

$\mathrm{LZn}$

weakly fluorescent

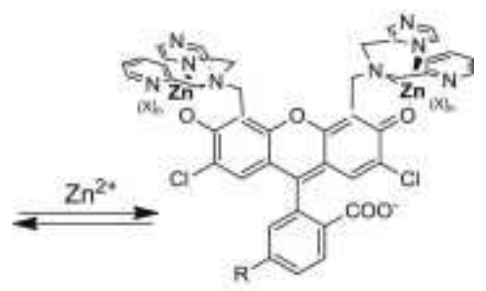

$\mathrm{LZn}_{2}{ }^{2+}$

stronly fluorescent

Scheme 40. Structure of compound $\mathbf{7 5}$ and its Zinc complexes.

These sensors exhibit a novel two-step fluorescence response toward zinc binding that can be applied to quantify chelatable zinc in biological samples (Scheme 40). The authors claim that the advantages of incorporating pyrazine into the metal-binding units in this kind of sensor can be generally applied to detect zinc, and other metals such as mercury.

A novel series of fluorescence dyes based on pyrazine-boron complexes $\mathbf{7 6}$ bearing a $\beta$ iminoketone ligand were prepared from methylpyrazine and benzoate derivatives (Scheme 
41) [65]. All synthesized complexes exhibited fluorescence in dichloromethane $\left(\lambda_{\max }: 472-\right.$ $604 \mathrm{~nm})$ and in the solid state $\left(\lambda_{\max }: 496-624 \mathrm{~nm}\right)$. Unlike common fluorescent boron complexes such as BODIPY dyes which have generally low Stokes shifts $\left(400-600 \mathrm{~cm}^{-1}\right.$, in most cases), these pyrazine-boron complexes exhibited large Stokes shifts $\left(3690-4900 \mathrm{~cm}^{-1}\right)$. This difference could be explained by the flexibility of the scaffold of $\mathbf{7 6}$, owing to the molecular rotation of the aryl group.
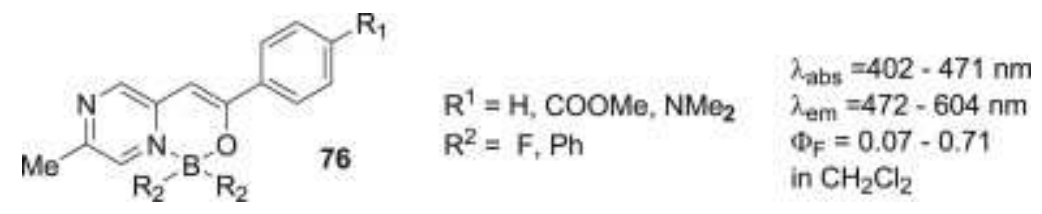

Scheme 41. Structure and photophysical data of compounds $\mathbf{7 6 .}$

The synthesis and luminescence of two iridium (III) pyrazine complexes $\mathbf{7 7}$ and $\mathbf{7 8}$ were investigated by Ge et al (Scheme 42) [66]. Yellow OLEDs were obtained with these phosphorescent complexes. The iridium pyrazine complex 77 emits yellow light $\left(\lambda_{\max }=575\right.$ nm). Efficient OLEDs using the complex 77 as phosphorescent dopant were demonstrated.

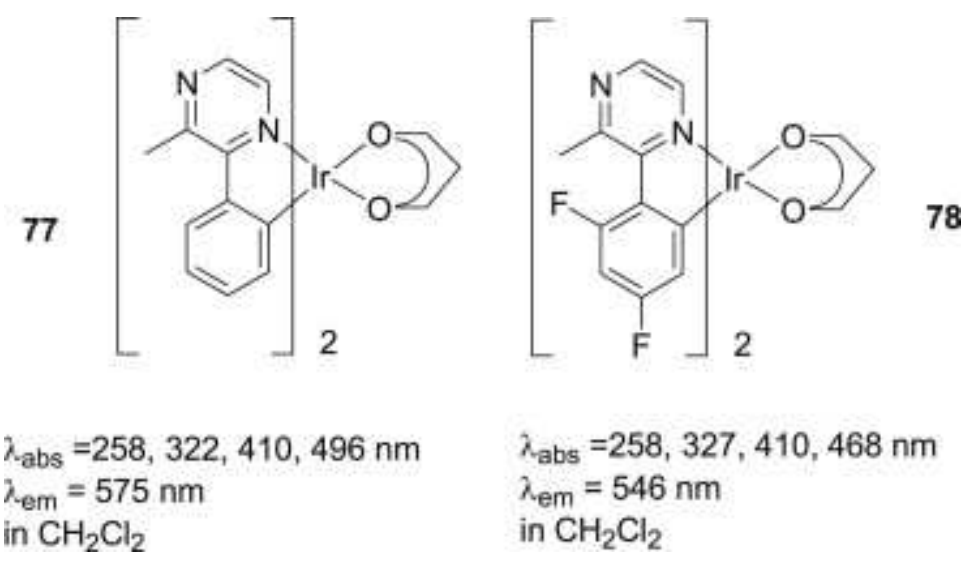

Scheme 42. Structure and photophysical data of compounds 77-78. 
Coe and coworkers have synthesized nonlinear optical (NLO) chromophores 79-81 with pyrazinyl-pyridinium electron acceptors complexing a known pro-ligand with electrondonating $\left\{\mathrm{Ru}^{\mathrm{II}}\left(\mathrm{NH}_{3}\right)_{5}\right\}^{2+}$ or trans- $\left\{\mathrm{Ru}^{\mathrm{II}}\left(\mathrm{NH}_{3}\right)_{4}(\mathrm{py})\right\}^{2+}(\mathrm{py}=$ pyridine) centers (Scheme 43$)$ [67]. These cationic complexes were characterized as their $\mathrm{PF}_{6}$ salts. Molecular first hyperpolarizability $\beta$ were determined by using hyper-Rayleigh scattering (HRS) with a 1064 $\mathrm{nm}$ laser exhibiting relatively large $\beta$ values. Depolarization measurements confirm the strongly $2 \mathrm{D}$ nature of the NLO responses for the symmetric complexes. The $\beta_{0}$ value increases on moving from $\mathbf{7 9}$ to bimetallic species $\mathbf{8 0}$.

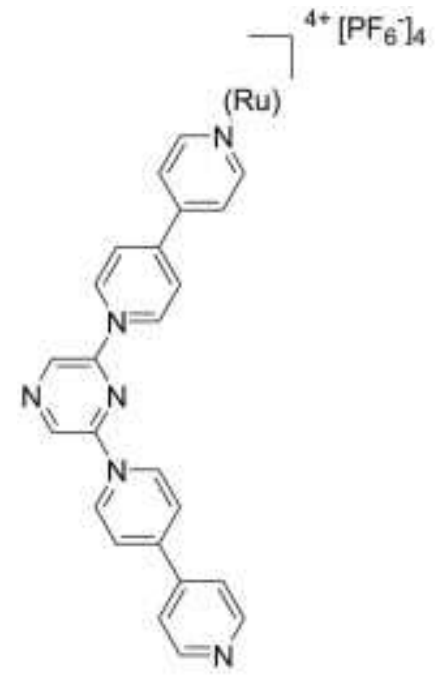

$79 \mathrm{a}(\mathrm{Ru})=\mathrm{Ru}^{\prime \prime}\left(\mathrm{NH}_{3}\right)_{5}$ $79 b(\mathrm{Ru})=$ trans- $-\mathrm{Ru}^{\prime \prime}\left(\mathrm{NH}_{3}\right)_{4}(\mathrm{py})$

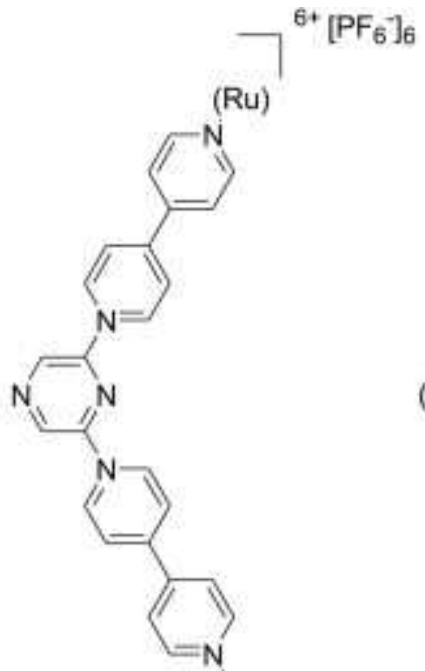

(Ru)

$$
\begin{aligned}
& \text { 80a }(\mathrm{Ru})=\mathrm{Ru}^{\prime \prime}\left(\mathrm{NH}_{3}\right)_{5} \\
& 80 \mathrm{~b}(\mathrm{Ru})=\operatorname{trans}-\mathrm{Ru}^{\prime \prime}\left(\mathrm{NH}_{3}\right)_{4}(\mathrm{py})
\end{aligned}
$$$$
\lambda_{\text {abs }}=665-713 \mathrm{~nm} \text { in } \mathrm{CH}_{2} \mathrm{Cl}_{2}
$$

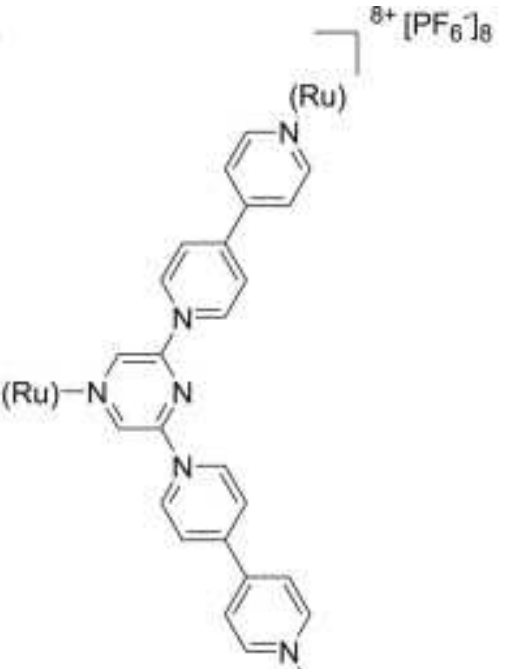

$(\mathrm{Ru})$

$$
\begin{aligned}
& \text { 81a }(\mathrm{Ru})=\mathrm{Ru}^{\prime \prime}\left(\mathrm{NH}_{3}\right)_{5} \\
& \mathbf{8 1 b}(\mathrm{Ru})=\operatorname{trans}-\mathrm{Ru}^{\prime \prime}\left(\mathrm{NH}_{3}\right)_{4}(\mathrm{py})
\end{aligned}
$$

Scheme 43. Structure and photophysical data of compounds 79-81.

Synthesis, electronic properties, and second-order nonlinear optical (NLO) response of asymmetric heteronuclear push-pull bimetallic complexes were reported by Pizzotti et al. [68]. The pyrazine moiety was used as polarizable linker, connecting the "W(CO) $)_{5}$ " fragment 
(acting as donor group) and "cis- $\mathrm{Rh}(\mathrm{CO})_{2} \mathrm{Cl}$ ", "cis- $\mathrm{Re}(\mathrm{CO})_{4} \mathrm{Cl}$ ”, and $\mathrm{BF}_{3}$ fragments (acting as acceptor groups) leading to structures 82-86 (Scheme 44). In this case, the asymmetrical pyrazine bimetallic complexes can be considered as organometallic counterparts of classical push-pull aromatic chromophores. These derivatives exhibit higher NLO response (assessed by EFISH technique and solvatochromic studies) than the related push-pull benzenic chromophores, but it is strongly dependent as sign and absolute value on the electronic structure of the pull inorganic and in particular organometallic group. So, an opposite sign of the response is observed when " $c i s-\mathrm{Rh}(\mathrm{CO})_{2} \mathrm{Cl}$ " (86) is used as acceptor group.

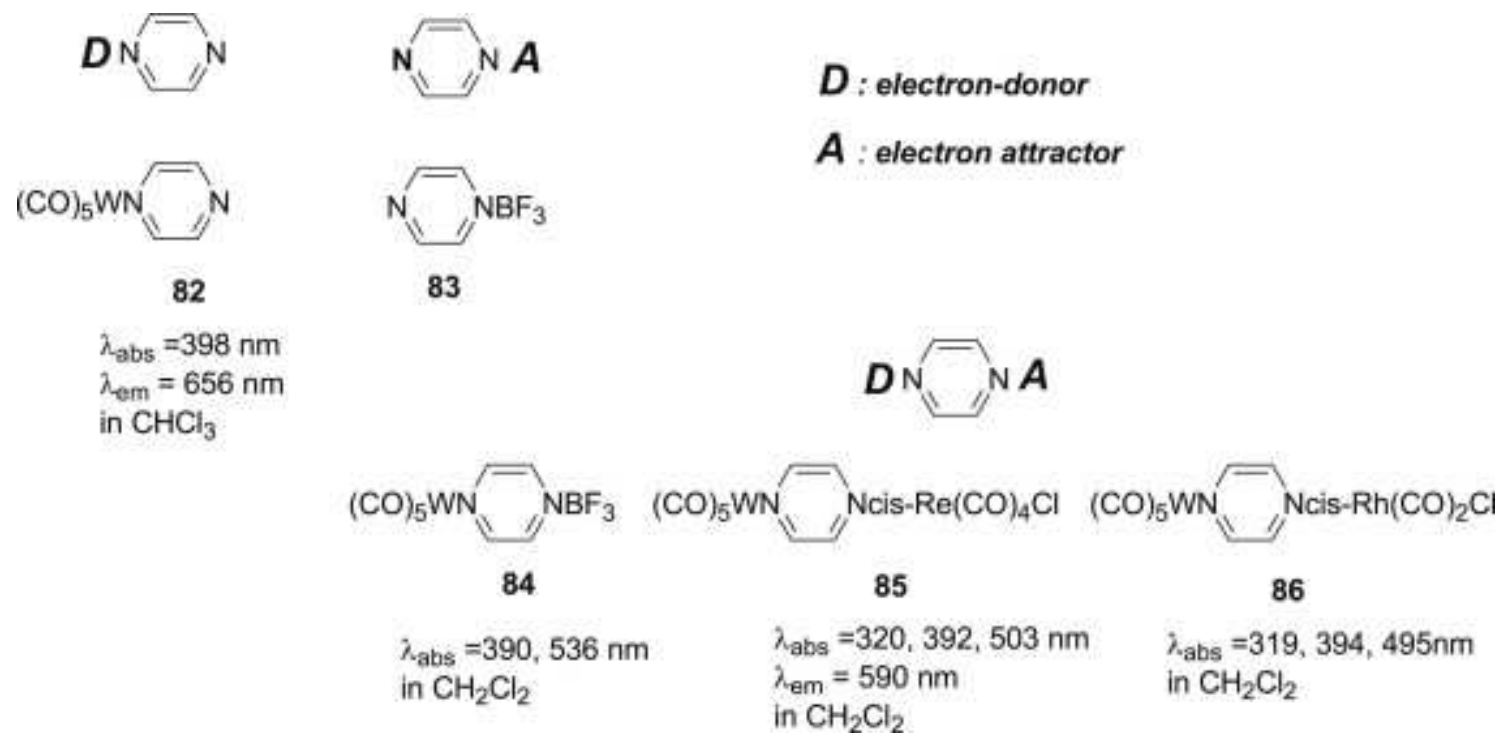

Scheme 44. Structure and photophysical data of compounds 82-86.

\section{Quinoxalines derivatives}

\subsection{Arylvinylquinoxalines}

The push-pull molecule PQX 87 with a quinoxaline as $\pi$-deficient moiety, linked to a pyrrole ring through an ethenyl linker was designed by Kudo and coworkers (Scheme 45) [69]. This compound, soluble in many common solvents, exhibits a full-color solvatochromic 
fluorescence ( $\lambda_{\text {em }}=430-607 \mathrm{~nm}$ ) and was described as a promising fluorescent sensor for binding sites in proteins or other host molecules, especially in aqueous solution.

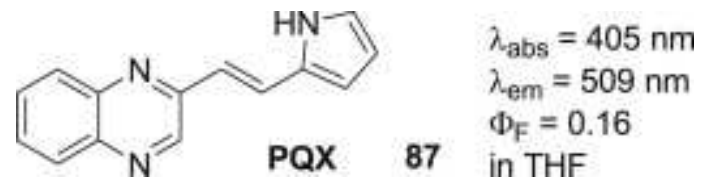

Scheme 45. Structure and photophysical data of compounds 87.

Some of us have also described a series of arylvinylquinoxaline compounds (Scheme 46) [43]. In addition to fluorescence solvatochromism and halochromism, these structures exhibit second order NLO properties assessed by EFISH measurements. With a value of $\mu \beta=30010^{-}$ ${ }^{48}$ esu, the quinoxaline derivative $\mathbf{8 8 d}$ exhibits a better value than the pyrimidine, pyrazine and pyridazine derivative.

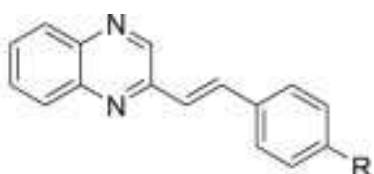

$\mathrm{R}=\mathrm{Cl}(88 \mathrm{a}), \mathrm{Br}(88 \mathrm{~b}), \mathrm{SMe}(88 \mathrm{c}), \mathrm{NMe}_{2}(88 \mathrm{~d})$ piperidinyl (88e), $\mathrm{NPh}_{2}(88 \mathrm{f}), \mathrm{C}_{6} \mathrm{H}_{4}-\mathrm{pNMe}_{2}(88 \mathrm{~g})$. $\mathrm{C}_{6} \mathrm{H}_{4}-p \mathrm{NPh}_{2}(88 \mathrm{~h}), \mathrm{C}_{6} \mathrm{H}_{4}-p \mathrm{OMe}(88 \mathrm{i})$

$\lambda_{\text {abs }}=355-427 \mathrm{~nm}$

$\lambda_{\text {em }}=416-632 \mathrm{~nm}$

$\Phi_{\mathrm{F}}$ up to 0.7

in $\mathrm{CH}_{2} \mathrm{Cl}_{2}$

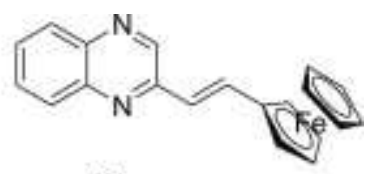

$88 \mathrm{j}$

$$
\begin{aligned}
& \lambda_{\mathrm{abs}}=502 \mathrm{~nm} \\
& \lambda_{\mathrm{em}}=624 \mathrm{~nm} \\
& \Phi_{\mathrm{F}}<0.01 \\
& \text { in } \mathrm{CH}_{2} \mathrm{Cl}_{2} .
\end{aligned}
$$

Scheme 46. Structure and photophysical data of compounds $\mathbf{8 8 .}$

Other fluorescent arylvinylquinoxalines $\mathbf{8 9}$ were reported by Bachowska et al. and are described as pale blue luminescent structures (Scheme 47) [70]. 

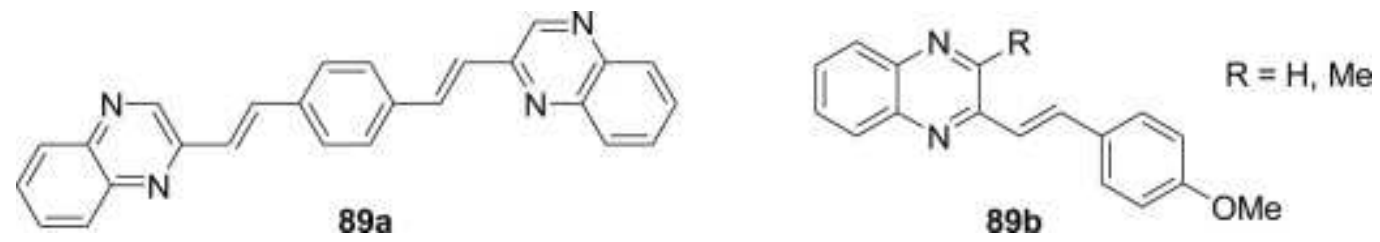

Scheme 47. Structure of compounds 89.

A series of 2,3-bis(arylvinyl)quinoxaline 90 and 2,3-bis(arylvinyl)pyridopyrazine 91 derivatives have been synthesized by Thirumugan and coworkers (Scheme 48) [71]. Quinoxaline derivatives show two absorption maxima and three ones for the pyridopyrazines. All these compounds present good photophysical properties, stable fluorescence $\left(\lambda_{\mathrm{em}}=431-\right.$ $558 \mathrm{~nm})$ as well as very good fluorescence lifetimes. Moreover, the pyridopyrazine derivatives exhibit halochromism.<smiles></smiles>

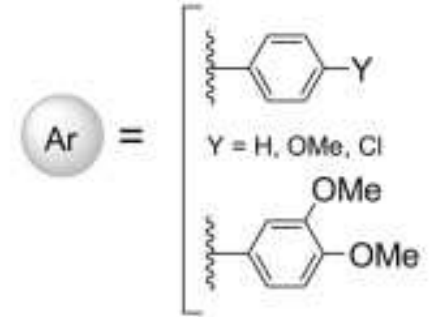

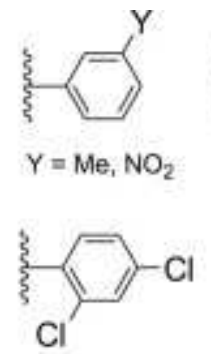

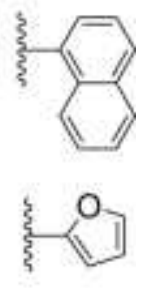

$90 \mathrm{X}=\mathrm{CH}$

$\lambda_{\text {abs }}=294-398 \mathrm{~nm}$

$\lambda_{\mathrm{em}}=431-513 \mathrm{~nm}$

in $\mathrm{MeCN}$

$91 \mathrm{X}=\mathrm{N}$

$\lambda_{\text {abs }}=395-425 \mathrm{~nm}$

$\lambda_{\text {em }}=470-558 \mathrm{~nm}$

in $\mathrm{MeCN}$

Scheme 48. Structure and photophysical data of compounds 90 and 91.

Various 6,7-bis-(3-methylbutoxyl)quinoxaline derivatives 92 (Scheme 49), with different electron-donating arylvinyl moieties were described and studied by Jaung [72] These 
compounds are fluorescent $\left(\lambda_{\mathrm{em}}=470-567 \mathrm{~nm}\right.$ in $\mathrm{CHCl}_{3} / \mathrm{MeOH} 10 / 1$ mixture $)$ with a redshifted emission in acidic media.

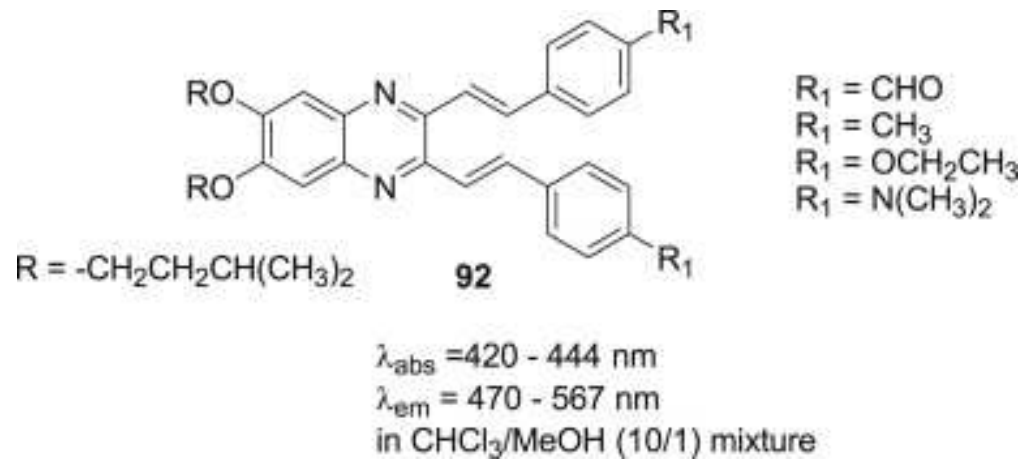

Scheme 49. Structure and photophysical data of compounds 92.

A series of quinoxalines derivatives 93 with a 2,2',6',2' '-terpyridine moiety in one arm have also been synthesized and studied (Scheme 50) [73]. The absorption and fluorescence maximum of these compounds were observed at 398-443 $\mathrm{nm}$ and $484-586 \mathrm{~nm}$, respectively. These compounds were used as fluorescence probes for transition metal ions such as $\mathrm{Co}^{2+}$, $\mathrm{Ni}^{2+}, \mathrm{Cu}^{2+}$ and $\mathrm{Fe}^{3+}$.

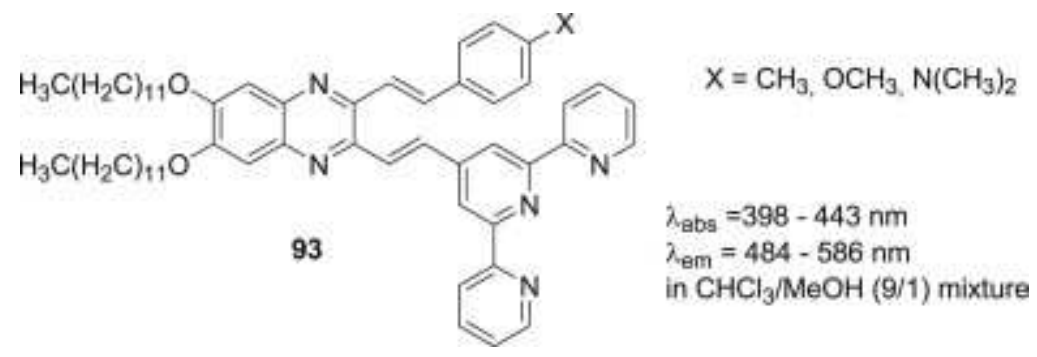

Scheme 50. Structure and photophysical data of compounds $\mathbf{9 3 .}$ 


\subsection{Azomethine Quinoxalines}

The synthesis of a new Schiff base 94, derived from 3-hydroxyquinoxaline-2-carboxaldehyde and 2,3-diaminomaleonitrile was reported by Arun et al. and studied as a fluorescent bisazomethine dye (Scheme 51) [74]. Like other 2-hydroxyquinoxaline derivatives, it exhibits prototropic tautomerism. Compound 94 presents positive absorption and emission solvatochromism and a large Stokes shift, making it as a suitable candidate for application as fluorescent and charge transport dyes.<smiles>N#C/C(N=Cc1nc2ccccc2[nH]c1=O)=C(/C#N)N=Cc1nc2ccccc2[nH]c1=O</smiles>

Major amido form<smiles>N#C/C(N=Cc1nc2ccccc2nc1O)=C(/C#N)N=Cc1nc2ccccc2nc1O</smiles>

Minor iminol form

Scheme 51. Tautomer equilibrium of compound 94.

Another Schiff base, the 3-hydroxyquinoxaline-2-carboxalidine-4-aminoantipyrine 95, was prepared by the same team (Scheme 52) [75]. Spectroscopic studies have revealed that 95 exists predominantly in the amide tautomeric form and exhibits both absorption and fluorescence solvatochromism with a large Stokes shift. Otherwise, the values of third-order non-linear absorption coefficient: $\beta\left(1.48 \times 10^{-6} \mathrm{cmW}^{-1}\right)$, imaginary part of the third-order non-linear optical susceptibility: $\operatorname{Im} \chi^{(3)}\left(3.36 \times 10^{-10} \mathrm{esu}\right)$ and its optical limiting threshold (340 MW cm $\mathrm{cm}^{-2}$ ), make that 95 could be used for applications in photonic age. 


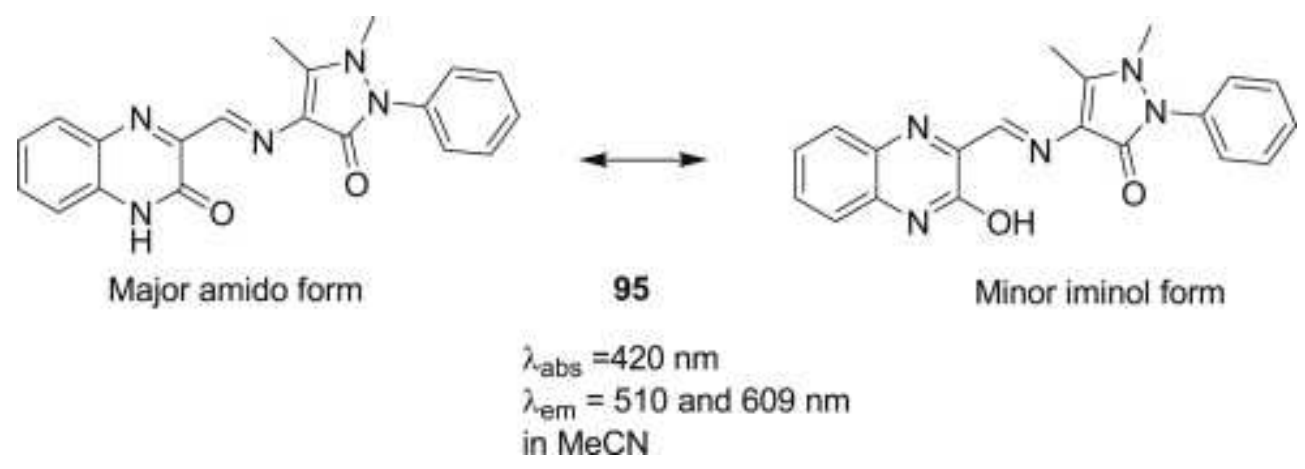

Scheme 52. Tautomer equilibrium of coumpond 95.

If substitution of the quinoxaline core with arylvinyl or arylimine moities gave generally good fluorescent compounds, other quinoxaline structures bearing aryl moieties with different electronic characters have also intensively reported.

\subsection{Arylquinoxalines}

A series of dipolar quinoxaline derivatives substituted with electron-rich terminal $\mathrm{N}$ hexylcarbazole or triphenylamine moieties 96-98 were synthesized and fully characterized (Scheme 53) [76]. As expected, these compounds exhibit excellent blue-green fluorescence $\left(\lambda_{\mathrm{em}}=493-560 \mathrm{~nm}\right)$ and are presented as potential emissive and electron-transport materials for organic light-emitting diodes. 


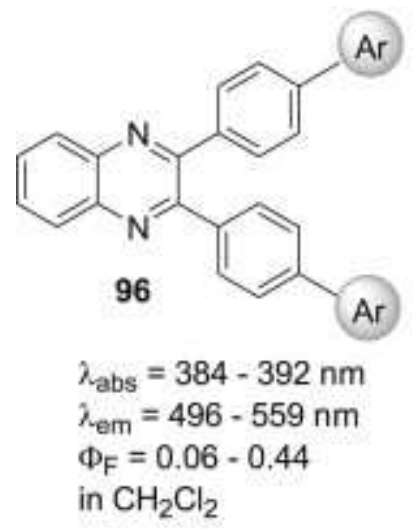

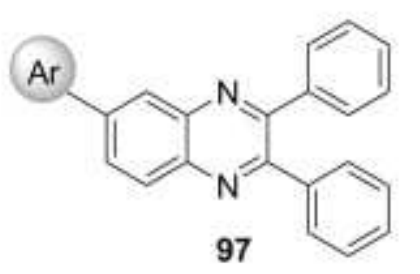

$\lambda_{\text {abs }}=351-380 \mathrm{~nm}$

$\lambda_{\text {em }}=498-552 \mathrm{~nm}$

$\Phi_{\mathrm{F}}=0.23-0.52$

in $\mathrm{CH}_{2} \mathrm{Cl}_{2}$<smiles>Oc1ccc(-c2nc3ccc(Cl)cc3nc2-c2ccc(Cl)cc2)cc1</smiles>

$\lambda_{\text {abs }}=404-410 \mathrm{~nm}$

$\lambda_{\text {em }}=493-560 \mathrm{~nm}$

$\Phi_{\mathrm{F}}=0.60-0.78$

in $\mathrm{CH}_{2} \mathrm{Cl}_{2}$
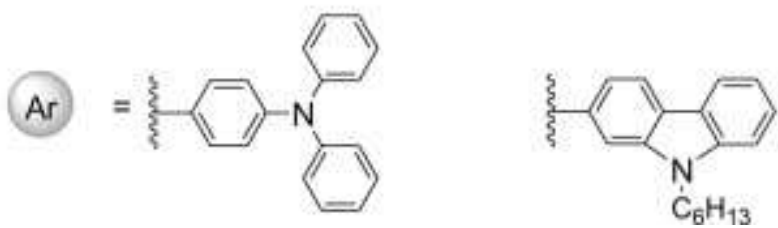

Scheme 53. Structure and photophysical data of compounds 96-98.

Cao et al. have developped ethoxyphenyl and triphenylamine-modified quinoxaline 99 and benzoquinoxaline 100 (Scheme 54) [77]. Their linear spectroscopy and two-photon absorption properties were investigated. The quinoxaline-type compounds 99 exhibited significantly higher fluorescence quantum yields than the benzoquinoxalines-type ones 100. The triphenylamine species presented $2 \mathrm{PA}$ cross sections values $\left(\delta_{2 \mathrm{PA}}\right)$ around $160 \mathrm{GM}$ in the laser light wavelength range of $780-820 \mathrm{~nm}$.<smiles>[R]c1ccc(-c2nc3ccccc3nc2-c2ccc([R])cc2)cc1</smiles>

$\lambda_{\text {abs }}=371-419 \mathrm{~nm}$

$\lambda_{\text {em }}=439-555 \mathrm{~nm}$

$\Phi_{F}=0.12-0.15$

in $\mathrm{CHCl}_{3}$<smiles>[R]c1ccc(-c2nc3cc4ccccc4cc3nc2-c2ccc([R])cc2)cc1</smiles><smiles>[R]OCCN(C)c1ccc([N+](=O)[O-])cc1</smiles>

Scheme 54. Structure and photophysical data of compounds 99 and 100. 
A series of dipolar compounds featuring quinoxaline 101 or pyridopyrazine 102 cores as acceptors and various triarylamines as donors were synthesized by Thomas et al. (Scheme 55) [78]. The emission colors of these compounds can be easily tuned from bluish green to orange by independent suitable modifications of the amine or quinoxaline units.<smiles></smiles>

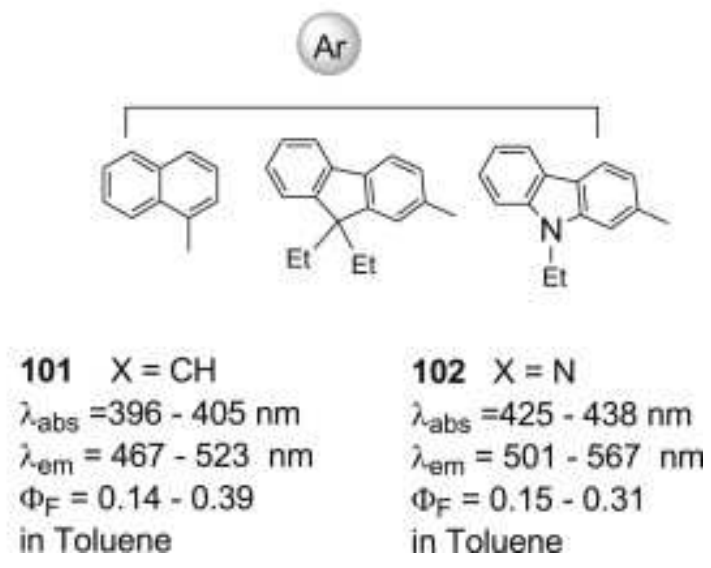

Scheme 55. Structure and photophysical data of compounds 101-102.

More recently, the same authors have synthesized a series of electroluminescent materials $\mathbf{1 0 3}$ comprising quinoxaline, triarylamine, and bulky and rigid aromatic fluorophores such as carbazole, pyrene, and fluorene (Scheme 56) [79]. These products exhibit a strong green fluorescence in film and devices were fabricated using these materials as hole-transporters and emitters with intense light emission.
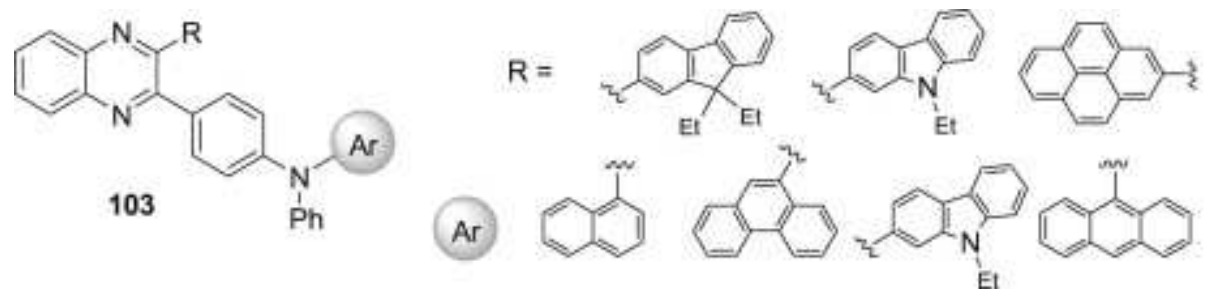

$\lambda_{\text {abs }}=394=408 \mathrm{~nm}$ $\lambda_{\text {em }}=475-500 \mathrm{~nm}$ $\Phi_{F}=0.08-0.34$ in Toluene

Scheme 56. Structure and photophysical data of compounds $\mathbf{1 0 3 .}$ 
A series of multi-branched fluorophores with a quinoxaline or with a di- or a tetraquinoxalinylethylene as the core and diphenylaminofluorene units incorporated at the peripheral positions was synthesized by Lin and coworkers (Scheme 57) [80]. These derivatives (104-106) possess good fluorescence quantum yields $\left(\Phi_{\mathrm{F}}>0.5\right.$ in THF and toluene) and a strong solvent effect on emission and life-time behaviors. These compounds exhibit two-photon activities and effective optical power limiting properties in the near-IR region under the irradiation of nanosecond laser pulses.

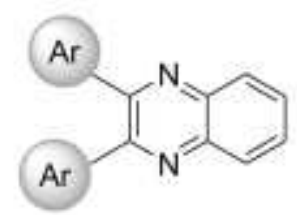

104

$$
\begin{aligned}
& \lambda_{\text {abs }}=394 \mathrm{~nm} \\
& \lambda_{\text {em }}=501 \mathrm{~nm} \\
& \Phi_{\mathrm{F}}=0.50 \\
& \text { in Toluene }
\end{aligned}
$$<smiles></smiles>
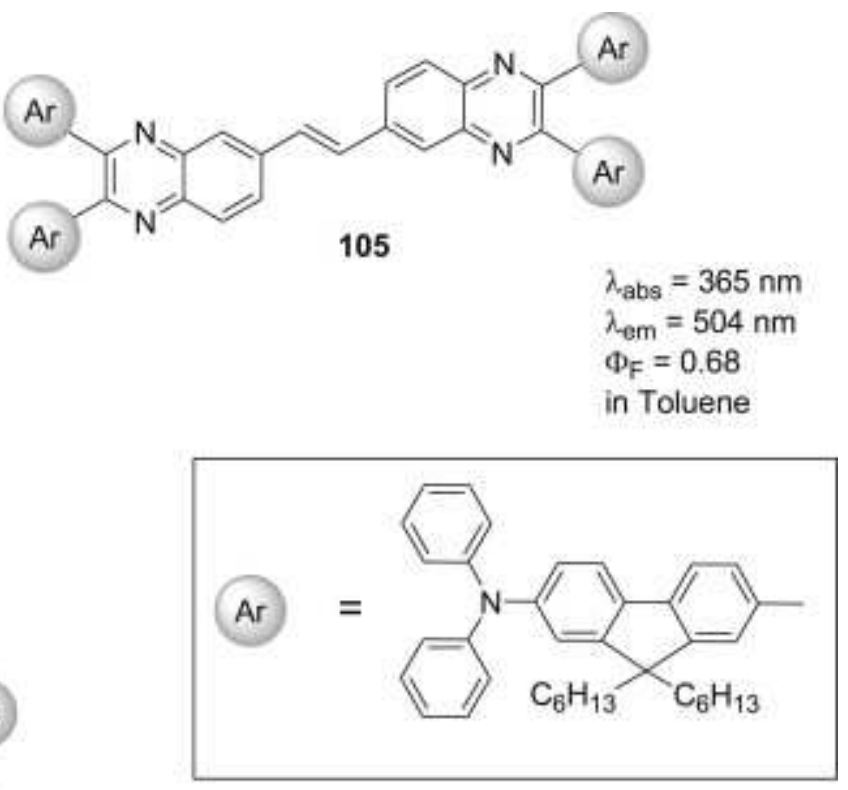

$\lambda_{\mathrm{abs}}=425 \mathrm{~nm}$

$\lambda_{\text {em }}=498 \mathrm{~nm}$

$\Phi_{\mathrm{F}}=0.66$

in Tolvene

Scheme 57. Structure and photophysical data of compounds 104-106.

The synthesis and photophysical properties of a series of bipolar compounds 107, 108 including a quinoxaline unit and substituted triarylamine groups were reported by Burrows 
and coworkers (Scheme 58) [81]. Incorporation of the bulky dehydroabietic methyl ester group in the scaffold of compounds $\mathbf{1 0 8}$ was achieved to improve solubility and to prevent crystallization, without affecting their photophysical behaviors. These compounds exhibited relatively strong fluorescence, their emission maximum are dependent from the nature of the substituents present on the stilbene group. These molecules were evaluated as electroluminescent materials: the devices prepared with these materials and with magnesium cathodes show efficiencies up to $0.03 \mathrm{~cd} / \mathrm{A}$. This result is about one order of magnitude higher than the efficiency obtained with the related diphenylstylbeneamines [82].

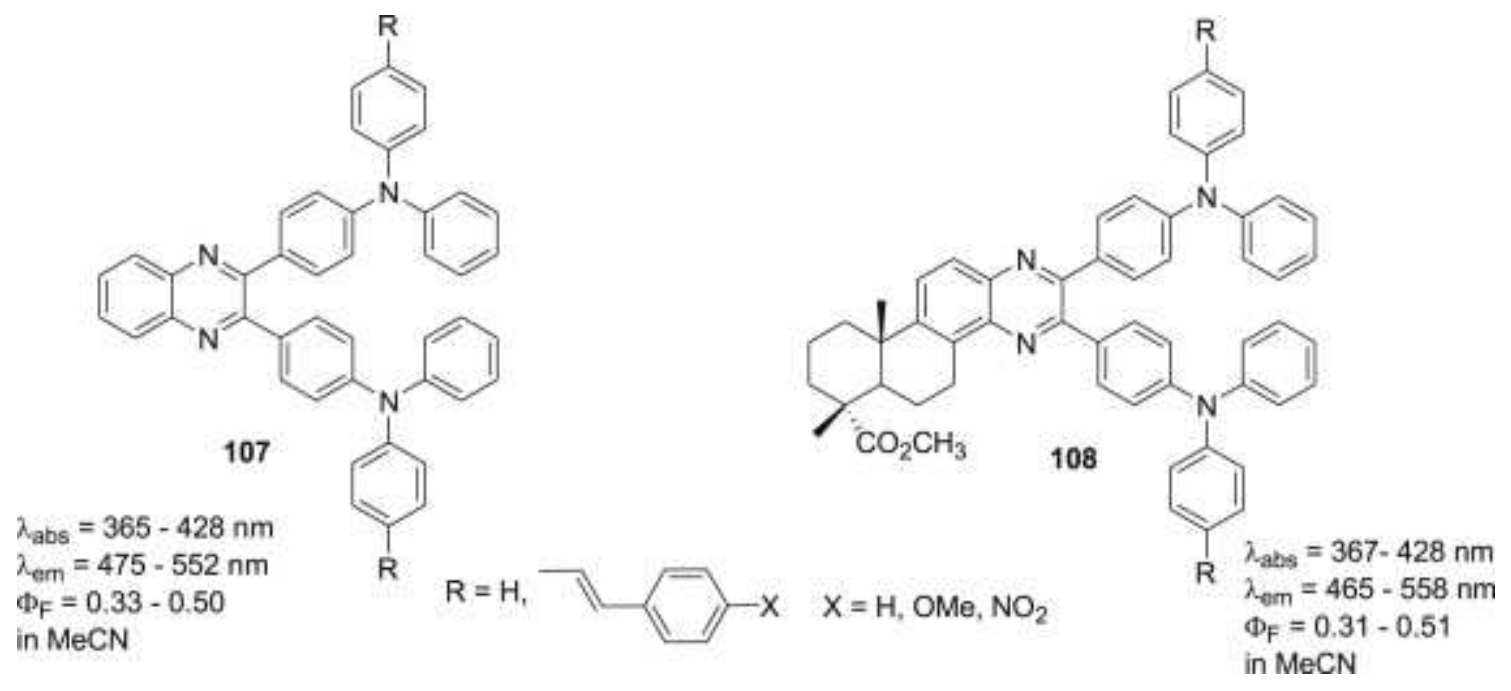

Scheme 58. Structure and photophysical data of compounds 107 and 108.

The photophysical properties of two polyphenylphenyl compounds CPQ 109 and MPQ 110 with a quinoxaline core were investigated in aqueous solutions (Scheme 59) [83]. For these compounds, the abnormal photoluminescent phenomena observed in THF-water mixtures could be explained by combinational effects of intramolecular rotation, intermolecular hydrogen bonds, solvent viscosity, hydration and formation of nanoparticles. Based on detection of the fluorescence observed during formation of nanoparticles, when CPQ or MPQ 
and nucleobases are present in aqueous medium, an application as nucleobase sensing was reported with a sensitivity of guanine $>$ adenine $>$ thymine $\geq$ cytosine.

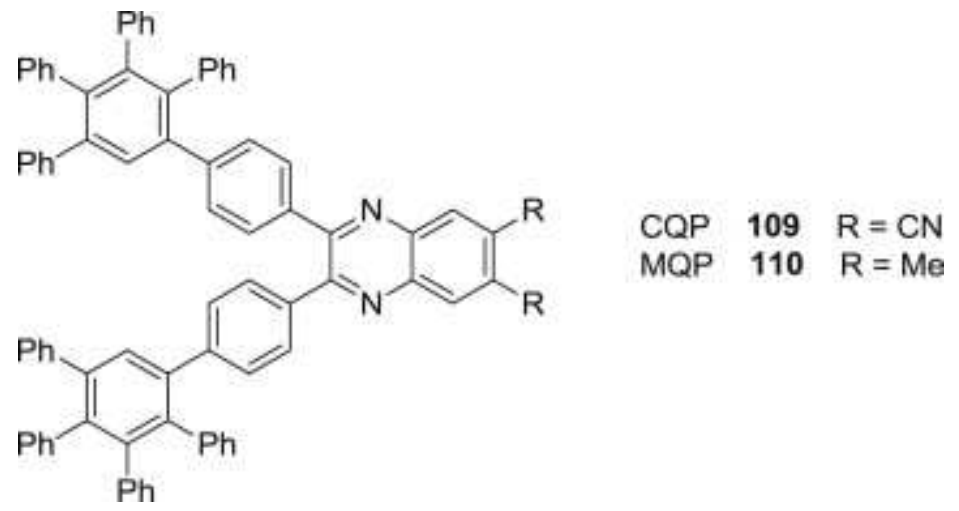

Scheme 59. Structure of compounds $\mathbf{1 0 9}$ and $\mathbf{1 1 0 .}$

Various 5,8-dithienyl quinoxaline derivatives 111 substituted on the thienyl ring were described by Hemgesberg and coworkers (Scheme 60) [84]. Compound 111a is fluorescent with high Stokes shift $\left(\lambda_{\mathrm{abs}}=273 \mathrm{~nm}\right.$ and $\left.\lambda_{\mathrm{em}}=542 \mathrm{~nm}\right)$ and could be used to access fluorescent sol-gel precursors.
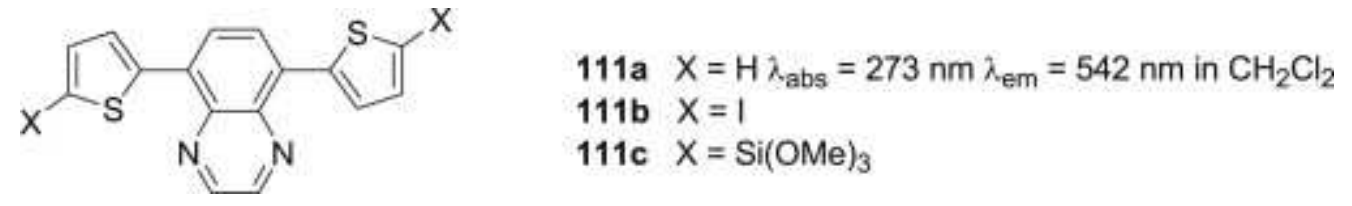

Scheme 60. Structure and photophysical data of compounds 111.

The 2,3-dipyrrole-2'-ylquinoxaline (DPQ) 112 [85] and its derivatives with substituents either on the pyrrole ring 113-115 or on the phenyl ring of the quinoxaline moiety, leading to extended chromophores 116-119 (Scheme 61), are described as sensors for inorganic anions 
such as fluoride and pyrophosphate [86]. The quinoxaline derivatives bearing dipyrromethane or tripyrromethane substituents $\mathbf{1 1 4}$ and $\mathbf{1 1 5}$ act as better anion receptors than the unsubstituted dipyrrolylquinoxaline (DPQ) 111 from which they are derived. The extension of the conjugation provides an enhancement of the fluorescence affinity and an increased affinity for inorganic anions with a stronger selectivity.

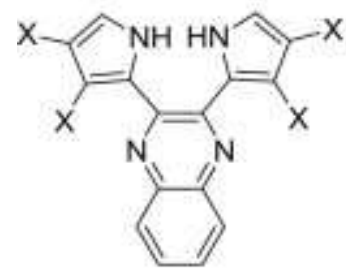

DPQ $112 \times=H$ $113 X=F$

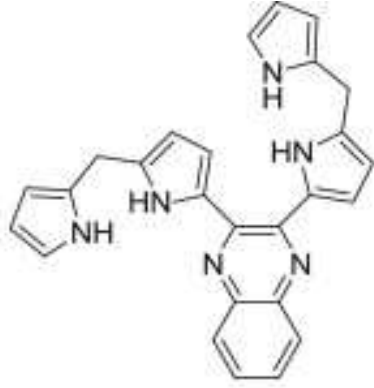

114

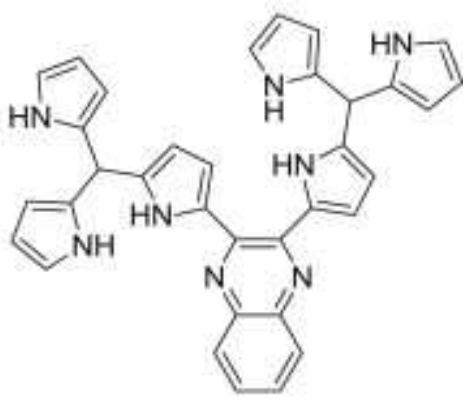

115
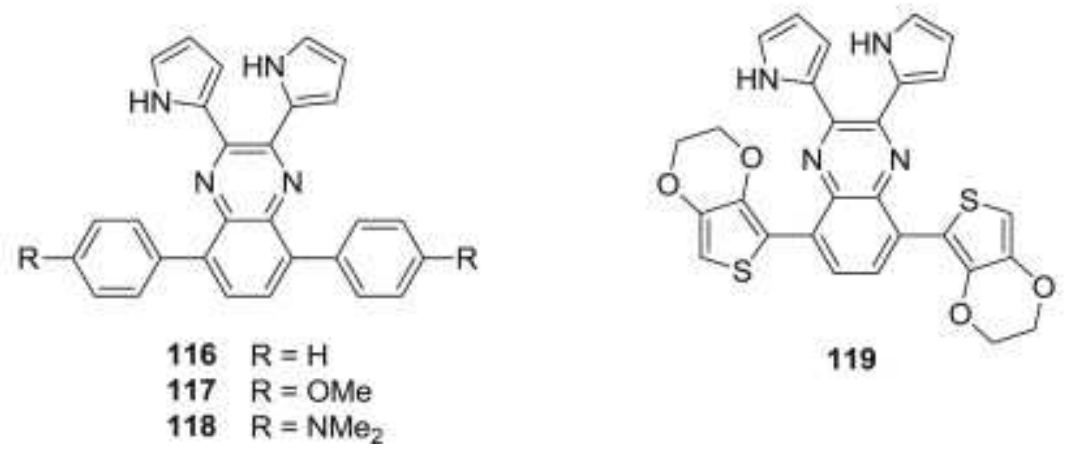

119

Scheme 61. Structure of compounds 112-119.

Quinoxaline-bridged porphyrinoids 120, macrocycles containing dipyrrolylquinoxaline (DPQ) subunits, were also reported with the same sensing applications as well as encapsulation of $\mathrm{CHCl}_{3}$ in solid state (Scheme 62) [87]. 


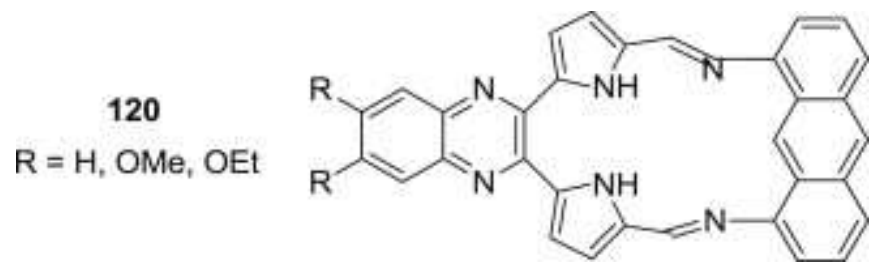

Scheme 62. Structure of compounds $\mathbf{1 2 0 .}$

Wang and coworkers have described a series of dipyrroloquinoxaline-bridged Schiff bases 121 as fluorescent sensors for $\mathrm{Hg}^{2+}$ ion [88]. More recently, other Schiff bases 122, synthesized and studied by $\mathrm{Hu}$ et al. were reported as fluorescent ON/OFF switching system (Scheme 63) [89]. These compounds displayed good sensitivity toward transition metal ions with $\mathrm{Cd}(\mathrm{II}), \mathrm{Zn}$ (II) turn-on and $\mathrm{Cu}(\mathrm{II}), \mathrm{Hg}$ (II) turn-off in fluorescence.
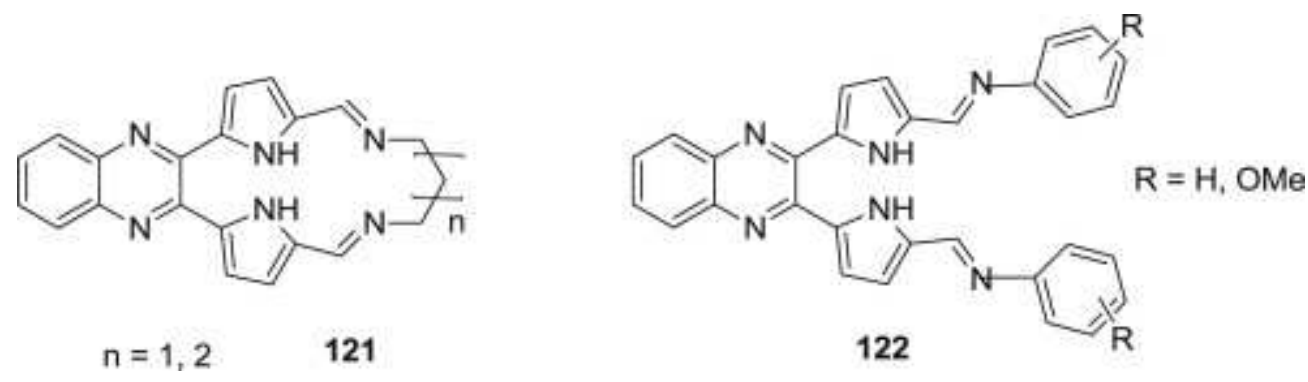

Scheme 63. Structure of compounds 121-122.

\subsection{Micellaneaous substituted Quinoxalines}

Synthesis of the 2-(quinoxalin-2-yl)-2,3-dihydro-1H-perimidine $\mathbf{1 2 3}$ was performed by Varsha and coworkers (Scheme 64) [90]. The fluorescent compound $\mathbf{1 2 3}\left(\lambda_{\mathrm{em}}=386 \mathrm{~nm}, \Phi_{\mathrm{F}}=\right.$ 0.81 in ethyl acetate), exhibits a negative fluorosolvatochromism in polar solvents, and presents interesting antibacterial activities. 


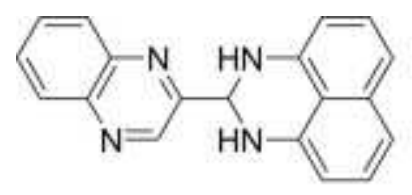

$$
123 \quad \begin{array}{ll}
\lambda_{\text {abs }}=346 \mathrm{~nm} \\
& \lambda_{\text {em }}=386 \mathrm{~nm} \\
& \Phi_{\mathrm{F}}=0.81 \\
& \text { in ethyl acetate }
\end{array}
$$

Scheme 64. Structure and photophysical data of compound 123.

Katoh and coworkers have described the strong fluorescence of the 2,3-dimorpholino-6aminoquinoxaline (Qx) 124 [91]. Two other fluorescent monomers 125 and 126 incorporating the quinoxaline skeleton Qx in their scaffold were described by the same group (Scheme 65) [92]. Compounds $\mathbf{1 2 5}$ and $\mathbf{1 2 6}$ showed intense solvatochromism in their fluorescence. Thermo-responsive copolymers of N-isopropylacrylamide (NIPAM) and a small amount of these fluorescent monomers were synthesized and their fluorescence properties investigated. Contrary to Qx 124, both compounds 125 and 126 having double bond on their structure can thus sense and report microenvironnemental changes in thermo-responsive polymers and could be applicable as new intramolecular fluorescent probes.

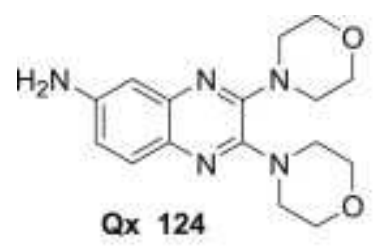

$\lambda_{\mathrm{abs}}=381 \mathrm{~nm}$

$\lambda_{\mathrm{em}}=508 \mathrm{~nm}$

$\Phi_{\mathrm{F}}=0.6$

in $\mathrm{MeOH}$

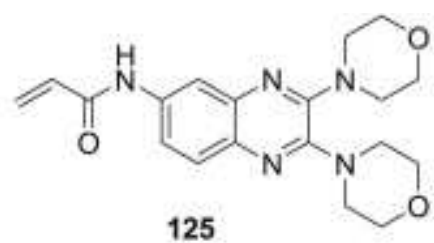

$\lambda_{\mathrm{abs}}=371 \mathrm{~nm}$

$\lambda_{\text {em }}=445 \mathrm{~nm}$

$\Phi_{\mathrm{F}}=0.02$

in $\mathrm{MeOH}$

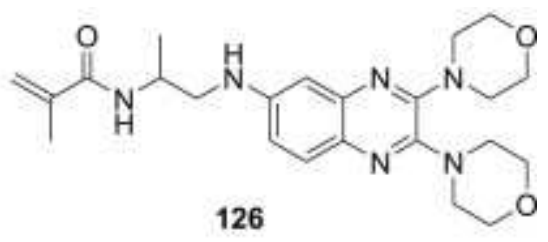

$\lambda_{\mathrm{abs}}=395 \mathrm{~nm}$

$\lambda_{\mathrm{em}}=508 \mathrm{~nm}$

$\Phi_{\mathrm{F}}=0.66$

in $\mathrm{MeOH}$

Scheme 65. Structure and photophysical data of compounds 124-126.

Touzani and coworkers have described two 2,3-functionalized quinoxalines 127 (Scheme 66) [93]. These compounds exist as the keto-enamine form in both solution and solid state. These 
structures are slightly fluorescent $\left(\lambda_{\mathrm{em}}=488-523 \mathrm{~nm}, \Phi_{\mathrm{F}}=0.06-0.14\right.$ in dichloromethane solution) and are presented as interesting ligand for metallo-organic NLO-phores.

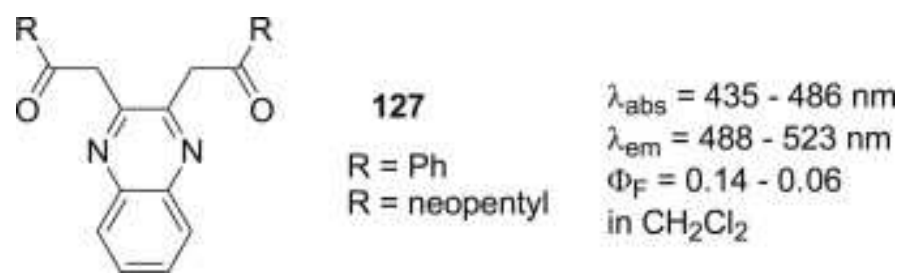

Scheme 66. Structure and photophysical data of compounds $\mathbf{1 2 7 .}$

With the aim of forming a pre-organized molecular cleft, the quinoxaline derivative 128, possessing a 2,6-pyridyl-based amidothiourea moiety, was developed by Duke et al. and was studied as a fluorescent anion sensor (Scheme 67) [94]. The anion-sensing occurs most likely via deprotonation of the amidothiourea receptor, adjacent to the quinoxaline fluorophore. In this case, significant changes are observed with a red-shift in the absorption spectra, and in the emission spectra with a significative quench due to interaction of $\mathbf{1 2 8}$ with anions such as $\mathrm{AcO}^{-}$and $\mathrm{OH}^{-}$.

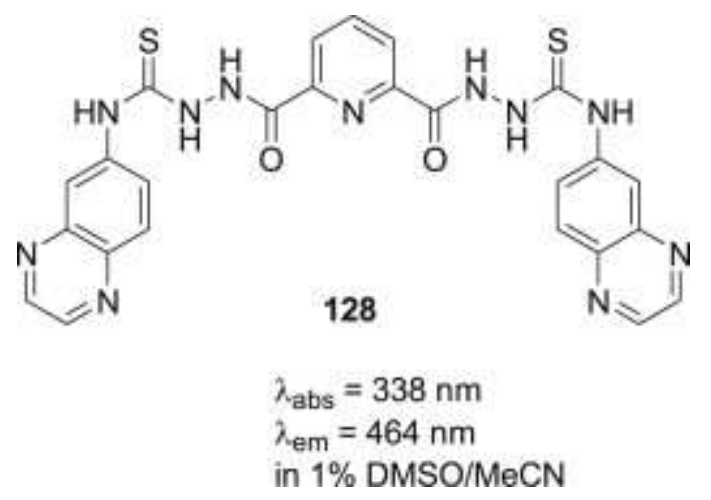

Scheme 67. Structure and photophysical data of compound 128. 


\section{5. $\quad$ Fused Quinoxalines}

Two quinoxaline derivatives reported by Benzeid et al. (Scheme 68) have proved their ability to stain amyloid fibers, such as aggregated lysozyme and $A \beta(1-40)$-peptide by a fluorescence “turn on' mechanism [95]. Thienoquinoxaline 129 allowed the detection of lysozyme and $\mathrm{A} \beta(1-40)$ fibers at $\lambda=555$ and $532 \mathrm{~nm}$, respectively, with excitation at $\lambda=450 \mathrm{~nm}$. Styrylquinoxaline 130 stained lysozyme and $A \beta(1-40)$ fibers with fluorescence at $\lambda=579$ and 567 $\mathrm{nm}$, respectively, upon excitation at $\lambda=453 \mathrm{~nm}$. The apparent $K_{d}$ values for $A \beta(1-40)$ fibers were 77 and $294 \mathrm{nM}$ for $\mathbf{1 2 9}$ and 130, respectively. Due to their unique fluorescence properties compared to other dyes reported in the field, they can be considered as additional staining tools for the detection and studies of peptide/protein aggregation.
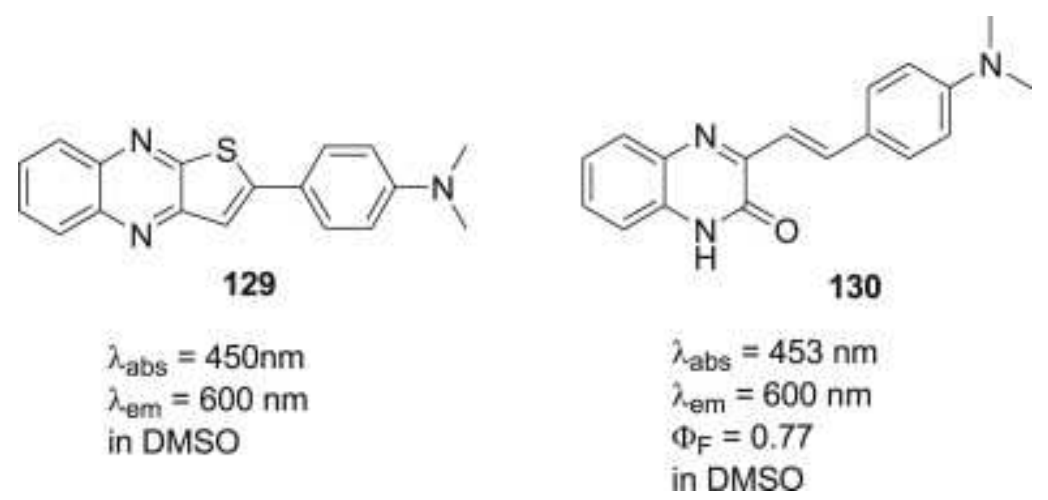

Scheme 68. Structure and photophysical data of compounds $\mathbf{1 2 9}$ and $\mathbf{1 3 0 .}$

A series of $6 \mathrm{H}$-indolo[2,3-b]quinoxaline compounds 131-136, containing triarylamines with aromatic units such as phenyl, naphthyl, pyrene, anthracene, or fluorene were synthesized by Thomas et al. ( Scheme 69) [96].

For the derivatives 131-134, in which the amines were directly anchored on the $6 \mathrm{H}$ indolo[2,3-b]quinoxaline nucleus, the absorption data are significantly influenced by the 
nature of the diarylamine segment and they displayed green or yellow emission $\left(\lambda_{\mathrm{em}}=544-\right.$ $\left.586 \mathrm{~nm}, \Phi_{\mathrm{F}}=0.01-0.08\right)$. For the derivatives 135 and 136, with an insertion of a conjugating aromatic linker between the amine and the indoloquinoxaline unit, a hyperchromism and a bathochromic shift of the absorption values are observed, due to an extended conjugation.
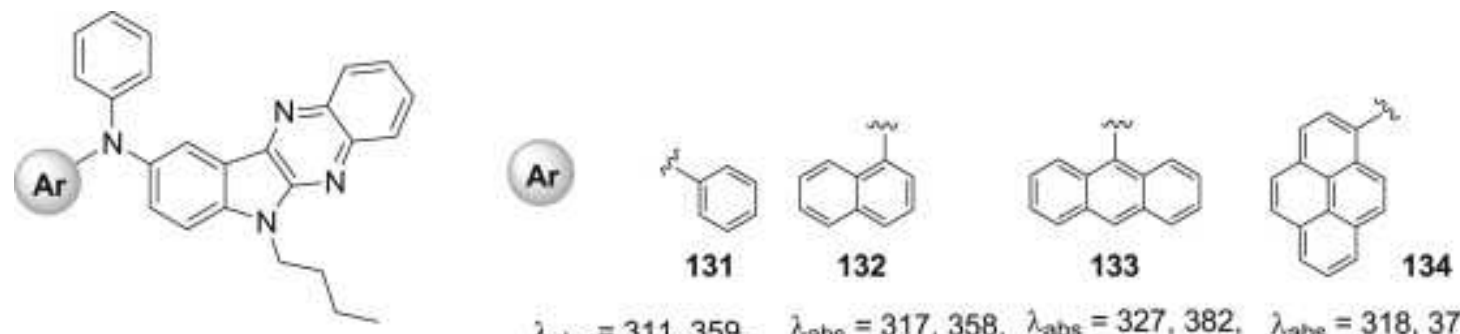

$\lambda_{\text {abs }}=311,359$, $377,447 \mathrm{~nm}$

$$
\begin{aligned}
& \lambda_{\mathrm{abs}}=317,358, \\
& 377,455 \mathrm{~nm} \\
& \lambda_{\mathrm{em}}=579 \mathrm{~nm} \\
& \Phi_{\mathrm{F}}=0.08 \\
& \text { in Toluene }
\end{aligned}
$$
$\lambda_{\text {em }}=578 \mathrm{~nm}$ $\Phi_{\mathrm{F}}=0.01$

in Toluene
$\lambda_{\text {abs }}=327,382$, $422 \mathrm{~nm}$ $\lambda_{\text {em }}=586 \mathrm{~nm}$ $\Phi_{\mathrm{F}}=0.01$ in Toluene

$$
\begin{aligned}
& \lambda_{\text {abs }}=318,379, \\
& 408 \mathrm{~nm} \\
& \lambda_{\mathrm{em}}=584 \mathrm{~nm} \\
& \Phi_{\mathrm{F}}=0.01 \\
& \text { in Toluene }
\end{aligned}
$$

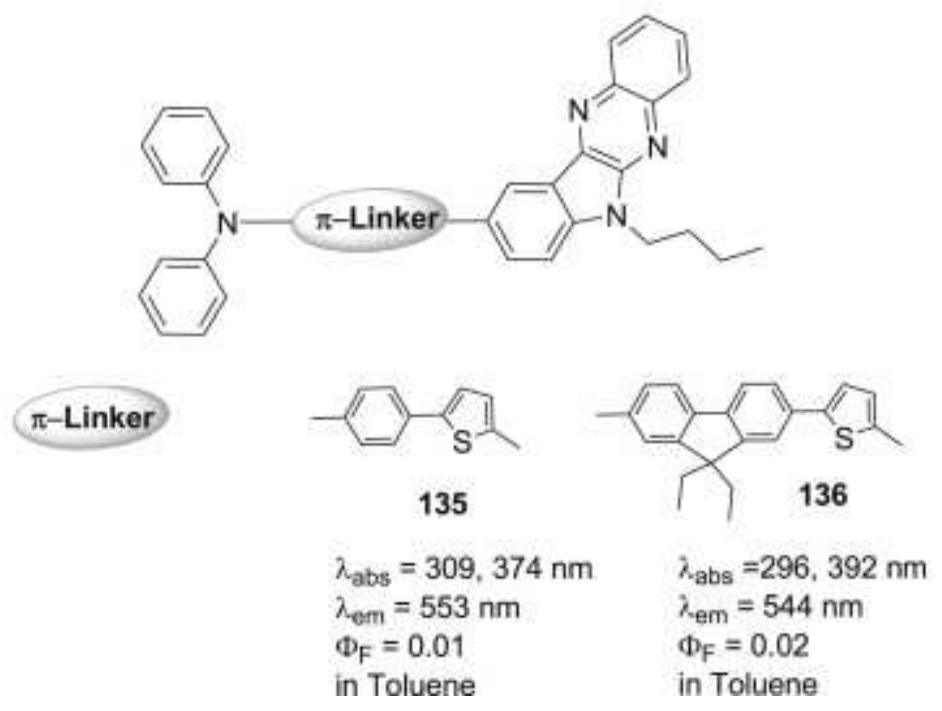

Scheme 69. Structure and photophysical data of compounds 131-136.

Gemma and coworkers have studied a class of pyrroloquinoxaline and imidazoloquinoxaline hydrazones 137 and 138 as fluorescent probes for $A \beta_{1-42}$ fibrils (Scheme 70) [97]. All these compounds were able to bind amyloid fibrils formed in vitro and some of them displayed an increase of their fluorescence upon binding, allowing the stain of amyloid structures. The 
described pyrrolo(imidazo)quinoxalines could be useful for studying amyloid structures in vitro. Moreover, their experimentally proven ability to cross the blood-brain barrier in mouse opens the possibility of developing these compounds as potential amyloid imaging agents for in vivo applications.

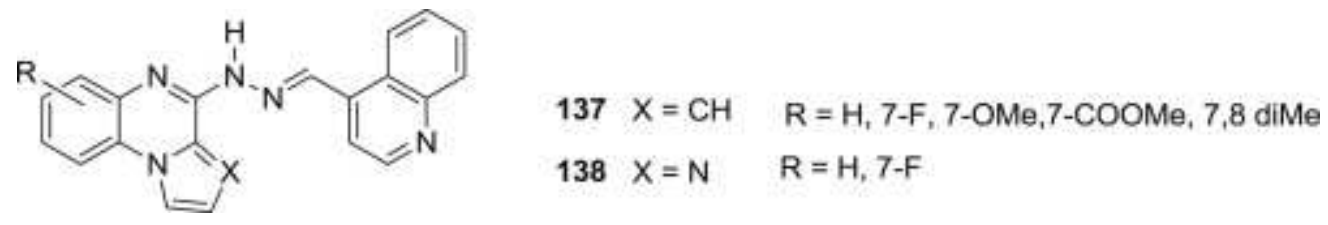

Scheme 70. Structure of compounds 137 and 138.

Diimidazo[1,2-a:2',1'-c]quinoxalines 139 were described by Matsumoto et al. (Scheme 71) [98]. These derivatives exhibit blue fluorescence with high quantum yield $\left(\lambda_{\mathrm{em}}=415-454\right.$ $\left.\mathrm{nm}, \Phi_{\mathrm{F}}=0.47-0.93\right)$. They were also applied to organic light-emitting devices (OLED) as emitters, in which the diphenyl derivative emits a nearly pure blue light.
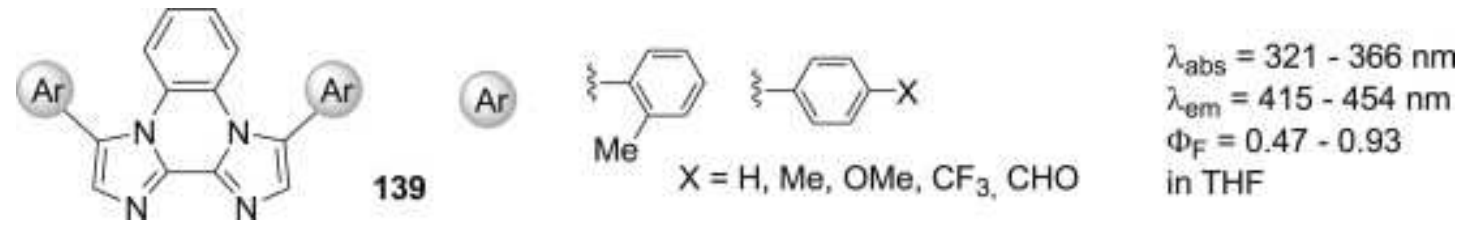

Scheme 71. Structure and photophysical data of compounds 139.

A series of substituted 2-phenylbenzo[g]quinoxalines $\mathbf{1 4 0}$ with a rotatable para-substituted phenyl moiety were synthesized and used as fluorophore for viscosity-sensitive probes (Scheme 72) [99]. The fluorescence properties of these compounds were investigated in the media of the ethylene glycol-glycerol mixture with varied viscosity. Compounds bearing the 
stronger electron-donating groups show more sensitive fluorescence response to viscosity, revealing their potential use in viscosity detection and the key role of the substituted groups. These compounds exhibit also solvatochromism and halochromism.

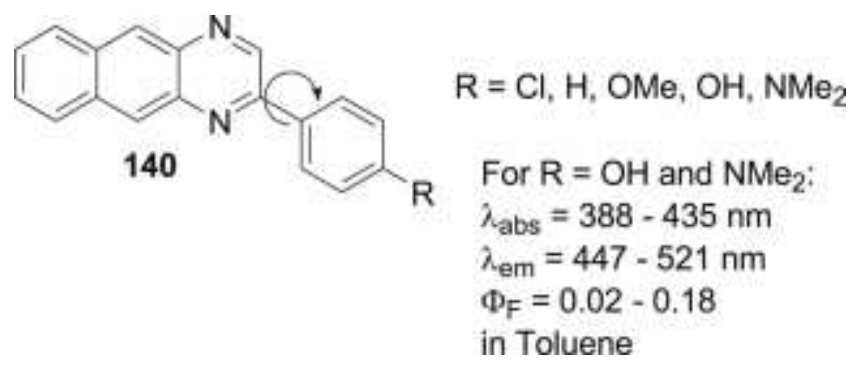

Scheme 72. Structure and photophysical data of compounds 140.

Several new 1H-pyrazolo[3,4-b]quinoxaline derivatives 141, 142 with N,N-dialkylamino as the electron-donating group were reported (Scheme 73) [100]. Their electroluminescence and photoluminescence were investigated. In solution, these compounds show emission at about 520-540 nm with a fluorescence quantum yield close to unity. EL devices fabricated, using these compounds as dopants, highlight green emission with efficiencies of 7.5-9.7 cd. $\mathrm{A}^{-1}$ and a narrow bandwidth of $65-70 \mathrm{~nm}$ peaking at $530-545 \mathrm{~nm}$.
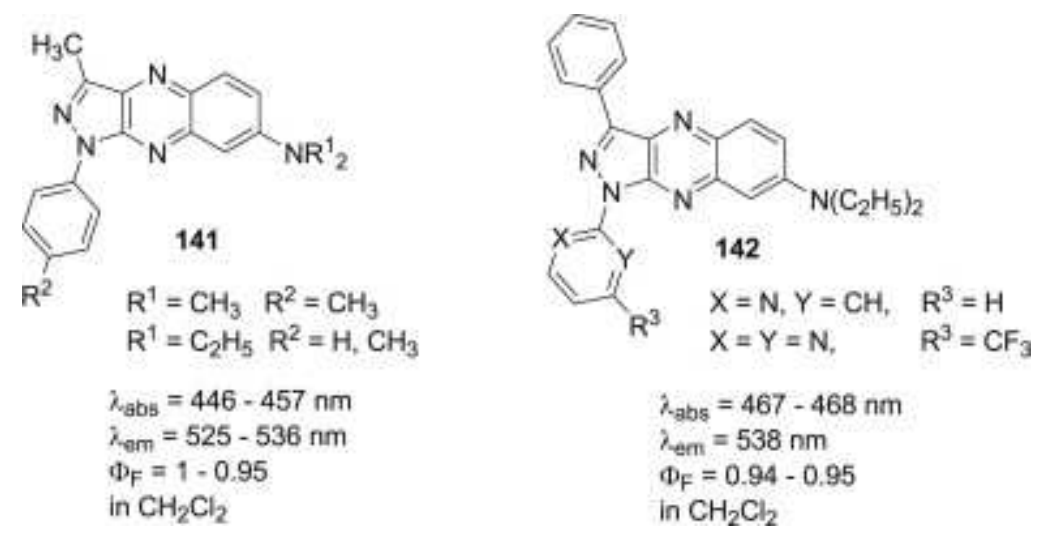

Scheme 73. Structure and photophysical data of compounds 141 and 142. 
A series of compounds based on the 8-halogeno-5,12-dihydroquinoxalino[2,3-b]quinoxaline skeleton 143, were synthesized and studied by Podsiadly and coworkers (Scheme 74) [101]. These new dyes emit blue light with fluorescence quantum yield ranging from 0.24 to 0.90 . When combined with pyridinium or iodonium salts, these compounds may have practical applications as visible-light photo-initiators for free radical and/or cationic polymerization. Their chemical structure is determinant to use these compounds as photoinitiator. Their quantum yields of singlet oxygen generation $\left[\Phi\left({ }^{1} \mathrm{O}_{2}\right)\right]$ have been measured, in accordance with the "heavy atom effects" the much greater $\left[\Phi\left({ }^{1} \mathrm{O}_{2}\right)\right]$ values was determined for the 6bromo-2,3-dichloroquinoxaline.

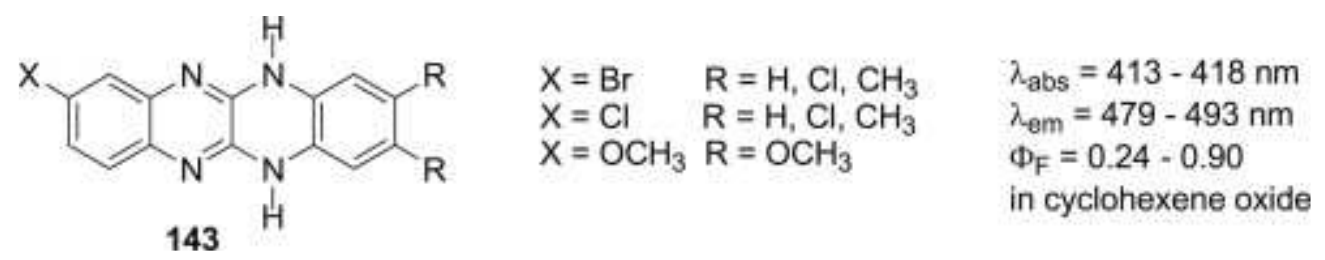

Scheme 74. Structure and photophysical data of compounds 143.

Bolligarla et al. have synthesized new acceptor-donor-acceptor (A-D-A) compounds 144, 145 incorporating the electron donor tetrathiafulvalene (TTF) as central unit, which is fused with acceptors such as quinoxaline and dipyrido[3,2-a:2',3'-c]phenazine (dppz) moities (Scheme 75) [102]. These compounds exhibit good emission in visible region at room temperature with a large dependence on the polarity of the solvent, which indicates that the excited state is stabilized in more polar solvents due to the intramolecular charge transfer. 
<smiles>[R]c1nc2cc3c(cc2nc1[R])SC(=C1Sc2cc4nc([R])c([R])nc4cc2S1)S3</smiles>

$\mathrm{R}=\mathrm{Cl}, \mathrm{Ph}$

$\lambda_{\text {abs }}=465-474 \mathrm{~nm}$

$\lambda_{\mathrm{em}}=616-664 \mathrm{~nm}$

$\Phi_{F}=0.05-0.10$

in $\mathrm{CHCl}_{3}$

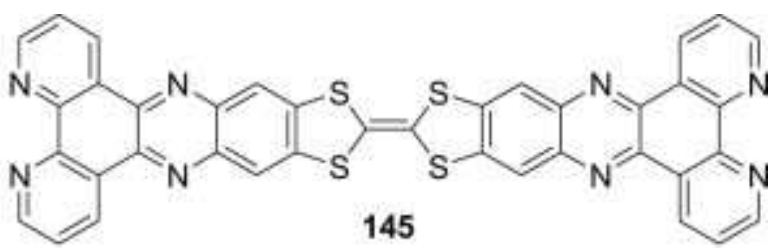

$\lambda_{\text {abs }}=530 \mathrm{~nm}$

$\lambda_{\text {em }}=675 \mathrm{~nm}$

$\Phi_{\mathrm{F}}=0.02$

in $\mathrm{CHCl}_{3}$

Scheme 75. Structure and photophysical data of compound 144 and 145.

Another $\pi$-conjugated donor-acceptor based on tetrathiafulvalene (TTF) functionalized with quinoxaline was synthesized by Jia et al. (Scheme 76) [103]. Spectroscopic and electrochemical behaviors of compound 146 demonstrate that the donor (TTF) unit strongly interacts with the electron-accepting pyridine groups through the quinoxaline bridge giving weak fluorescence. The interaction of compound 146 with metallic ions induces a progressive decrease of its fluorescence.

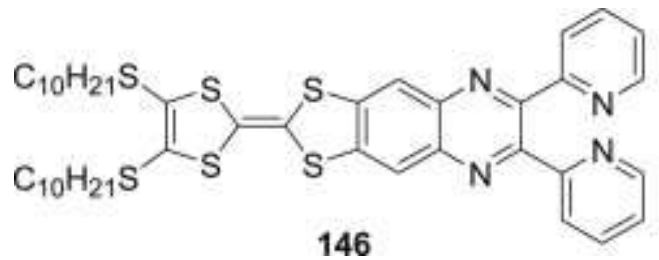

Scheme 76. Structure and photophysical data of compound 146.

\section{Conclusion and outlooks}

The research efforts in the field of synthesis and use of luminescent materials have strongly increased within the last few years. The considerable interest for these compounds is due to their wide range applications in various fields. They can be used as fluorescent sensors 
(polarity, $\mathrm{pH}$, metal cations, or more particularly to detect explosives), as stain for microscopy and diagnostic in medicine, for lighting in organic light-emitting devices (OLEDs) and NLO materials.

The research efforts in the field of pyrazine and quinoxaline luminescent molecules have strongly increased during the past decade. Indeed, due to their $\pi$-deficient character, incorporation of a $\mathrm{N}$-heterocycle such as pyrazine or quinoxaline in the backbone of luminescent molecules leads to significant modifications of the photophysical properties of $\pi$ conjugated materials. The electron-deficiency of the pyrazine or the quinoxaline ring can be used as a dipolar moiety, which favors the internal charge transfer. As largely illustrated in this review, this kind of molecules exhibits important fluorescence solvatochromism and good NLO properties. Quadrupolar (D- $\pi-A-\pi-D)$ and octopolar structures with a pyrazine central core exhibit also $3^{\text {rd }}$ order NLO properties such as two photon absorptions with high cross sections.

Moreover, presence of nitrogen atoms with lone electron pairs allows to the pyrazine and the quinoxaline rings to act as effective and stable complexing agents making of them good cation sensors. For the same reasons, pyrazine and quinoxaline derivatives can be protonated exhibiting halochromism, that has been illustrated by numerous examples given in this review. Specific interactions of some pyrazine compounds with particular forms of DNA and specific proteins lead to anticipate their use as promising tools for medical diagnosis of diseases such as cancer or Alzheimer disease.

Another aspect of the luminescence of pyrazine and quinoxaline is the electroluminescence properties leading to OLEDs. Some examples are details along the reviews.

This review emphasizes the great interest to incorporate pyrazine or quinoxaline moieties in $\pi$-extended conjugated systems, owing to their applications in various fields. The elaboration 
of new efficient structures with such a target is always topical and constitutes an interesting challenge.

[1] a) Barlin GB, (1982). In Chemistry of Heterocyclic Compounds, Vol. 41. New York: John Wiley and Sons. b) Mangalagiu II, Recent achievements in the chemistry of 1,2-diazines Curr Org Synth 2011;15:730-53.

[2] Brown J, (1962). In Chemistry of Heterocyclic Compounds, Vol. 16. New York: John Wiley and Sons.

[3] Castle RN, (1962). In Chemistry of Heterocyclic Compounds, Vol. 23. New York: John Wiley and Sons.

[4] Simpson JCE (1953). In Chemistry of Heterocyclic Compounds, Vol. 5. New York: John Wiley and Sons.

[5] See for example: a) Buron F, Plé N, Turck A, Queguiner G, Synthesis of pyrazine alcaloids from Botryllus leachi. Diazines 43., J Org Chem 2005;70:2616-21. b) Pettit GR, Mendonça RF, Knight JC, Pettit RK, The cephalostatins. 21. Synthesis of bis-steroidal pyrazine rhamnosides. J Nat Prod 2011;74:1922-30. c) Moser BR, Review of cytotoxic cephalostatins and ritterazines: isolation and synthesis. J Nat Prod 2008;71:487-91. d) Y. Takahashi Y, Iinuma Y, Kubota T, Tsuda M, Sekiguchi M, Mikami Y, Fromont J, Kobayashi J'i, Hyrtioseragamines A and B, new alkaloids from the sponge Hyrtios species., Org Lett 2011;13:628-31.

[6] Maier HG, Volatile flavoring substances in foodstuffs. Angew Chem Int Ed 1970;9:91726. 
[7] Sloot D, Hofman HJ, Alkylpyrazines in emmental cheese J Agric Food Chem $1975 ; 23: 358$.

[8] Flament I, Kohler M, Aschiero R, Sur l'arôme de viande de bœuf grillée. Dihydro-6,7-5Hcyclopenta[b]pyrazines, identification et mode de formation Helv Chim Acta 1976;59:230813.

[9] a) Weissleder R, Pittet MJ, Imaging in the era of molecular oncology Nature 2008;452:580-9. b) Vance E, Profile: What is that smell? Nature 2008;455:726-8.

[10] See for example: a) Ellsworth BA, Wang Y, Zhu Y, Pendri A, Gerritz SW, Sun C, Kang L, Baska RA, Yang Y, Huang Q, Burford NT, Cullen MJ, Johnghar S, Behnia K, Pelleymounter MA, Washburn WN, Ewing WR, Discovery of pyrazine carboxamide CB1 antagonists: the introduction of a hydroxyl group improves the pharmaceutical properties and in vivo efficacy of the series, Bioorg Med Chem Lett 2007;17:3978-82. b) Corbett JW, Rauckhorst MR, Qian F, Hoffman RL, Knauer CS, Fitzgerald LW, Heteroatom-linked indanylpyrazines are corticotropin releasing factor type-1 receptor antagonists., Bioorg Med Chem Lett 2007;17:6250-6. c) Dolezal M, Cmedlova P, Palek L, Vinsova J, Kunes J, Buchta V, Jampilek J, Kralova K, Synthesis and antimycobacterial evaluation of substituted pyrazinecarboxamides., Eur J Med Chem 2008;43:1105-13. d) Corona P, Carta A, Loriga M, Vitale G, Paglietti G, Synthesis and in vitro antitumor activity of new quinoxaline derivatives. Eur J Med Chem 2009;44:1579-91.

[11] a) Heravi MM, Bakhtiari K, Tehrani MH, Javadi NM, Oskooie HA, Facile synthesis of quinoxaline derivatives using o-iodoxybenzoic acid (IBX) at room temperature, Arkivoc. 2006;16:16-22. b) Gosh P, Mandal A, Greener approach toward one pot route to pyrazine synthesis, Green Chem Lett Rev 2011;5:127-34. c) Cheeseman GWH, Werstiuk ESG, Recent Advances in pyrazine chemistry, 14 (1972) 99-209. 
[12] a) Turck A, Plé N, Mongin F, Quéguiner G, Advances in the directed metallation of azines and diazines (pyridines, pyrimidines, pyrazines, pyridazines, quinolines, benzodiazines and carbolines). Part 2: Metallation of pyrimidines, pyrazines, pyridazines and benzodiazines, Tetrahedron. 2001;57:4489-505. b) Chevallier F, Mongin F, Functionalization of diazines and benzo derivatives through deprotonated intermediates, Chem Soc Rev 2008;37:595-609. c) Toudic F, Heynderickx A, Plé N, Turck A, Quéguiner G, Regioselective synthesis and metallation of tributylstannylfluoropyrazines. Application to the synthesis of some new fluorinated liquid crystals diazines. Part 34, Tetrahedron. 2003;59:6375-84. d) Baillie SE, Blair VL, Blakemore DC, Hay D, Kennedy AR, Pryde DC, Hevia E, New lithium-zincate approaches for the selective functionalisation of pyrazine: direct dideprotozincation vs. nucleophilic alkylation. Chem Commun 2012:1985-7.

[13] Littke AF, Fu GC, Palladium-catalyzed coupling reactions of aryl chlorides Angew Chem Int Ed 2002:41;4176-211.

[14] a) Delvare C, Harris CS, Hennequin L, Koza P, Lambert-van der Brempt C, Pelleter J, Willerval O, Efficient three-step one-pot synthesis of a novel 2,3,5-substituted pyrazine library., ACS Combin Sci. 2011:13;449-52. b) Makarasen A, Kuse M, Nishikawa T, Isobe M, Substituent effect of imino-O-arenesulfonates, a coupling partner in Suzuki-Miyaura reaction for substitution of the pyrazine ring: a study for the synthesis of coelenterazine analogs. Bull Chem Soc Jap 2009:82; 870-8. c) Dias N, Jacquemard U, Baldeyrou B, Lansiaux A, Goossens JF, Bailly C, Routier S, Mérour JY, Synthesis of 2,6-diphenylpyrazine derivatives and their DNA binding and cytotoxic properties. Eur J Med Chem 2005:40;1206-13.

[15] a) Darabantu M, Boully L, Turck A, Plé N, Synthesis of new polyaza heterocycles. Part 42: Diazines, Tetrahedron 2005:61;2897-2905. b) Gündisch D, Harms K, Schwarz S, Seitz G, Stubbs MT, Wegge T, Synthesis and evaluation of diazine containing bioisosteres of (-)- 
ferruginine as ligands for nicotinic acetylcholine receptors., Bioorg Med Chem 2001:9;268391.

[16] Milne JE, Buchwald SL, An extremely active catalyst for the Negishi cross-coupling reaction J Am Chem Soc. 2004:126;13028-32.

[17] a) Shook BC, Chakravarty D, Jackson PF, Microwave-assisted Sonogashira-type cross couplings of various heterocyclic methylthioethers, Tetrahedron Lett. 2009:50;1013-5. b) Tang BX, Wang F, Li JH, Xie YX, Zhang MB, Reusable $\mathrm{Cu}_{2} \mathrm{O} / \mathrm{PPh}_{3} / \mathrm{TBAB}$ system for the cross-couplings of aryl halides and heteroaryl halides with terminal alkynes., J Org Chem 2007:72;6294-7.

[18] Malik I, Hussain M, Ali A, Tengho Toguem SM, Basha FZ, Fischer C, Langer P, Synthesis of 2,3-disubstituted pyrazines and quinoxalines by Heck cross-coupling reactions of 2,3-dichloropyrazine and 2,3-dichloroquinoxaline. Influence of the temperature on the product distribution, Tetrahedron. 2010:66;1637-42.

[19] a) Fürstner A, Leitner A, Méndez M, Krause H, Iron-catalyzed cross-coupling reactions., J Am Chem Soc 2002:124;13856-63. b) Boully L, Darabantu M, Turck A,. Plé N, Aryl-aryl bonds formation in pyridine and pyazine series. Diazines part 41, J Heterocycl Chem 2005:42;1423-8.

[20] a) Vanden Eynde JJ, Pascal L, Van Haverbeke Y, Dubois P, Quaternary ammonium saltassisted synthesis of extended pi-systems from methyldiazines and aromatic aldehydes, Synth Commun 2001:32;3167-73. b) Lipunova GN, Nosova EV, Trashakhova TV, Charushin VN, Azinylarylethenes: synthesis and photophysical and photochemical properties, Russ Chem Rev 2011:80;1115-33.

[21] a) Achelle S, Plé N, Pyrimidine as building block for the synthesis of functionalized piconjugated materials, Curr Org Synth 2012:9;163-87. b) Achelle S, Plé N, Turck A, 
Incorporation of pyridazine rings in the structure of functionalized pi-conjugated materials, RSC Adv 2011:1;364-88.

[22] a) Shirai K, Yanagisawa A, Takahashi H, Fukunishi K, Matsuoka M, Syntheses and Fluorescent Properties of 2,5-Diamino-3,6-dicyanopyrazine Dyes, Dyes Pigm 1998:39;49-68. b) Kim JH, Shin SR, Matsuoka M, Fukunishi K, Self-assembling of aminopyrazine fluorescent dyes and their solid state spectra, Dyes Pigm 1998:39;341-57.

[23] Shirai K, Matsuoka M, Fukunishi K, New syntheses and solid state fluorescence of azomethine dyes derived from diaminomaleonitrile and 2,5-diamino-3,6-dicyanopyrazine, Dyes Pigm 2000:47;107-15.

[24] Angulo G, Dobkowski J, Kapturkiewicz A, Luminescence properties of diamino-dicyano substituted benzene and 1,4-pyrazine., J Photochem Photobiol A: Chem. 2011:225;52-57.

[25] Hong Kim J, Rim Shin S, Matsuoka M, Fukunishi K, Self-assembling of aminopyrazine fluorescent dyes and their solid state spectra, Part 2, Dyes Pigm 1999:41;183-91.

[26] Poreddy AR, Asmelash B, Neumann WL, Dorshow RB, A Highly Efficient Method for the N-Alkylation of Aminopyrazines: Synthesis of Hydrophilic Red Fluorescent Dyes, Synthesis. 2010:2383-92.

[27] Rajagopalan R, Neumann WL, Poreddy AR, Fitch RM, Freskos JN, Asmelash B, Gaston KR, Galen KP, Shieh JJ, Dorshow RB, Hydrophilic pyrazine dyes as exogenous fluorescent tracer agents for real-time point-of-care measurement of glomerular filtration rate., $\mathrm{J}$ Med Chem 2011:54;5048-58.

[28] a) Sun G, Cui H, Lin LY, Lee NS, Yang, C, Neumann WL, Freskos JN, Shieh JJ, Dorshow RB, Wooley KL, Multicompartment polymer nanostructures with ratiomeric dualemission pH-sensitivity, J Am Chem Soc 2011:133;8534-43. b) Lee NS, Sun G, Lin LY, Neumann WL, Freskos JN, Karwa A, Shieh JJ, Dorshow RB, Wooley KL, Tunable dual- 
emitting shell-crosslinked nano-objects as single-component ratiometric $\mathrm{pH}$-sensing materials, J Mater Chem 2011:14193-202.

[29] a) Zhao C, Dai Q, Seino T, Cui YY, Nishizawa S, Teramae N, Strong and selective binding of amiloride to thymine base opposite AP sites in DNA duplexes: simultaneous binding to DNA phophate backbone. Chem Commun 2006:1185-7. b) Sato Y, Ichihashi T, Nishizawa S, Teramae N, Strong and selective binding of amiloride to an abasic site in RNA duplexes: thermodynamic characterization and microRNA detection. Angew Chem Int Ed 2012:51;6369-72.

[30] a) Jaung JY, Matsuoka M, Fukunishi K, Syntheses and properties of new styryl dyes derived from 2,3-dicyano-5-methylpyrazines, Dyes Pigm 1996:31;141-153. b) Jaung JY, Matsuoka M, Fukunishi K, Dicyanopyrazine studies. Part V: Syntheses and characteristics of chalcone analogues of dicyanopyrazine, Dyes Pigm 1998:40;11-20.

[31] a) Jaung JY, Matsuoka M, Fukunishi K, Syntheses and characterization of new styryl fluorescent dyes from DAMN. Part II, Dyes Pigm 1997:34;255-66. b) Jaung JY, Matsuoka M, Dicyanopyrazine studies. Syntheses and characterization of new bis-styryl fluorescent dyes from DAMN. Part III, Dyes Pigm 1998:36;395-405.

[32] a) Kim JH, Choi YC, Kim BS, Choi DH, Kim SH. Crystal morphology and their lattice contraction control for the topochemical reaction of bis(phenyl- ethenyl)-dicyanopyrazines. Dyes Pigm 2008;76:422-8. b) Kim JH, Matsuoka M, Fukunishi K. Selective topochemical photodimerization of styryldicyanopyrazines in the solid state. J Chem Res Synop 1999;2:132-3. c) Ahn KS, Lee DK, Kim JH, Kim SH, Domino-like thermal phase transition of 2,3-bis(phenylethenyl)-5,6-dicyanopyrazine crystal, Dyes Pigm 2011;89:93-5.

[34] Matsumoto S, Horiguchi-Babamoto E, Eto R, S. Sato S, Kobayashi T, Naito H, Shiro M, Takahashi H, J-aggregate structure in a chloroform solvate of a 2,3-dicyanopyrazine dye - 
Separation of two-dimensional stacking dye layers by solvate formation, Dyes Pigm 2012; 95:431-5.

[35] Cristiano R, Westphal E, Bechtold IH, Bortoluzzi AJ, Gallardo H, Synthesis and optical/thermal properties of low molecular mass V-shaped materials based on 2,3dicyanopyrazine, Tetrahedron. 2007;63:2851-8.

[36] a) Jang CK, Song CJ, Jung SJ, Jaung JY, Topochemically photoreacted fluorescent dimers of 2,3-dicyanopyrazines, Dyes Pigm 2012;94:49-54. b) Jang CK, Jaung JY, Synthesis of 2,3-Dicyanopyrazine Dimers Linked with Cyclobutane Ring by [2+2]Photocycloaddition, Bull Kor Chem Soc 2011;32:2165-6.

[37] a) Lee BH, Jaung JY, Synthesis and characteristics of dicyanopyrazine dyes containing spiropyran group, Dyes Pigm 2003;59:135-42. b) Lee B, Jaung J, Jeong SH, Synthesis of spiropyran substituted 2, 3-dicyanopyrazines, Bull Kor Chem Soc 2002;23:5-6.

[38] Chew S, Wang P, Hong Z, Kwong H, Tang J, Sun S, Lee CS, Lee ST, Photoluminescence and electroluminescence of a novel green-yellow emitting material-5,6Bis-[4-(naphthalene-1-yl-phenyl-amino)-phenyl]- pyrazine-2,3-dicarbonitrile, $\quad \mathbf{J} \quad$ Lumin $2007 ; 124: 221-7$.

[39] Jaung JY, Synthesis of new porphyrins with dicyanopyrazine moiety and their optical properties, Dyes Pigm 2007;72:315-21.

[40] Hill JP, Subbaiyan NK, D’Souza F, Xie Y, Sahu S, Sanchez-Ballester NM, Richards GJ, Mori T, Ariga K, Antioxaydant-substituted tetrapyrazinoporphyrazine as a fluorescent sensor for basic anions, Chem Commun 2012;3951-3.

[41] Bureš F, Čermáková H, Kulhánek J, Ludwig M, Kuznik W, Kityk IV, Mikysek T, Růžička A, Structure-Property Relationships and Nonlinear Optical Effects in DonorSubstituted Dicyanopyrazine-Derived Push-Pull Chromophores with Enlarged and Varied $\pi$ Linkers, Eur J Org Chem 2012:529-38. 
[42] Haroutounian SA, Katzenellenbogen JA, 4'-Hydroxystylyldiazines: Synthesis and Fluorescence Properties, Tetrahedron 1995;51:1585-98.

[43] Achelle S, Barsella A, Baudequin C, Caro B, Robin-Le Guen F, Synthesis and photophysical investigation of a serie of push-pull arylvinyldiazine chromophores, J Org Chem 2012;77:4087-96.

[44] Aranda AI, Achelle S, Hammerer F, Mahuteau-Betzer F, Teulade-Fichou MP, Vinyldiazine triphenylamines and their N-methylated derivatives : Synthesis, photophysical properties and application for staining DNA. Dyes Pigm 2012;95:400-7.

[45] Schmitt V, Fischer J, Detert H, Linear and Angular Distyrylpyrazines with Terminal Donor Groups: Synthesis, Solvatochromism, and Acidochromism of the Electronic Spectra, ISRN Org Chem 2011:589012 doi:10.5402/2011/589012.

[46] Nemkovich NA, Detert H, Schmitt V, Localized excitation effect on dipole moments of oligophenylenevinylenes in their excited Franck-Condon state, Chem Phys 2010;378:37-41.

[47] a) Al-Hazmy SM, Babaqi AS, Daltrozzo E, Klink M, Sauter J, Ebeid EM, A new diolefinic laser dye: 2, 5-bis-2-(2-naphthyl) vinyl pyrazine (B2NVP), J Photochem Photobiol A: Chem 1999:122;17-22. b) El-Daly S, M Ebeid EZ, El-Hazmy SM, Babaqi AS, El-Gohary Z, Duportail G, The spectra, lifetime and laser activity of 2,5-bis-2(1-naphthyl)vinylpyrazine and 2,5-bis-2(2-naphthyl)vinylpyrazine Proc Indian Acad Sci 1993;105:651-8.

[48] Rumi M, Pond SJK, Meyer-friedrichsen T, Zhang Q, Bishop M, Zhang Y, Barlow S, Marder SR, Perry JW, Tetrastyrylarene Derivatives : Comparison of One- and Two-Photon Spectroscopic Properties with Distyrylarene Analogues, J Phys Chem C. 2008;128:8061-71. [49] Wink C, Detert H, Donor-substituted distyrylpyrazines: influence of steric congestion on UV-Vis absorption and fluorescence, J Phys Org Chem 2013 :26:144-50

[50] Boländer A, Kieser D, Voss C, Bauer S, Schön C, Burgold S, Bittner T, Hölzer J, Heynyvon Haussen R, Mall G, Goetschy V, Czech C, Knust H, Berger R, Herms J, Hilger I, 
Schmidt B, Bis(arylvinyl)pyrazines, -pyrimidines, and -pyridazines As Imaging Agents for Tau Fibrils and $\beta$-Amyloid in Alzheimer's Disease Models , J. Med Chem. 2012;55:9170-80. [51] Collette JC, Harper AW, Chemically-responsive fluorophores exhibiting large color changes. Proc SPIE 2002;4809:122-35.

[52] Yan S, Huang R, Zhou Y, Zhang M, Deng M, Wang X, Weng X, Zhou X, Aptamerbased turn-on fluorescent four-branched quaternary ammonium pyrazine probe for selective thrombin detection., Chem Commun 2011;47:1273-5.

[53] Wu FY, Bae SW, Hong JI, A selective fluorescent sensor for Pb(II) in water, Tetrahedron Lett 2006;47:8851-4.

[54] Wu FY, Xiang YL, Wu YM, Xie FY, Study of interaction of a fluorescent probe with DNA, J Lumin. 2009;129:1286-91.

[55] Hebbar N, Ramondenc Y, Plé G, Dupas G, Plé N, Push-pull structures with a pyrazine core and hexatriene chain: synthesis and light-emitting properties, Tetrahedron. 2009;65:4190-200.

[56] Hebbar N, Fiol-Petit C, Ramondenc Y, Plé G, Plé N, A new series of rod-like conjugated molecules with a pyrazine or a bipyrazine core. Synthesis and light emitting properties, Tetrahedron. 2011;67:2287-98.

[57] Zhao L, Perepichka IF, Tu F, Findlay KS, M.R. Bryce MR, 2,5Di(aryleneethynyl)pyrazine derivatives: synthesis, structural and optoelectronic properties, and light-emitting devices “, New J Chem 2004;28:912-8.

[58] Türksoy F, Hughes G, Batsanov A, Bryce MR, Phenylene-2,5-dimethylpyrazine cooligomers : synthesis by Suzuki couplings, X-ray structures of neutral and diprotonated teraryl species and efficient blue emission, J Mater Chem 2003;13:1554-7. 
[59] Fugisawa FP, Ramos AP, Filho PCDS, Serra OA, Zaniquelli MED, Formation of thin luminescent $\mathrm{Eu}^{3+}-\mathrm{LB}$ films by in situ coordination with Langmuir monolayers, J Lumin 2012;132:1116-21.

[60] Saito R, Machita S, Suzuki S, Katoh A, Synthesis and spectroscopic properties of 2,5bis(benzoazol-2-yl)pyrazines, Heterocycles 2008;75:531-6.

[61] Saito R, Matsumura Y, Suzuki S, Okazaki N, Intensely blue-fluorescent 2,5bis(benzoimidazol-2-yl)pyrazine dyes with improved solubility: their synthesis, fluorescent properties, and application as microenvironment polarity probes, Tetrahedron 2010;66:82739.

[62] Thirumurugan P, Perumal PT, The synthesis and photophysical studies of pyridinyl1,2,4-triazine derivatives and use as a fluorescent sensor for ferric salts, Dyes Pigm 2011;88:403-12.

[63] a) Walkup GK, Burdette SC, Lippard SJ, Tsien RY, A new cell-permeable fluorescent probe for $\mathrm{Zn}^{2+}$, J Am Chem Soc 2000;122:5644-5. b) Burdette SC, Walkup GK, Spingler B, Tsien RY, Lippard SJ, Fluorescent sensors for $\mathrm{Zn}^{2+}$ based on a fluorescein platform: synthesis, properties and intracellular distribution., J Am Chem Soc 2001;123:7831-41.

[64] a) Zhang XA, Hayes D, Smith SJ, Friedle S, Lippard SJ, New strategy for quantifying biological zinc by a modified zinpyr fluorescence sensor., J Am Chem Soc 2008;130:157889. b) Buccella D, Horowitz JA, Lippard SJ, Understanding zinc quantification with existing and advanced ditopic fluorescent Zinpyr sensors., J Am Chem Soc 2011;133:4101-14.

[65] Kubota Y, Hara H, Tanaka S, Funabiki K, Matsui M, Synthesis and fluorescence properties of novel pyrazine-boron complexes bearing a $\beta$-iminoketone ligand., Org Lett 2011;13:6544-7. 
[66] Ge G, He J, Guo H, Wang F, Zou D, phosphorescent iridium (III) diazine complexes for OLEDs: Different photophysical property between iridium (III) pyrazine complex and iridium (III) pyrimidine complex, J Organomet Chem 2009;694:3050-7.

[67] Coe BJ, Fielden J, Foxon SP, Asselberghs I, Clays K, Brunschwig BS, Two-dimensional, pyrazine-based nonlinear optical chromophores with ruthenium(II) ammine electron donors., Inorg Chem 2010;49:10718-26.

[68] Pizzotti M, Ugo R, Roberto D, Bruni S, Organometallic Counterparts of Push-Pull Aromatic Chromophores for Nonlinear Optics: Push-Pull Heteronuclear Bimetallic Complexes with Pyrazine and trans-1 , 2-Bis(4-pyridyl)ethylene as Linkers, Organometallics 2002;21:5830-40.

[69] Kudo K, Momotake A, Kanna Y, Nishimura Y, Arai T, Development of a quinoxalinebased fluorescent probe for quantitative estimation of protein binding site polarity., Chem Commun 2011:3867-9.

[70] Bachowska B, G. Matusiak G, 2, 2'-(1, 4-phenylenedivinylene) bis-quinoxaline and a series of styryl derivatives of quinoxaline and quinoline as promising electro-and photoluminescent materials, Chem Heterocycl Compd 2009;45:80-4.

[71] Thirumurugan P, Muralidharan D, Perumal P, The synthesis and photophysical studies of quinoxaline and pyridopyrazine derivatives, Dyes Pigm 2009;81:245-53.

[72] Jaung JY, Synthesis and halochromism of new quinoxaline fluorescent dyes, Dyes Pigm 2006;71:245-50.

[73] Jang CK, Lee YH, Han SY, Jaung JY, The synthesis and optical characterization of quinoxalines bearing 2,2':6',2"-terpyridine, Dyes Pigm 2008;79:101-4.

[74] Arun V, Robinson PP, Manju S, Leeju P, Varsha G, Digna V, Yusuff KKM, A novel fluorescent bisazomethine dye derived from 3-hydroxyquinoxaline-2-carboxaldehyde and 2,3diaminomaleonitrile, Dyes Pigm 2009;82:268-75. 
[75] Arun V, Mathew S, Robinson PP, Jose M, Nampoori VPN, Yusuff KKM, The tautomerism, solvatochromism and non-linear optical properties of fluorescent 3hydroxyquinoxaline-2-carboxalidine-4-aminoantipyrine, Dyes Pigm 2010;87:149-57.

[76] Wang H, Chen G, Liu Y, Hu L, Xu X, Ji S, The synthesis and characterization of novel dipolar fluorescent materials based on a quinoxaline core, Dyes Pigm 2009;83:269-75.

[77] Cao X, Jin F, Li YF, Chen WQ, Duan XM, Yang LM, Triphenylamine-modified quinoxaline derivatives as two-photon photoinitiators, New J Chem 2009;33:1578-82.

[78] Thomas K, Lin J, Tao Y, Quinoxalines incorporating triarylamines: potential electroluminescent materials with tunable emission characteristics, Chem Mater 2002;14: 2796-802.

[79] Thomas KRJ, Velusamy M, Lin JT, Chuen CH, Tao YT, Chromophore-labeled quinoxaline derivatives as efficient electroluminescent materials, Chem Mater 2005;17: $1860-6$.

[80] Lin TC, Huang YJ, Huang BR, Lee YH, Synthesis and two-photon properties of a multipolar chromophore based on tetra-quinoxalinylethylene scaffold, Tetrahedron Lett 2011;52:6748-53.

[81] Burrows HD, Fonseca SM, Gigante B, Esteves MA, Guerreiro AM, Fluorescence study of dehydroabietic acid-based bipolar arylamine-quinoxalines., J Fluoresc 2006;16:227-31.

[82] Bernardo G, Esteves MA, Guerreiro AM, Gigante B, Morgado J, Luminescence properties of bipolar stylbeneamine-quinoxalines, Optical Mater 2008;31:320-7.

[83] Xu X, Chen S, Li L, Yu G, Di C, Liu Y, Photophysical properties of polyphenylphenyl compounds in aqueous solutions and application of their nanoparticles for nucleobase sensing, J Mater Chem 2008;18:2555-61. 
[84] Hemgesberg M, Ohlmann DM, Schmitt Y, Wolfe MR, Müller MK, Erb B, Sun Y, Gooßen LJ, Gerhards M, Thiel WR, Simple Access to Sol-Gel Precursors Bearing Fluorescent Aromatic Core Units, Eur J Org Chem 2012:2142-51.

[85] a) Black CB, Andrioletti B, Try AC, Ruiperez C, Sessler JL, Dipyrrolylquinoxalines : Efficient Sensors for Fluoride Anion in Organic Solution, J Am Chem Soc 1999;121:104389. b) Anzenbacher P, Try AC, Miyaji H, Jursı K, Lynch VM, Marquez M, Sessler, JL, Fluorinated Calix [ 4 ] pyrrole and Dipyrrolylquinoxaline : Neutral Anion Receptors with Augmented Affinities and Enhanced Selectivities, J Am Chem Soc 2000;122:10268-72. c) Sessler JL, Maeda H, Mizuno T, Lynch VM, Furuta H, Quinoxaline-oligopyrroles: Improved pyrrole-based anion receptors Chem Commun 2002:862-3.

[86] Aldakov D, Anzenbacher P, Dipyrrolyl quinoxalines with extended chromophores are efficient fluorimetric sensors for pyrophosphate., Chem Commun 2003:1394-5.

[87] Sessler JL, Maeda H, Mizuno T, Lynch VM, H. Furuta H, Quinoxaline-bridged porphyrinoids., J Am Chem Soc 2002;124:13474-9.

[88] Wang L, Zhu XJ, Wong WY, Guo JP, Wong WK, Li ZY, Dipyrrolylquinoxaline-bridged Schiff bases: a new class of fluorescent sensors for mercury(II)., Dalton Trans 2005:3235-40. [89] Hu Y, Li QQ, Li H, Guo QN, Lu YG, Li ZY, A novel class of Cd(II), Hg(II) turn-on and $\mathrm{Cu}(\mathrm{II}), \mathrm{Zn}(\mathrm{II})$ turn-off Schiff base fluorescent probes., Dalton Trans 2010:11344-52.

[90] Varsha G, Arun V, Robinson PP, Sebastian M, Varghese D, Leeju P, Jayachadran VP, Yusuff KKM, Two new fluorescent heterocyclic perimidines: first syntheses, crystal structure, and spectral characterization, Tetrahedron Lett 2010;51:2174-7.

[91] Katoh A, Takahashi M, Ohkanda J, Synthesis of 2,3-disubstituted 6-aminoquinoxalines and their application to new fluorescence derivatization reacgents for carboxylic acids. Chem Lett 1996;25:369-70. 
[92] Matsumura Y, Katoh A, Synthesis of 2,3-dimorpholino-6-aminoquinoxaline derivatives and application to a new intramolecular fluorescent probe, J Lumin 2008;128:625-30.

[93] Touzani R, Ben-hadda T, Elkadiri S, Ramdani A, Maury O, Le Bozec H, Toupet L, Dixneuf PH, Solution, solid state structure and fluorescence studies of 2,3-functionalized quinoxalines : evidence for a $\pi$-delocalized keto-enamine form with $\mathrm{N}-\mathrm{H} \cdots \mathrm{O}$ intramolecular hydrogen bonds, New J Chem 2001;25:391-5.

[94] Duke RM, Gunnlaugsson T, Fluorescent sensing of anions using a bis-quinoxaline amidothiourea based supramolecular cleft; an example of an anion-induced deprotonation event, Tetrahedron Lett 2010;51:5402-5.

[95] Benzeid H, Mothes E, Essassi EM, Faller P, Pratviel G, A thienoquinoxaline and a styryl-quinoxaline as new fluorescent probes for amyloid- $\beta$ fibrils, CR Chimie 2012;15:79-85. [96] Thomas KRJ, Tyagi P, Synthesis, spectra, and theoretical investigations of the triarylamines based on 6H-indolo[2,3-b]quinoxaline., J Org Chem 2010;75:8100-11.

[97] Gemma S, Colombo L, Forloni G, Savini L, Fracasso C, Caccia S, Salmona M, Brindisi M, Joshi BP, Tripaldi P, Giorgi G, Tagliatela-Scafati O, Novellino E, Fiorini I, Campiani G, Butini S, Pyrroloquinoxaline hydrazones as fluorescent probes for amyloid fibrils., Org Biomol Chem 2011;9:5137-48.

[98] Matsumoto S, Batmunkh E, Akazome M, Takata Y, Tamano M, Novel formation of diimidazo[1,2-a:2',1'-c]quinoxaline derivatives and their optical properties., Org Biomol Chem 2011;9:5941-4.

[99] Wang K, Shi W, Jia J, Chen S, Ma H, Characterization of 2-phenylbenzo[g]quinoxaline derivatives as viscosity-sensitive fluorescent probes., Talanta 2009;77:1795-9.

[100] a) Wang P, Xie Z, Wong O, Lee CS, Wong N, Hung L, Lee S, New 1H-pyrazolo[3,4b]quinoxaline derivatives as sharp green-emitting dopants for highly efficient electroluminescent devices, Chem. Commun. 2002:1404-5. b) Wang P, Xie Z, Hong Z, Tang 
J, Wong O, Lee CS, Synthesis, photoluminescence and electroluminescence of new $1 \mathrm{H}$ pyrazolo[3,4-b]quinoxaline derivatives, J Mater Chem 2003:13;1894-9.

[101] Podsiadły R, Szymczak AM, Podemska K, The synthesis of novel, visible-wavelength, oxidizable polymerization sensitizers based on the 8-halogeno-5,12-dihydroquinoxalino[2,3b]quinoxaline skeleton, Dyes Pigm 2009:82;365-71.

[102] Bolligarla R, Das SK, Synthesis of new intramolecular charge transfer A-D-A tetrathiafulvalene-fused triads exhibiting large solvent sensitive emission behavior, Tetrahedron Lett 2011;52:2496-500.

[103] Jia C, Zhang J, Bai J, Zhang L, Wan Z, Yao X, Synthesis, physical properties and selfassembly of conjugated donor-acceptor system based on tetrathiafulvalene and functionalized with binding sites, Dyes Pigm 2012;94:403-9. 